\title{
Essays on Household Consumption and Spending
}

\author{
Li Zhang \\ Shenzhen, China
}

H.B.Sc., University of Toronto, 2007

M.A., University of Toronto, 2008

M.A., University of Virginia, 2011

A Dissertation presented to the Graduate Faculty of the University of Virginia in Candidacy for the Degree of Doctor of Philosophy

\section{Department of Economics}

University of Virginia

May, 2016 


\section{Abstract}

This dissertation studies household consumption and spending, using householdlevel microdata in the Consumer Expenditure Survey.

The first chapter studies consumption smoothing of households between monthly payments of mortgage or rent. My focus on regular payments contrasts with most of this literature that finds excess sensitivity to regular receipt of income. Using the Consumer Expenditure Survey (CEX) Diary survey from 1998 to 2011, I find that spending on non-durable goods is $\$ 3.34$ or $9.0 \%$ higher per day during the two weeks following the day when a housing payment occurs, compared to the two weeks prior to that day, inconsistent with the consumption smoothing predicted by the life cycle/permanent income hypothesis. My finding is robust to the coincident timing of households' regular housing payments and their regular income arrivals, and suggests that findings in the previous literature of excess sensitivity of consumption to regular income arrivals may in part reflect excess sensitivity to the timing of making regular payments. The increase in bi-weekly average spending following a housing payment day is larger for households in which the household head has lower educational attainment, larger for households with lower income, and has a U-shaped profile in age of household head. My finding is not fully consistent with existing theories that aim to explain departures from consumption smoothing between regular payments, including liquidity constraints and uncertainty about bank account balances.

In the second chapter, I provide the first nationwide study that empirically estimates the effect of casinos on the non-gambling economy. Using household spending data from the Consumer Expenditure Survey from 1996 to 2013, and a restricted access file containing the county codes of the CEX households, I find a positive effect of 
casinos on household spending on non-gambling goods. When casinos appear within 100 miles, households increase their quarterly non-gambling spending by up to $2.6 \%$. The positive effect suggests that casinos can have a complementary effect on the nongambling economy. The positive effect does not always significantly accumulate when more casinos are built in nearby areas. A comparison among income groups shows that the complementary effect of casinos on non-gambling sectors is largely driven by the spending changes of lower-income households. The complementary effect persists in the long run.

The third chapter studies the relationship between lottery jackpots and household spending. Large lottery jackpots that accumulate over time until winners appear generate massive ticket sales. To investigate how household spending changes when lottery jackpots increase, I focus on Powerball and Mega Millions, two multi-state lotto games that produce the highest jackpots among all the lotteries in the U.S. I find that spending on non-gambling goods is $\$ 4.28$ per day or $3.4 \%$ lower when either lottery has a jackpot above $\$ 100$ million, compared to when it is below $\$ 50$ million. This difference is larger for households in the lowest income tercile, at $\$ 4.81$ per day or $5.7 \%$. The changes in spending on subcategories suggest that most of the spending decrease of lower-income households during the periods when jackpots are high is driven by postponed housing payments. 


\section{Acknowledgements}

I would like to express my sincere gratitude to my advisors Leora Friedberg, John Pepper, and Edgar Olsen for their continuous support throughout the years of my Ph.D. study. Leora's course in Public Economics inspired me to pursue my current research interests, and her guidance further motivated me to keep developing my research ideas. John has always been there to listen and offer advice. His insightful comments greatly helped me in addressing many technical details in my research. Ed offered me the opportunity to work as a Research Assistant during my first summer in the program. The research experience I gained from working on Ed's project became a valuable asset in my later work on this dissertation.

I am deeply indebted to Leora. Her guidance, patience, and generosity helped me overcome many difficulties, finish this dissertation, and grow as an economist. There are no words to describe how thankful I am to her.

I benefited from the valuable discussions with the participants of the labor and public research group, and other fellow graduate students. I would like to particularly thank Tianying He and Fang Guo for their helpful suggestions on the first chapter. My special thanks to Gang Zhang for his enormous help during my last two years in the program.

I worked as a visiting researcher at the Bureau of Labor Statistics to gain access to the confidential data used in the second chapter of this dissertation. During my work in Washington, D.C., I received excellent support from the Consumer Expenditure Survey division, especially Arcenis Rojas. The completion of the second chapter would be impossible without his assistance.

Finally, I would like to thank my family for supporting me through this journey. 
To Vivi, my amazing wife, and to our three children, Celine, Charlotte, and Charles. 


\section{Contents}

1. Household Consumption Smoothing between Monthly Housing Payments

2. The Effect of Casinos on the Non-Gambling Economy: Evidence from Nationwide Household Spending Data

3. Lottery Jackpots and Household Spending 


\section{Chapter 1}

\section{Household Consumption Smoothing between Monthly Housing Payments}

\section{Introduction}

Predictable changes in resources should not affect consumption allocations over time. If a consumer knows that her wage will be paid monthly, then with diminishing marginal utility, it is in her interest to make her resources stretch throughout the whole month so she can smooth daily consumption. Researchers have debated the extent to which consumers successfully smooth consumption between regular anticipated income receipts, in accordance with the life-cycle/permanent-income hypothesis (LCPIH). Yet, in spite of the attention paid to regular positive resource changes, few have studied consumption smoothing when consumers face regular negative resource changes. Anticipated negative resource changes may be more common than positive ones - some households do not receive income regularly but are often committed to paying bills on a regular basis. Moreover, while household members may face different frequencies and timing of paycheck receipts, which may mitigate any difficulty with consumption smoothing over regular income receipt, they usually share a common stream of negative resource changes, such as monthly payments for utilities. Motivated by these arguments, this paper studies daily consumption patterns between the days on which households make the payment of a major, yet predictable, monthly expenditure item - mortgage or rent. 
Since the frequency and amount of each housing payment are predictable, the timing of housing payments should not affect daily consumption of non-housing goods, according to the LCPIH. To test this hypothesis, I use the Consumer Expenditure Survey (CEX) Diary microdata from 1998 to 2011 published by the Bureau of Labor Statistics (BLS). Since daily expenditures are recorded for up to 14 days, I am able to identify the change in daily spending between a typical day and the day when a housing payment was made (the "housing payment day") for a window covering up to two weeks prior to the housing payment day for some households, and up to two weeks after for others. One concern is that households can choose to make housing payments upon paycheck arrivals, the timing of which is unobservable in my data. ${ }^{1}$ To reduce any confounding responsiveness in spending to the timing of paycheck arrival, I first restrict my sample to households deriving more than $70 \%$ of their income from bi-weekly or weekly earnings. In addition, since my sample selection criteria lead to a sample with disproportionally more days that are closer to the housing payment day, I assign weights to the diary days in my sample so that my results will be driven evenly by each day over the 28-day window. I show that, with the appropriate sample selection and weighting, the fluctuations in spending between paycheck days should be differenced out in my estimation.

Using a household fixed effect model and addressing the issues above, I find that on average daily spending on non-durable consumption goods is $\$ 3.34$ or $9.0 \%$ higher during the two weeks following the housing payment day, a statistically significant difference, compared to the two weeks prior to that day. Thus, households consume more for a while after making a housing payment and then reduce consumption before the next. The result also holds for spending on a narrower category of consumption

\footnotetext{
${ }^{1}$ Gelman et al.(2014) shows that $40 \%$ of excess sensitivity in total spending to income arrivals can be explained by the coincident timing of regular payments and regular income receipts.
} 
goods with a stricter definition of non-durability, which includes dining away from home, entertainment and sport activities, and perishable fresh food at home. Hence, my results suggest that household intertemporal consumption decisions between regular negative resource changes are inconsistent with the prediction of the LCPIH. The uneven spending cycle between housing payments is similar or stronger in magnitude compared to the cycle between paycheck arrivals documented in the literature. ${ }^{2}$ Moreover, the comparison between my estimates from the weighted and unweighted estimations suggests that many households in my sample make housing payments upon income arrivals. The coincident timing implies that the finding in literature of excess sensitivity in consumption to income arrivals may in part reflect the excess sensitivity to regular payments. Consequently, the benefits of certain policy recommendations, such as more frequent paycheck disbursements to induce consumption that is less sensitive to income arrivals, may be overestimated. ${ }^{3}$

The comparisons between socioeconomic groups in my sample show stronger cycles, ranging from $15.8 \%$ to $22.6 \%$ higher spending following a housing payment, for households with lower educational attainment, lower income, or in the youngest or oldest age tercile than for others. The characteristics of these households are very similar to those of households that have a consumption cycle between regular income arrivals. ${ }^{4}$ Therefore, for these subgroups, the correlation between the excess sensitivity in consumption to regular payments and the excess sensitivity to regular income can be higher.

\footnotetext{
${ }^{2}$ The drop in spending on non-durable goods or food consumption between monthly income arrivals is estimated to be $7 \%$ in Stephens (2002, U.K. workers), 11\% in Stephens (2003, U.S. Social Security recipients), and $10 \%$ to $15 \%$ in Shapiro (2005, U.S. food stamp recipients).

${ }^{3}$ See Shapiro (2005) and Parsons and van Wesep (2013) for discussions of the implications of increasing pay frequency.

${ }^{4}$ The youngest and poorest are more likely to be liquidity constrained, a group with a stronger cycle between paychecks found by Gelman et al.(2014). Shapiro (2005) and Kuhn (2013) find a declining food consumption between food stamp arrivals for recipients. Stephens (2003) find excess sensitivity in spending on non-durable goods to arrivals of Social Security income.
} 
The higher consumption following a regular housing payment is not fully consistent with existing theories that aim to explain departures from consumption smoothing between regular resource changes, including liquidity constraints and uncertainty about bank account balances. If households cannot smooth consumption due to liquidity constraints, then they should spend less following a housing payment, which is a negative resource change. Spending may decrease due to higher levels of uncertainty (Deaton, 1992), and researchers have argued that households may spend less before making housing payments due to uncertainty about their cash holding or bank account balances (Evans and Moore, 2012; and Vellekoop, 2012). However, it seems unclear why households in my sample, a group that receive mostly weekly or bi-weekly labor income, would have a fluctuating level of uncertainty over a month.

The rest of the paper is organized as follows. The next section reviews the literature. Section 3 shows the prediction of the LCPIH. Section 4 provides the details of the data. Section 5 discusses the empirical strategy. Results appear in Section 6. Section 7 discusses the implications of my results, and also why they are not fully consistent with existing theories that explain departures from consumption smoothing. Section 8 checks the robustness of my finding. Section 9 concludes.

\section{Literature}

This study is related to two strands of literature: (i) empirical tests of consumption smoothing between regular arrivals of income, including income from social welfare programs (Stephens, 2003; Shapiro, 2005; Mastrobuoni \& Weinberg, 2009; and Kuhn, 2013), and regular paychecks (Stephens, 2006; and Gelman et al., 2014); and (ii) household consumption commitments (Chetty \& Szeidl, 2007; Postlewaite et al., 2008; and Vellekoop, 2012). 
The first set of papers I discuss are those that use daily data to test the hypothesis derived from the LCPIH, that consumption should not respond to anticipated income arrivals. Stephens (2003) finds that Social Security recipients in the CEX Diary, especially those who have little other income, increase their expenditures on goods that are immediately consumed after purchase, such as food away from home, on the check arrival day. Shapiro (2005) and Mastrobuoni and Weinberg (2009) both study the intra-month fluctuation in calorie intake for Social Security and food stamp recipients, respectively. Both papers show that the magnitude of the drop in food consumption over a month is difficult to reconcile mathematically with traditional geometric discounting, while the decline can be calibrated with more plausible parameter values in a hyperbolic discounting model. ${ }^{5}$ Kuhn (2013) shows that, in addition to the declining food consumption pattern over a food stamp month, the magnitude of decline decreases in response to the implementation of the Electronic Benefit Transfer (EBT), which establishes more dictatorial control for EBT cardholders over food stamp resources compared to the old-style vouchers. All these papers focus on recipients of social welfare programs instead of a more representative sample of population. One reason might be that the timing of paycheck arrivals of workers are typically unavailable in public-use data, while information about social welfare pay dates are available from many sources. Hence, external validity can be a concern for results based on social welfare recipients. In contrast, the results to be delivered in my paper are based on a more representative sample - households with mortgage or rent obligations, and deriving most (at least 70\%) of their income in the two most popular frequencies (weekly and bi-weekly, accounting for $30 \%$ and $52 \%$, respectively, of all earners in the CEX Diary).

As the timing of paycheck arrivals are generally not reported in U.S. public survey

\footnotetext{
${ }^{5}$ See Laibson (1997) and Harris and Laibson (2001) for details of hyperbolic discounting models.
} 
data, Stephens (2006) uses the Family Expenditure Survey (FES), the U.K. version of the CEX Diary. The FES has information about the timing of paycheck arrivals, although the exact dates need to be imputed, thus measurement error can be a concern. Stephens find that, for monthly paid households, weekly spending on non-durable goods is $£ 8.47$ or $6.8 \%$ higher during the week containing a paycheck arrival, compared to the week before. A more recent research utilizes data generated by a personal finance app on smartphones. Gelman et al. (2014) find that total spending increases by $45 \%$ during the week following a paycheck arrival, among which over one third can be attributed to consumers paying regular bills, including mortgage and rent, upon paycheck arrivals. Excluding the recurring spending, there is still a $30 \%$ increase following a paycheck arrival, and such a sensitivity is concentrated on those with low liquidity. ${ }^{6}$ Based on these findings of excess sensitivity in spending to paycheck arrivals, I provide an estimation strategy that explicitly disentangles the spending cycle between paycheck arrivals from the cycle between housing payment days. I also show that many households in my sample choose to make housing payments upon income arrival, consistent with Gelman et al.(2014). Therefore, researchers who study spending or consumption cycle between paychecks should carefully consider the possibility that fluctuation in spending or consumption over time can be related to both regular income arrivals and regular payments.

The second set of papers I discuss are from the literature on household consumption commitments, defined as goods that involve transaction costs and are infrequently adjusted. Spending on housing is a typical consumption commitment. Chetty and Szeidl (2007) show that households only adjust consumption on both commitment and non-commitment goods when the magnitude of an income shock is sufficiently

\footnotetext{
${ }^{6}$ One disadvantage of the data generated by this app is the lack of demographic information associated with each account, making it impossible to investigate the heterogeneity among socioeconomic groups other than liquidity groups.
} 
large. Otherwise, the adjustment in consumption is concentrated on non-commitment goods. One implication of their model is that consumers can be risk-loving with respect to large-stake shocks, as marginal indirect utility of total wealth can be increasing due to the additional gain from re-optimization between commitment and non-commitment goods. Along this path, Postlewaite et al. (2008) derive optimal employment contracts in a risky market for workers who can choose the timing to start their consumption commitments. My paper illustrates another role of consumption commitment, that given a fixed level of consumption of commitment goods (housing) in the short run, the consumption of non-commitment goods can be responsive to the timing of payment for the commitments.

This paper is related to the analysis in Vellekoop (2012), the only paper that I am aware of that studies intertemporal spending decisions between payments for regular consumption commitments. Using the CEX Diary data, he finds a spike in nonhousing spending on the housing payment day, and the pattern prevails across groups of households with different pay frequencies. My paper furthers Vellekoop's work by investigating spending patterns over the month between housing payments, while controlling for the potential spending cycle between unobservable paycheck arrivals in the CEX Diary. As Gelman et al. (2014)'s finding suggests, it is common for households to make regular payments upon paycheck arrivals. Therefore, separating the cycle between paychecks from the cycle between housing payments is necessary.

\section{Prediction of the LCPIH}

In this section, I solve the optimization problem of a household committing to making regular housing payments, and derive the hypothesis to be tested. Consider a mortgage-carrying household receiving wage $w$ in each period and paying a fixed 
mortgage installment of $h$ in each of $T$ periods. The first installment is due in period $T$, the second in period $2 T$, and so on. The household solves the problem

$$
\max _{\left\{c_{t}\right\}_{0}^{\infty}} \sum_{t=0}^{\infty} \beta^{t} u\left(c_{t}\right)
$$

subject to the life-time budget constraint

$$
\sum_{t=0}^{\infty} \frac{c_{t}}{(1+r)^{t}} \leq \sum_{t=0}^{\infty} \frac{w}{(1+r)^{t}}-\sum_{m=0}^{\infty} \frac{h}{(1+r)^{T(m+1)}}+X_{0}
$$

where $u(\cdot)$ is an increasing, differentiable and strictly concave instantaneous utility function of non-housing consumption $c_{t} . \beta$ is the discount factor. $r$ is the interest rate in a perfect capital market that the household can access. $X_{0}$ is the initial asset held by the household in period $0 . t$ is the index for periods, and $m$ is the index for mortgage windows. The household takes the infinite mortgage contract as given and stays in the same property throughout its lifespan. ${ }^{7}$ Hence, the consumption of housing is omitted from the utility function for simplification. There is flexibility in interpreting the length of a period. If a period denotes one day, then $T$ can be thought as approximately 30. Alternatively, a period may represent a week or a bi-weekly period. $T$ can then be rounded to 4 or 2 respectively.

The solution of problem (1)-(2) satisfies the usual Euler equation:

$$
u^{\prime}\left(c_{t}\right)[\beta(1+r)]^{t}=u^{\prime}\left(c_{0}\right)
$$

\footnotetext{
${ }^{7}$ Here, I abstract from mortgage delinquency and foreclosure. As the question is whether household smooth consumption between housing payments, by construction the households of interest are those who make the payments on a regular basis and do not default. Households that default, if any in the CEX Diary, would appear the same as mortgagors or renters recording no housing payments in diaries, and hence would be excluded from my sample. See Section 4 for more details on my sample selection process.
} 
I apply the standard assumption $\beta(1+r)=1$. The solution then simplifies to

$$
c_{t}=c_{0} \forall t
$$

which can be formalized as the following testable hypothesis:

Consumption-smoothing hypothesis Consumption of non-housing goods should be constant over time, including during the four-week window surrounding the housing payment day. ${ }^{8}$

\section{Data}

I use the Consumer Expenditure Survey (CEX) Diary published by the Bureau of Labor Statistics (BLS) from 1998 to 2011. Each year, the CEX Diary samples about 6,000 to 7,000 households across the country, asking them to record all their daily expenditures, including mortgage payment and rent of dwelling, in two consecutive weekly diaries. ${ }^{9}$ Household demographics are also collected. For each entry of an expense, the calendar date is recorded. Households do not choose when to start the diaries. Instead, the starting day is predesignated by the BLS so that each day of the week has an equal chance to be the first diary day. The diaries are evenly spaced throughout the year. Knowing how long the purchased goods will last is crucial in

\footnotetext{
${ }^{8}$ Alternatively, I can assume some minimum impatience of households, i.e. $\beta(1+r)<1$. The consumption path of non-housing goods will then be decreasing over life cycle, in particular, over the four-week window surrounding the housing payment day. I abstract from this case because the magnitude of monthly decline should be small. Following Shapiro's (2005) assumption of log utility and annual discount factor of 0.8 , and further assuming a $3 \%$ annual interest rate, the decline in daily consumption over a month will be only $1.5 \%$. This magnitude should be considered as an upper bound since those choices of discount factor and interest rate are well below the estimates based on life cycle consumption profiles.

${ }^{9}$ Some households quit after one week. I keep these one-week diaries in my sample.
} 
studies of consumption using expenditure data. The more durable a good is, the less expenditure tracks consumption. In the CEX Diary, durability can be inferred from the name of most records thanks to a detailed categorization provided by the BLS.

The frequency of housing payments are not reported in the CEX Diary. However, external data sources, such as the Survey of Consumer Finances (SCF), suggest that the vast majority of mortgage and rent payments in the U.S. are made monthly. For example, Vellekoop (2012) documents that $99.3 \%$ renters and $98.1 \%$ mortgagors pay their dues monthly, using SCF data from 1998 to 2010. Meanwhile, starting from 1998, a new variable was created in the CEX Diary to report the length of period covered by the most recent paycheck received by each labor income earner in a household. I use this length of period as a proxy for paycheck frequency. Unfortunately, the date of paycheck arrival has never been reported.

I focus on a sample of households that have mortgage or rent obligations. Unlike Vellekoop (2012), homeowners who have paid off their mortgages are not included, since the distance from a spending day to the housing payment day is not welldefined for these households. ${ }^{10}$ For the same reason, mortgagors and renters must have a housing payment day in their diaries to be considered, as otherwise the data

\footnotetext{
${ }^{10}$ Including homeowners without mortgages as in Vellekoop (2012) may lead to unclear definition of variables in the econometric specification. On the other hand, there might be a sample selection concern by excluding these households, as households that have bought their home with cash or paid off mortgages more quickly might be wealthier or more debt-averse, and potentially also have more smoothed intra-month consumption. Overall, the benefit of excluding homeowners without mortgages appears to outweigh the cost, considering that not many households can afford to buy a home with all cash, the majority of U.S. mortgage loans have a 30-year term, and a penalty can result if mortgages are paid early.
} 
do not provide any information about the timing of housing payments. ${ }^{11}$

Most lenders allow 14-day grace period for mortgage payments after the official due date, which is usually the first of month. Similarly, there is no reason to expect that landlords would not let tenants choose a convenient day to pay, as long as the payments are made on a regular basis. Hence, a convenient choice of households is to make housing payments upon paycheck arrivals and avoid the bad consequences of temporary illiquidity (Gelman et al., 2014). To reduce potential confounding response in spending to unobserved income arrivals, I further restrict my attention to households that derive most of their before-tax annual income from weekly or bi-weekly earnings, and compare their average daily spending during the two weeks following a housing payment, and the two weeks before that day. This comparison should substantially reduce the influence of any confounding spending cycle between income arrivals, which should occur on weekly or bi-weekly basis for households in my sample. Following Stephens (2003). I choose $70 \%$ as the minimum share of these types of earnings in total income. ${ }^{12}$

I restrict my attention to diary days that fall in the 28-day window surrounding the housing payment day, so that all months are treated symmetrically. ${ }^{13}$ For households that have recorded their two weekly diaries in two consecutive weeks, I can observe spending on days that are as far as 13 days after the housing payment day (if the

\footnotetext{
${ }^{11}$ Note that the diaries of the mortgagors and renters recording no housing payments are just those do not cover a housing payment day, because the BLS designated their diary periods to be so. Since the diaries are evenly spaced over a year, excluding these households should not cause a sample selection problem if housing payments are truthfully recorded. In this case, the expectation is that $50 \%$ of households that have recorded 2 weekly diaries and $75 \%$ of one-week recorders will be dropped. In my sample, I lose $74.8 \%$ of one-week recorders and $62.2 \%$ two-week recorders, the latter possibly due to a survey fatigue effect that a housing payment made in the second diary week was less likely to be recorded.

${ }^{12}$ In Section 8, I show that my results are robust to choices of a higher minimum share of $90 \%$.

${ }^{13}$ This step also follows Stephens(2003). If the window is 29-day or longer, then the order of a diary day in the window may not be unique. For example, if a 29-day window starts from the 1st of each month, then the 29th day of the window starting from February 1st in a common year would be March 1st, which is also the 1st day of the next 29-day window.
} 
first diary day is the housing payment day), and 13 days before the housing payment day (if the last diary day is the housing payment day). These households allow me to construct a 27-day window surrounding the housing payment day. Moreover, among the households that have recorded two weekly diaries, $43 \%$ started the second weekly diary two or more days after finishing the first weekly diary. Therefore, I can also observe days that are farther away than 13 days after or before the housing payment day. In particular, I can observe the spending on days that are 14 days before a housing payment, which completes my construction of a 28-day window. The above sample selection gives me a sample of 7,602 households and 90,112 diary days. The Appendix shows how I construct my sample from the full CEX Diary in more details.

Table 1 reports the summary statistics for those whose weekly or bi-weekly earnings account for at least $70 \%$ of total income, and for the full CEX Diary sample. All income and expenditure numbers are inflation-adjusted to 2010 dollars. My housing payment sample is similar to the full sample in many ways, including the gender and educational attainment of household head, family size and percentage of minorities. Consumers are about 8 years younger in my sample for two reasons. First, among homeowners, older households are more likely to be mortgage-free, hence excluded from my sample. Second, older households receive more Social Security income, which is distributed monthly, a pay frequency not considered in this study. Homeownership is lower by 11 percentage points in my sample, as most of the housing payment-free households excluded are homeowners. ${ }^{14}$ Households in my sample have higher income, a natural result given the exclusion of Social Security recipients. The variance of income is also lower in my sample, as the $70 \%$ requirement on housing paymentto-income ratio excludes (i) households with zero or negative income, mostly those

\footnotetext{
${ }^{14}$ Among those households that are housing payment-free, only $7.1 \%$ are renters paying no cash rent, while $92.9 \%$ are mortgage-free homeowners.
} 
that have suffered from losses in farm or business operation; and (ii) the households with very high income, a group with a small share, if any at all, derived from regular paychecks. Figure 1 shows that the timing of making housing payment in a month is very similar between my sample and all households making housing payments in the CEX Diary. Overall, despite some deviation from the full CEX Diary, which is a random sample of the U.S. population, the representativeness of my sample remains fairly high, especially compared to the sample of social welfare recipients in many previous studies. ${ }^{15}$

To ensure that expenditures closely track consumption, I focus on spending on non-durable goods, with durability defined as about two weeks, the period of interest. ${ }^{16}$ I also define two more categories with stricter criteria of non-durability. Strictly non-durable goods include items that are consumed at the time of purchase, including meals away from home, admission tickets to entertainment and sport events, plus perishable foods at home, such as fresh vegetables, fruit, eggs and milk. Instantaneous consumption goods include only the items with zero durability, by further excluding perishable foods at home. Households in my sample spend $\$ 37.15$ per day on non-durable goods over the diary period, $\$ 15.93$ on strictly non-durable goods, and $\$ 12.92$ on instantaneous consumption goods. Unsurprisingly, they spend more on all categories compared to the full sample, as they earn more and are slightly larger in family size.

To determine the non-durability for some items in the CEX Diary, there is no clear criteria to follow other than using the discretion of researchers. Yet, if nondurability is reasonably defined, the total spending on non-durable goods and strictly

\footnotetext{
${ }^{15}$ There is a high similarity between my sample and the smartphone app users in Gelman et al. (2014). See Section 6 for a comparison.

${ }^{16}$ The non-durable goods include all food and alcoholic beverages, tobacco products, lodging away from home, gasoline, diesel, public transportation fares, admission to theaters and sport events, gambling, and personal care products.
} 
non-durables over two weeks should not be zero for too many households. ${ }^{17}$ Table 1 shows that average spending on non-durable goods over the diary period is zero for only $0.09 \%$ households in my sample. The share remains low for strict non-durables, at $0.74 \%$.

Since each household is observed in at most 14 days, different households contribute to the 28-day window in my analysis. Therefore, I examine whether the days before the housing payment day (the "Before" subsample) and the days on or after the housing payment day (the "On/After" subsample) are contributed by similar households. Table 2 compares the household characteristics of the two subsamples. There are more days in the On/After subsample, because all the days of a household that made the housing payment on the first diary day will be included in the On/After subsample, while by construction it is impossible for a household to have all diary days in the Before subsample. ${ }^{18}$

To examine whether household characteristics are statistically different between the two subsamples. I estimate

$$
C H A R_{i s}=\zeta_{0}+\zeta_{1} \text { POSTHP } P_{i s}+e_{i}
$$

where $C H A R_{\text {is }}$ is a household characteristic, such as age of household head, of household $i$ that has contributed day $s$ to my sample. POSTHP $P_{i s}=1$ if household $i$ 's diary day $s$ is on or after the housing payment day, and 0 if before that day. The associated parameter $\zeta_{1}$ represents the difference in a household characteristic between the two subsamples.

\footnotetext{
${ }^{17}$ For instantaneous consumption goods, observing zero spending should not be a concern, as by definition the items almost always have zero durability (unless households "stockpile" restaurant meals, movie tickets, etc., for future consumption). Hence, zero spending on these goods can be interpreted as zero consumption.

${ }^{18}$ Even if the housing payment day is the last diary day of a household, there will still be one day (the housing payment day) in the On/After subsample.
} 
As shown in Table 2, there is no statistically significant difference between the two subsamples for most household characteristics. The exceptions are that days in the On/After subsample are contributed by more minorities and lower-income households, but compared to the mean, the magnitudes of the differences remain small. Overall, household characteristics do not appear to change substantially over the 28-day window in my sample.

\section{Estimation}

\subsection{Empirical specification}

My goal is to empirically test the Consumption-smoothing hypothesis, which predicts that expenditures on non-durable goods, strictly non-durable goods, and instantaneous consumption goods should be constant during the four week window surrounding a housing payment day. Considering that households may make housing payments upon paycheck arrivals, and paycheck arrival dates are unobservable in my data, it is necessary to minimize the confounding responsiveness in spending to paycheck arrivals. ${ }^{19}$

Given the above concern, I abstract from fluctuations in daily spending. Instead, I examine the difference in average daily spending between the bi-weekly period before versus on or after a housing payment day. Since households in my sample derive most of their income from weekly or bi-weekly earnings, if there is a spending cycle between

\footnotetext{
${ }^{19}$ One possibility that the timings of housing payments and income arrivals are independent is automatic online withdrawal of housing payments. However, not many households (20\% of mortgagors and $3 \%$ of renters) automate their housing payments, as shown in a national survey (AARP, 2007).
} 
income arrivals, it should recur on a bi-weekly basis. ${ }^{20}$ Therefore, the comparison of average spending over two bi-weekly periods should difference out the bi-weekly spending cycle, and a difference in spending shown by the comparison should be attributable to the timing of the housing payment. Figure 2 provides examples of three cases: that daily average spending over the two weeks following a housing payment day is higher, unchanged, or lower, compared to two weeks prior to that day. For a clearer graphical presentation, I assume households in these examples make housing payments upon (every other) paycheck arrival. In general, housing payment days and paycheck arrivals may be aligned in many different ways. However, the spending cycle between housing payments should always be uncovered by the difference between the two averages as shown in Figure 2, as long as each bi-weekly period contains a full spending cycle between paychecks.

Following the above arguments, I specify the following reduced-form model to distinguish between average daily spending in the two-week period before and following the housing payment:

$$
c_{i s}=\alpha_{i}+\gamma \text { POSTHP } P_{i s}+\sum_{k=2}^{7} \eta_{k} D O W_{s k}+\sum_{l=2}^{14} \lambda_{l} D O S_{i s l}+\epsilon_{i s}
$$

where $c_{i s}$ is household $i$ 's daily expenditure on non-durable non-housing goods on day s. The household fixed-effect $\alpha_{i}$ captures the time-invariant factors affecting daily spending, such as household size, permanent household income, etc. The indicator POSTHP $P_{i s}$, the variable of interest, equals 1 if day $s$ falls in the bi-weekly period after household $i$ 's day of mortgage payment or rent payment, and 0 otherwise. The $D O W_{s k}$ 's are day-of-week indicators, for Sunday, Monday, etc. The associated

\footnotetext{
${ }^{20}$ Weekly paid households should have two identical weekly cycles over a two-week period. Therefore, in general, the spending cycle of these households can also be thought as a bi-weekly spending cycle.
} 
parameters $\eta_{k}$ 's capture differences in spending by day of the week; this is especially important for weekends. The $D O S_{i s l}$ 's are day-of-sequence indicators in a diary for day 1 to 14 . The associated parameters $\lambda_{l}$ 's capture the "survey fatigue" effect, as households tend to record less spending as they move towards the end of a diary. The zero-mean error term $\epsilon_{i s}$ accounts for any unpredictable variations in spending over time.

The parameter of interest is $\gamma$, which represents the difference in average daily expenditure between the bi-weekly period before the housing payment day, and the bi-weekly period on or after. According to the Consumption-smoothing Hypothesis in Section 3, $\gamma$ should be zero.

\subsection{Bias correction}

A key requirement for differencing out the spending cycle between bi-weekly paychecks as in Figure 2 is that spending is observable for all of the four weeks surrounding the housing payment day, as shown in Figure 2. However, in the CEX Diary, I observe at most 14 days for each household. Therefore, with my sample selection criteria that there must be one housing payment day during each household's diary period, my sample consists of disproportionally more days that are closer to the housing payment day, while less days are farther away. Figure 3 provides an example using 4 households to show the distribution of spending days over the 28-day window. Such

a distribution of days generalizes to a bell-shaped distribution of spending days in my sample, as shown in Figure 4. Therefore, an unweighted estimation of (5) will lead to an estimate of $\gamma$ that is mainly driven by the spending days relatively closer to the housing payment day. If the timing of housing payments is not random with respect to paycheck arrivals, the estimate of $\gamma$ can be biased. Figure 5 provide two 
examples. Without loss of generality, consider a household that spend the same average amount before and following a housing payment, i.e. with a true value of $\gamma=0$. Figure 5a shows that if the household make payments upon paycheck arrivals, then an unweighted estimation of (5) will give a positive, thus upward-biased, estimate of $\gamma$. Similarly, a negative and downward-biased estimate of $\gamma$ will follow if households make payments in the middle of a paycheck window, as shown in Figure 5b.

My solution to correct the bias is to assign weights to diary days over the 28-day window, so that the estimate of $\gamma$ will be evenly driven by each day. Specifically, the weight of day $s, w_{s}$, is proportional to the inverse of the share of day $s$ in my sample, for each $s \in\{-14,-13, \ldots, 13\}$. Therefore, the sum of weights conditional on $s$ is a constant for all values of $s$, allowing each day $s$ to contribute evenly to the estimation. For example, consider two types of diary days that are, respectively, seven and two days before a housing payment day, i.e. $s=-7$ or -2 . I observe 2,206 days with $s=-7$ and 5,410 days with $s=-2$. Hence, the weights are $w_{-7}=\frac{Q}{2,206}$ and $w_{-2}=\frac{Q}{5,410}$. Since I observe fewer days that are 7 days before a housing payment day, $w_{-7}>w_{-2}$.

In addition to yielding an unbiased estimation of the spending cycle between housing payments, the weighted estimation can also reveal how households in my sample time their housing payments with respect to paycheck arrivals. For example, as long as households have a declining spending profile over two weeks, as shown in Figure 5a, the bias is positive for households that match housing payments with paycheck arrivals, while Figure $5 \mathrm{~b}$ shows that the bias is negative if housing payments are made in the middle of paycheck windows. Although in these examples, average spending over two weeks remains unchanged, it should be easy to see that the link between the sign of bias and the relative timing of housing payments and paycheck arrivals is independent of whether average spending is higher, unchanged, or lower 
following a housing payment.

\section{$6 \quad$ Results}

In this section, I first report the main results, showing that spending is higher following a housing payment. I also replicate the daily spending pattern as in Vellekoop (2012), and discuss why the daily pattern does not necessarily reflect the response in spending to housing payments. Then, I compare the magnitude of the spending cycle I find between housing payments with other researchers' finding of spending cycle between income arrivals. Lastly, I investigate how the spending cycle between housing payments differs across socioeconomic groups in my sample.

\subsection{Main results}

Table 3 reports the estimated value of $\gamma$, the coefficient on POSTHP in (5), which represents the difference in average daily spending between the bi-weekly period before a housing payment day and the bi-weekly period on or after, for households that derive at least $70 \%$ of income from weekly or bi-weekly earnings. A positive estimate means higher spending after a housing payment. Each column reports the estimate for a different category of consumption goods as the outcome variable. The first three columns show the results from the weighted estimation. As a comparison, the biased estimates from the unweighted estimation, in which the days are unevenly concentrated around the housing payment day and hence possibly the income receipt day, are reported in Columns (4) through (6).

In the first three columns, the estimates are statistically significant for the two broader categories of non-durables but not for the instantaneous consumption goods. Column (1) shows that, average daily spending on non-durable goods during the bi- 
weekly period on or after the housing payment day is an average of $\$ 3.34$ higher than the daily spending during the two weeks before the housing payment, rejecting the Consumption-smoothing hypothesis. Compared to mean daily spending, the increase after a housing payment day is $9.0 \%$. Thus, households consume more for a while after making a housing payment, then reduce consumption before the next housing payment. In Column (2), the outcome variable is replaced by the spending on strictly non-durable goods, including those instantaneously consumed after purchase, and perishable foods at home, and the coefficient indicating a $\$ 1.01$ increase in daily spending of this type is statistically significant at the $10 \%$ confidence level. In Column (3), perishable foods are further excluded so that all goods are immediately consumed after purchase, and the coefficient of 0.61 is statistically insignificant. Two factors might cause the lack of significance. First, the stricter criteria on non-durability could make fluctuations in this smaller group difficult to detect. Second, there are about $45 \%$ days with zero spending on instantaneous consumption goods in my sample. This share is $24 \%$ and $35 \%$ for spending on non-durable goods and strictly non-durable goods, respectively. Therefore, spending on instantaneous consumption goods does not have as much variation as do the other two categories.

Columns (4) through (6) reports the unweighted version of the estimates. These estimates may be biased by the inclusion of more days close to the housing payment and perhaps the income receipt day, and they are larger than the weighted estimates by $40 \%$ to $65 \%$, suggesting that weighting is necessary. The sign of the bias is positive, suggesting that the responsiveness in spending to housing payments is positively correlated with that to paycheck arrivals, which can also cause a burst of spending. Hence, in my sample, there should be so many households that have made housing payments upon paycheck arrivals to the extent that an upward bias results, as suggested by Figure 5a. This finding is consistent with Gelman et al. (2014), in which 
$40 \%$ excess sensitivity of total spending to income arrivals can be attributed to the coincident timing of regular payments and regular receipt of income.

\subsection{Replicating Vellekoop's (2012) daily pattern}

Since the exact dates are observable in the CEX Diary, I can also estimate the daily fluctuation in spending as in Vellekoop (2012), by replacing POSTHP in Equation (5) with 27 indicators of spending days, with one day omitted as the base. Weighting is no longer necessary since average daily spending, by definition, will not be distorted with spending observed at daily frequency. The estimates of the coefficients on 27 spending day indicators, with the day before the housing payment day being the base, are plotted against the 28-day window surrounding a housing payment day in Figures 6(a) through 6(c) for the three categories of interest, respectively. In these figures, I also plot the $95 \%$ confidence interval of each coefficient estimate.

Across all categories, the daily spending pattern is qualitatively similar to Vellekoop's (2012) finding, that there is a spike in spending on the housing payment day, and spending appears to be smooth over the rest of the 28-day period. The spike is particularly large for spending on all non-durable goods, perhaps because some goods that can be considered as non-durable over two weeks should be re-classified as durable for daily consumption, such as gasoline and frozen meat. Spending on strictly nondurable and instantaneous consumption goods tracks consumption more closely, and the spending spikes on the housing payment day are smaller in magnitude. The confidence interval becomes wider for days farther away from the housing payment day, an unsurprising result of fewer observations of these days.

Since all these coefficient estimates may have been confounded by the spending cycle between paycheck arrivals, it is difficult to quantify how large a part of the 
spending spike on the housing payment day represent the excess sensitivity in spending to the housing payment. If income arrivals could be controlled for, daily spending between housing payments may exhibit a different pattern without a spike on a single day. Hence, it would be premature to interpret the daily spending fluctuations shown in Figures 6(a) through 6(c) as a cycle that can be explicitly attributed to the timing of housing payments.

\subsection{Comparisons with cycle between income arrivals}

The intra-month spending cycle between housing payment days is at least similar in magnitude, and may be stronger, compared to what has been documented in papers about the cycle between regular income arrivals. For example, Stephens (2006) finds that monthly-paid U.K. workers increase spending on non-durable goods by $7 \%$ during the week when a paycheck arrives, compared to the week before. In addition, I can control for income receipt in two particular cases that seek to make my results comparable with other papers on spending cycle between regular income arrivals. Stephens (2003) estimates that Social Security recipients increase spending on non-durables by an average of $10 \%$ during the first week after receiving a monthly check. The increase diminishes to an insignificant $2 \%$ in the second week, leading to an bi-weekly average responsiveness of $6 \%$. The bi-weekly increase is stronger, at $10.6 \%$, for those recipients deriving at least $70 \%$ of income from Social Security. To provide comparable results, I estimate (5) separately for mortgagors and renters using the definition of sample in Stephens (2003), and controlling for the timing of Social Security income arrival. ${ }^{21}$ In Table 4, Columns (1) through (3) show that the

\footnotetext{
${ }^{21}$ The arrival date of monthly Social Security payments is identifiable (third of month) only till 1996. Starting from 1997, the arrival date is based on the Social Security Number of recipients. When I estimate (5) for Social Security recipients, I further control for how far each day is from their most recent receipt of Social Security payment.
} 
cycle between housing payments is strong for households with Social Security income, ranging from $55 \%$ to $67 \%$ of the sample mean across categories. ${ }^{22}$

Another comparison is with Gelman et al. (2014), who focus on users of a mobile banking app. As Table 5 shows, their group of smartphone app users better resembles the households in my sample than do Social Security recipients. The authors find that non-recurring spending, defined as total spending minus regular payments, is $30 \%$ higher during the first week after households receiving their regular paychecks. With the same definition of non-recurring spending, Column (4) of Table 4 shows that the average daily spending is $\$ 64.86$ per day or $58 \%$ higher during the bi-weekly period following a housing payment, compared to the two weeks before.

These comparisons show that regular housing payments, arguably the main consumption commitment for many households, may play a role as important as regular income arrivals in intra-month household consumption smoothing. Since the cycle between regular income arrivals can be easily entangled with the cycle between regular housing payments, existing findings about intra-month consumption or spending patterns without considering the role of consumption commitments may be subject to further scrutiny.

\subsection{Comparisons between socioeconomic groups}

To investigate the difference in consumption smoothing performance between socioeconomic groups, I replace the indicator POST HP in regression equation (5) with interaction terms between POSTHP and indicators for subgroups. Hence, the associated parameters show the spending cycle between housing payments for each group of households, and I can test whether the cycle strength is statistically different between

\footnotetext{
${ }^{22}$ These magnitudes are sensitive to the exclusion of a few households with very high spending from this small sample. Removing the top $1 \%$ households from the distribution of household-level average spending will reduce the spending cycle to around $30 \%$ for these households.
} 
groups. $^{23}$

Table 6 shows the comparisons between groups of households based on a set of household characteristics available in the CEX Diary. Each panel shows the estimates of all groups that differ by one characteristic. For each coefficient estimate, the mean of daily spending of the group is also reported to illustrate relative strength of the cycle. The $p$-values of $F$-tests are shown at the bottom of each panel.

Based on the $p$-values of $F$-tests, differences appear along three dimensions. First, Panel (a) shows that the higher spending following a housing payment is concentrated among lower-educated households, in which the head does not have a college degree. These households spend $\$ 4.88$ more per day on non-durable goods, or $13.9 \%$ more, over the two weeks following a housing payment day, compared to the two weeks before. In comparison, the spending cycle is insignificantly estimated for households in which the head holds a college degree. As the negative estimates suggest, bettereducated households might even spend less following a housing payment, although these noisy estimates are sensitive to the exclusion of households with very high spending. ${ }^{24}$

Second, the magnitude of the cycle is decreasing in household income. I compare three income groups, using all households in the CEX Diary during my sample period to determine the tercile cutoffs. Panel (b) shows that households in the lowest income tercile (with mean income of $\$ 10,849$ ) spend $\$ 5.36$ more per day on non-durable goods or $22.6 \%$ following a housing payment. The increment decreases to $\$ 3.70$ per day or $12.1 \%$ for the middle income tercile (with mean income of $\$ 37,450$ ), and to

\footnotetext{
${ }^{23}$ An alternative to this method is to estimate the cycle separately for different groups using split samples, allowing for more functional flexibility. However, testing the difference between groups will be difficult. The comparisons between groups are qualitatively similar using this alternative approach.

${ }^{24}$ For this better-educated group, the estimates become positive after excluding households in the top $1 \%$ of distribution of average spending over diary period.
} 
an insignificant $\$ 2.45$ or $5.1 \%$ for the highest income tercile (with mean income of $\$ 96,645)$. The results are similar for strictly non-durable goods and instantaneous consumption goods. Across three categories, some of the $F$ tests for differences among these coefficients have $p$-values of 0.10 to 0.16 , not far from conventional levels of statistical significance. A larger sample size may lead to greater levels of confidence in the differences between income groups.

Third, the increase in spending following a housing payment has a U-shaped age profile. I consider the age of household head. Again, I use the full sample of CEX Diary to determine tercile cutoffs. Panel (c) shows that both the youngest third (with mean age of 30) and the oldest third (with mean age of 60) spend significantly more after making a housing payment. For the youngest, spending on non-durables increases by $\$ 5.38$ per day or $15.8 \%$. For the oldest, $\$ 6.30$ per day or $18.2 \%$. The cycle almost vanishes for households in the middle age tercile (with mean age of 46).

The comparisons show less heterogeneity if households are grouped based on other characteristics. Panel (d) compares households that have higher ratios of housing payments to total household income with households that have lower ratios, using the sample median of the ratio as the cutoff. ${ }^{25}$ For the lower-ratio group, the increase in spending on non-durable goods following a housing payment is larger than that of the higher-ratio group, almost with statistical significance (Prob. $>F=0.110$ ). However, the increase is less for the lower-ratio group's spending on the other two categories, and the difference between groups are insignificant. Panel (e) compares homeowners with renters, Panel (f) compares individuals living alone with families with at least two members, and Panel (g) shows the comparison between households that are more active in financial markets, and households that are less active, with

\footnotetext{
${ }^{25}$ This ratio may suffer from measurement errors, due to the measurement errors in household income data in the CEX, as advised by BLS staff. Therefore, I compare between only two groups based on this ratio.
} 
financial activeness defined as any reporting of net gains (either positive or negative) during the 12 months before the diary period, or over the two-week diary period. Overall, difference in the spending cycle appears to be small or statistically insignificant among these groups of households.

\section{$7 \quad$ Interpreting the cycle}

My results suggest that households consume more after making housing payments, and many households make housing payments upon paycheck arrivals. Therefore, the finding in literature of excess sensitivity in consumption to income arrivals may in part reflect the excess sensitivity to regular payments of consumption commitments, such as housing. The spending cycle I find is stronger for households that are lowereducated, with lower-income, or in the youngest or oldest age tercile. These households are precisely those that are more likely to have excess sensitivity in consumption to to anticipated resource changes, based on evidence found on liquidity-constrained consumers who are more likely to be very young or have lower income (Gelman et al., 2014), food stamp recipients (Shapiro, 2005; and Kuhn, 2013), and Social Security recipients (Stephens, 2003; and Mastrobuoni \& Weinberg, 2009). Therefore, for those households, the likelihood of observing excess sensitivity in consumption to both regular payments and regular income arrivals may be higher.

Confounding the two types of excess sensitivity may be a concern for policy makers. For example, researchers have argued that the consumption decline between income arrivals can be attributed to present-biased preferences, and increasing frequency of pay may lead to a welfare gain (Shapiro, 2005; Parsons and van Wesep, 2013). The benefits of this policy may be overestimated, if the role of regular payments is not considered. It also suggests that having smaller and more frequent 
housing payments may similarly help.

The cycle found in this paper is not fully consistent with existing theories that explain departures from consumption smoothing. First, the cycle is unlikely to be a result of liquidity constraints, a typical explanation for consumption decline between regular income arrivals. For a cycle driven by liquidity constraints, consumption should be lower following a housing payment, which is a negative resource change that should tighten liquidity constraints on consumption. Second, Vellekoop (2012) argues that households with present-biased preferences can have a declining consumption path between housing payments, assuming that they follow pre-determined monthly budgets, although his model does not account for why households choose to budget for a month. Existing research has offered explanations for monthly budgeting per se. For example Y. Zhang (2013) shows that bi-weekly paid households spend more following months with three paychecks, suggesting that they may have adopted rulesof-thumb by naively extrapolating current income into the future. However, furthering Vellekoop's model by including endogenous monthly budgets will need an atypical setting in which households optimize inter-month consumption (by setting monthly budgets) on the housing payment day, while on the other days, they no longer solve the same optimization problem, but focus on intra-month consumption allocations given the budgets. Third, a lack of smoothing may result from uncertainty (Deaton, 1992), and the lower spending or consumption before a housing payment day may be due to households' uncertainty about their cash holding, or bank account balances (Evans and Moore, 2012; and Vellekoop, 2012). To that end, my results would suggest more uncertainty during the two weeks before a housing payment day so that households would consume less, compared to the two weeks following a housing payment. However, because I focus on a group with mostly weekly or bi-weekly labor income, it is unclear why the level of uncertainty would fluctuate in this way for 
households in my sample, as they should have a constant good knowledge about their cash holding or bank account balances over a month.

\section{Robustness checks}

In this section, I show that my results are robust to potential endogenous delay of housing payments, negative serial correlation of intra-month consumption, inclusion of controls for calendar days, and increasing the minimum share of weekly or bi-weekly earnings in total income.

\subsection{Endogenous delay of a housing payment}

Households, especially mortgagors, may time housing payments at their convenience, as long as they make regular monthly payments. Hence, a potential concern is that some unobserved factors may be correlated with both households' timing of housing payments and their spending decisions. For example, consider a mortgagor household that needs to provide some urgent financial support to relatives when its regular housing payment day is approaching. As in Chetty and Szeidl (2007), if this negative income shock is not large enough to induce moving, which involves a large fixed cost, the household may simply reduce spending on non-housing goods. Also, the household might be able to delay the mortgage payment for a few days if it needs to, given that many lenders offer a 14-day grace period after the typical due date of the 1 st of each month. In this case, lower spending before a housing payment day results from the delay of housing payment due to the financial support to relatives. ${ }^{26}$

\footnotetext{
${ }^{26}$ Here, I consider the case in which the reduction in spending on non-housing goods concentrates on the days before a housing payment. This scenario will be the least favored for the interpretation of my results because it causes an upward bias to my estimates. The upward bias would be lower if households choose to spread the reduction in spending over days before and after a housing payment.
} 
If my results are driven by lower spending during the delay of a housing payment, then spending on non-housing goods should be lowered by more if households can delay the housing payment by fewer days. For most mortgagors, a late fee up to $5 \%$ of monthly payment will apply if payments are not made by the 15 th, which marks the end of the 14-day grace period. Hence, this deadline can be binding for mortgagors who would like to delay a housing payment to some day after the 15th had the grace period been longer, so that they need to reduce non-housing spending by more before paying for housing. Therefore, if endogenous delay of housing payments causes an upward bias to my estimates, the spending cycle should be larger for mortgagors who have made a housing payment right before the 15th, as the deadline is more likely to bind for these households.

Table 7 shows the spending cycle for four groups of mortgagor households, by the timing of their housing payment in a calendar month. ${ }^{27}$ If endogenous delay causes an upward bias to my previous estimates, the spending cycle should be larger for households that have paid during the 8th through 15th. The results show a pattern that is opposite to this prediction - households that have paid right before the 15th have by far the smoothest spending on all categories, suggesting that my results is unlikely to be driven by the upward bias introduced by endogenous delay of housing payments. $^{28}$

\footnotetext{
${ }^{27}$ I focus on mortgagor households here because it is difficult to determine when a similar deadline is for renters, as the deadline can be set quite differently among lease contracts.

${ }^{28}$ These results do not reject the existence of endogenous delay. For instance, households that have delayed may have chosen to reduce spending by more after a housing payment than before, resulting in a smaller spending cycle. In this case, my results would provide lower bounds of the magnitude of the spending cycle between housing payments.
} 


\subsection{Negative serial correlation}

Another concern is that consumption is negatively serially correlated, particularly in the high-frequency context of this study. For example, patronizing a fast food restaurant on Monday may lower a household's willingness to go again on Tuesday, as the marginal utility of consecutive fast food meals can diminish. This concern may be mitigated by my comparison of average spending over two bi-weekly periods, since after fourteen days, daily serial correlation may be minimal or even vanish for the three categories of interest. As summarized by Kuchler and Tegene (2006), the consensus in the literature is that the vast majority of households shop for groceries on a weekly basis, indicating that negative serial correlation should be small after 7 days, conceivably even smaller after two weeks.

Besides the frequency of grocery shopping, another approach to investigate negative serial correlation is to examine whether the cycle is stronger for even more refined levels of consumption categories. Referring to the fast food example again, the negative serial correlation might be large for a very detailed category - fast food away from home, while the correlation should be substantially smaller for food away from home, and probably zero for all food.

Table 8 shows the estimation of the difference in categories of daily food spending before and after the housing payment. The greatest difference occurs for all food, in Column (1), at a significant $\$ 2.37$ per day. A smaller and insignificant difference arises for food consumption away from home, in Column (2), even smaller and also insignificant for fast food in Column (3) and food at full-service restaurants in Column (4). Relative to the mean in each category, households spend $9.7 \%$ more on all food after a housing payment, 5.0\% more on food away from home, and less than $4 \%$ more on fast food or in full-service restaurants. Columns (5) through (8) show that 
a similar monotonic pattern across different levels of food expenditures generally remains when considering the probability of having any spending. Overall, it appears that the volatility in spending increases when the category encompasses more items, which are less likely to exhibit negative serial correlation.

\subsection{Controlling for calendar days}

As shown in Figure 1, many households make housing payments by the end or at the beginning of each month. Hence, the estimated spending cycle between housing payments might be confounded by fluctuation in intra-month spending associated with calendar days. For example, Evans and Moore (2012) find higher mortality and household spending during the first week of a calendar month, suggesting that the start of the month is a focal point of economic activity. Therefore, I estimate the spending cycle between housing payments by further including 30 indicators of calendar days (omitting the indicator for the 1st). Columns (1) through (3) of Table 9 report the estimates, showing that the spending cycle still remains after controlling for calendar days.

\subsection{Increasing the minimum share of weekly or bi-weekly earnings}

Households in my sample derive at least $70 \%$ of total income from weekly or bi-weekly earnings. If there is a spending cycle related to income arrivals in other frequencies, especially monthly, then such a cycle may confound my estimates. Therefore, I re-estimate the spending cycle for households that have higher shares of weekly or bi-weekly earnings in total income. Columns (4) through (6) of Table 9 reports the results for smaller samples of households with a minimum share of $90 \%$. The 
spending cycle persists, at least with significance for the broadest category of nondurable goods. The significance disappears for the other two categories, perhaps due to smaller sample sizes. The last three columns reports the estimates for this smaller sample by further controlling for calendar days. The results remain similar.

\section{Conclusion}

This paper shows that there is an intra-monthly spending cycle surrounding the day when households make a mortgage or rent payment, arguably the most important consumption commitment for many households. Compared to the two weeks before a housing payment day, daily spending on non-durable goods is $\$ 3.34$ or $9.0 \%$ higher during the two weeks following that day. The result suggests that households consume more after making a housing payment, then reduce consumption before the next one, inconsistent with the prediction of the life cycle/permanent income hypothesis that predictable changes in resources should not affect consumption allocations over time.

My sample consists of mortgagors and renter households that derive most of their income from weekly or bi-weekly earnings. By comparing the average spending between two bi-weekly periods, I show that the difference can be explicitly attributed to the timing of housing payment rather than income arrivals. I use weighted estimation to address the potential bias introduced by the limited number of observations of days in my sample. The comparison between results from the weighted and unweighted estimations shows that my estimates would be positively biased by $45 \%$ to $60 \%$ without weighting, suggesting that many households in my sample make housing payments upon paycheck arrivals. This finding of coincident timing between regular payments and regular income arrivals is consistent with Gelman et al. (2014). Hence, the findings in literature of excess sensitivity of consumption to regular income arrivals may 
in part reflect excess sensitivity to the timing of making regular payments.

The cycle between housing payment days is at least similar in magnitude, and may be stronger, compared to what has been documented about the cycle between paycheck arrivals. Comparing the subgroups in my sample, the increase in spending following a housing payment is larger for lower-educated and lower-income households, and has a U-shaped age profile. Existing research shows that these households are also more likely to lack smooth consumption between paychecks. Therefore, confounding the spending cycle between housing payments and the cycle between income arrivals might be more likely for these households.

The cycle I find is not fully consistent with existing theories that aim to explain departure from consumption smoothing between regular payments, including liquidity constraints and uncertainty about bank account balances, suggesting the need for further research on developing a model to explain my finding. Other paths to expand this research include examining the cycle at daily frequency with data that contain both paycheck arrival dates and housing payment dates, and conducting experimental studies involving different regular spending and regular income schemes.

\section{References}

[1] AARP and Woelfel Research. (2007). Consumer Payment Study.

http://assets.aarp.org/rgcenter/consume/consumer_payment.pdf. Accessed on Aug. 23, 2015.

[2] Chetty, R. and A. Szeidl (2007). "Consumption Commitments and Risk Preferences". Quarterly Journal of Economics. 122.2, 831-877.

[3] Deaton, A. (1992). "Understanding Consumption". Clarendon Press. 
[4] Evans, W., T. Moore (2012). "Liquidity, Economic Activity and Mortality". Review of Economics and Statistics. 92.2, 400-418.

[5] Gelman, M., S. Kariv, M. Shapiro, D. Silverman and S. Tadelis (2014). "Harnessing Naturally Occurring Data to Measure the Response of Spending to Income". Science: Microeconomics. 345.6193, 212-215.

[6] Harris, C and D. Laibson (2001). "Dynamic Choices of Hyperbolic Consumers". Econometrica. 69.4. 935-957.

[7] Kuchler, F. and A. Tegene. "Did BSE Announcement Reduce Beef Purchases?". United States Department of Agriculture. Economic Research Report Number 34.

[8] Kuhn, M. (2013). "Curing the Calorie Crunch: The Effect of EBT on Household Present-Bias". working paper.

[9] Laibson, D. (1997). "Golden Eggs and Hyperbolic Discounting". The Quarterly Journal of Economics. May. 443-477.

[10] Mastrobuoni, G. and M. Weinberg. (2009). "Heterogeneity in Intra-Monthly Consumption Patterns, Self-Control, and Savings at Retirement". American Economic Journal: Economic Policy. 1.2, 163-189.

[11] Parsons, C., E, van Wesep (2013). "The Timing of Pay". Journal of Financial Economics. 109.2, 373-397.

[12] Postlewaite, A., L. Samuelson and D. Silverman (2008). "Consumption Commitments and Employment Contracts". Review of Economic Studies. 75, 559-578.

[13] Shapiro, J. (2005). "Is There a Daily Discount Rate? Evidence from the Food Stamp Nutrition Cycle". Journal of Public Economics. 89, 303-325. 
[14] Stephens, M. (2003). "3rd of tha Month: Do Social Security Recipients Smooth Consumption Between Checks?". American Economic Review. 93.1, 406-422.

[15] Stephens, M. (2006). "Paycheck Receipt and the Timing of Consumption". The Economic Journal. 116, 680-701.

[16] Vellekoop, N. (2012). "Explaining Intra-Monthly Consumption Patters: The Timing of Income or the Timing of Consumption Commitments?" working paper.

[17] Zhang, C.Y. (2013). "Monthly Budgeting Heuristics: Evidence from 'Extra Paychecks"'. working paper. 


\section{Figures}

Figure 1: Histogram of the calendar day of the housing payment day, sample of this study versus the CEX Diary.

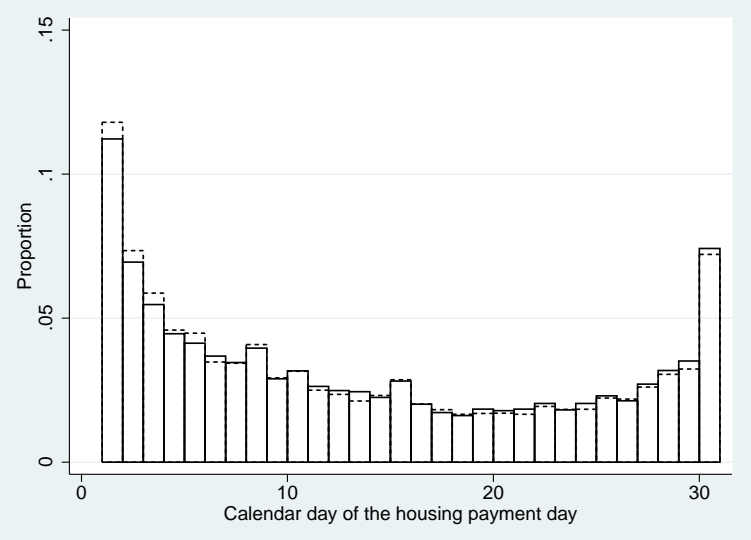

Solid = sample of this study; Dashed $=$ the CEX Diary. Number of weekly or bi-weekly paid households recording housing payments $=7,602$. Number of households recording at least one housing payment in the CEX Diary $=21,282$. Each bar represents a calendar day in a month. 
Figure 2: Uncovering the spending cycle with respect to the timing of a housing payment.

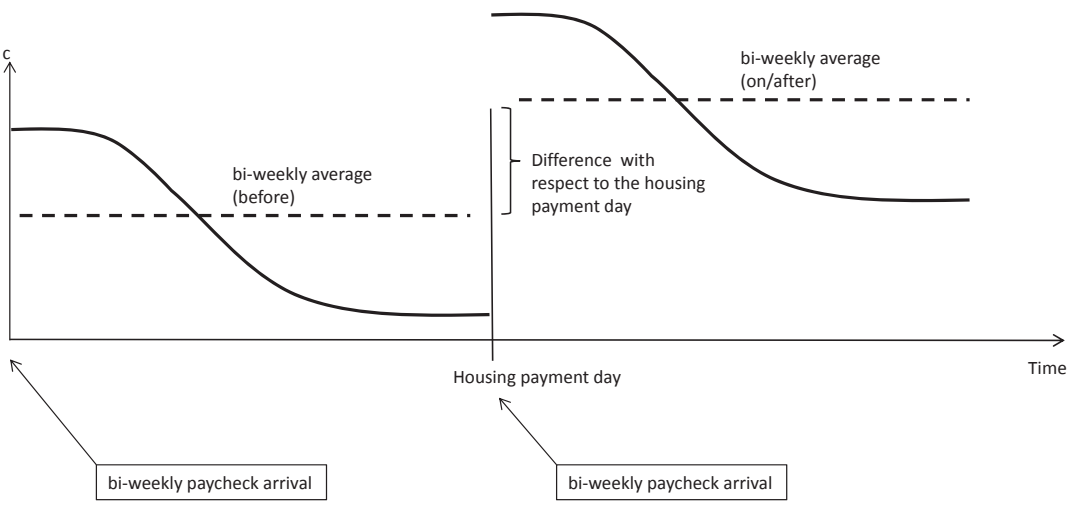

(a) Higher average spending following a housing payment

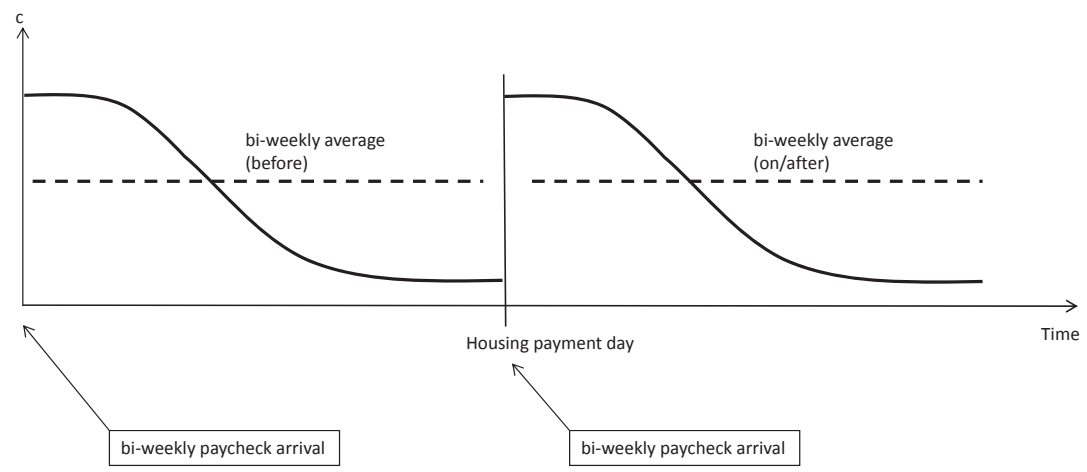

(b) Unchanged average spending following a housing payment

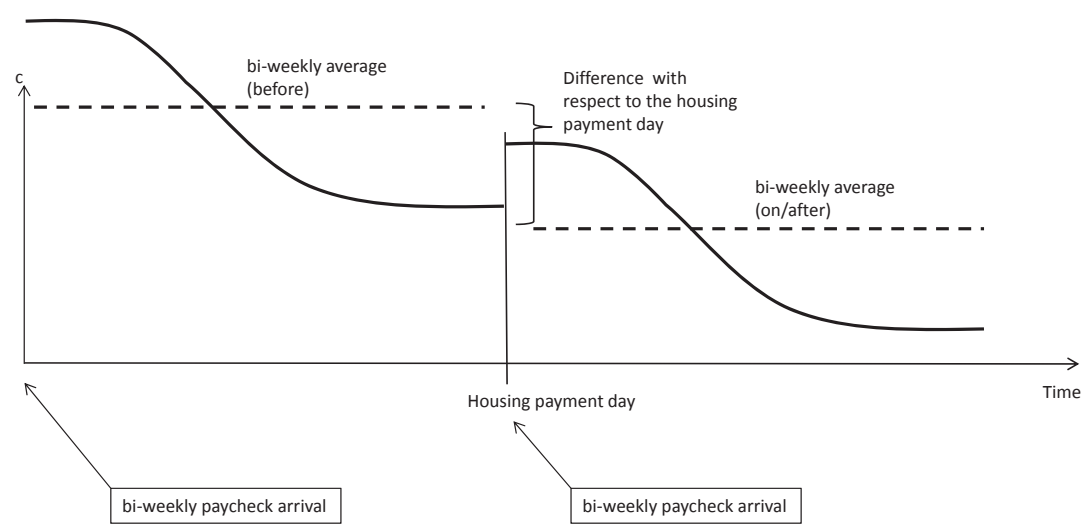

(c) Lower average spending following a housing payment 
Figure 3: Example of 4 households: why the distribution of diary days is non-uniform over the 28-day window.

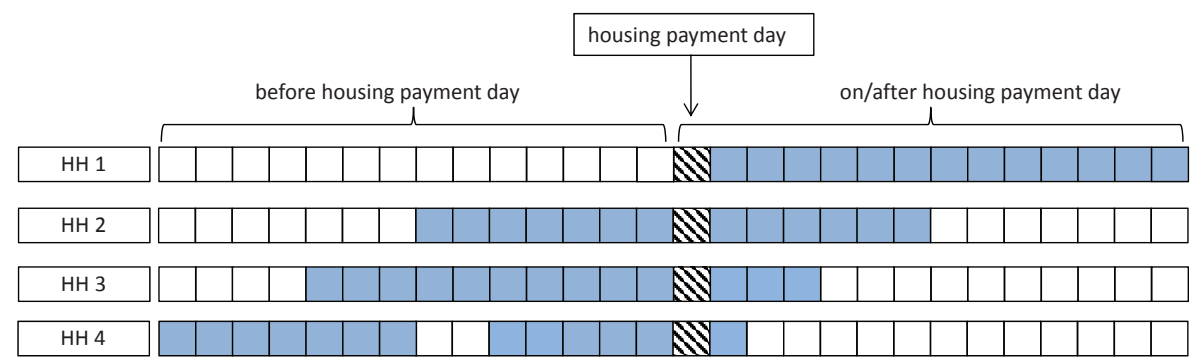

\begin{tabular}{|l|l|l|l|l|l|l|l|l|l|l|l|l|l|l|l|l|l|l|l|l|l|l|l|l|l|l|l|l|}
\hline Count of days & 1 & 1 & 1 & 1 & 2 & 2 & 2 & 2 & 2 & 3 & 3 & 3 & 3 & 3 & 4 & 4 & 3 & 3 & 2 & 2 & 2 & 1 & 1 & 1 & 1 & 1 & 1 & 1 \\
\hline
\end{tabular}

Each filled box represents an observation of diary day. The boxes with stripes are housing payment days. Each households are observed in 14 days, as households in the CEX Diary record only two weekly diaries. Household 4 starts its second weekly diary two days after finishing the first one.

Figure 4: Histogram of diary days by distance from the housing payment day recorded in a diary.

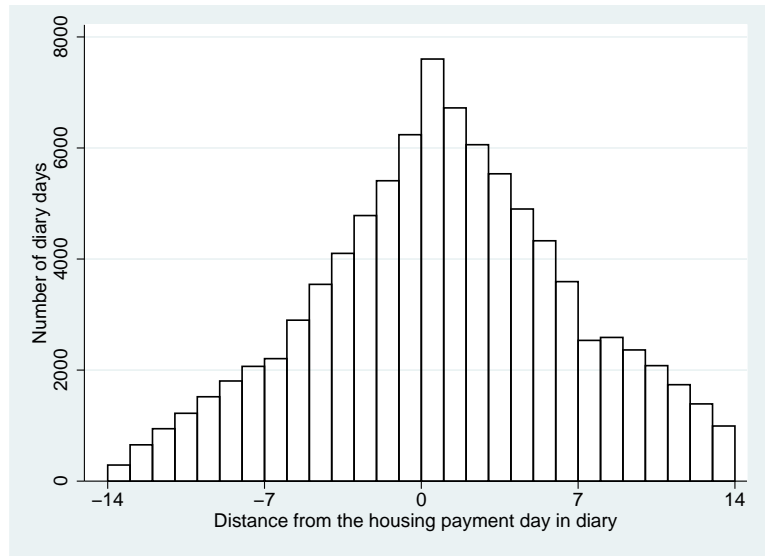

In the sample of this study, I only consider the days in the bi-weekly period before a housing payment day, and the days in the bi-weekly period that starts from a housing payment day, so that the 28-day window covers exactly one housing payment day, even in the shortest month (i.e. February in common years). 
Figure 5: Potential bias introduced by the bell-shaped distribution of spending days, assuming the same average spending between the two bi-weekly periods surrounding a housing payment day.

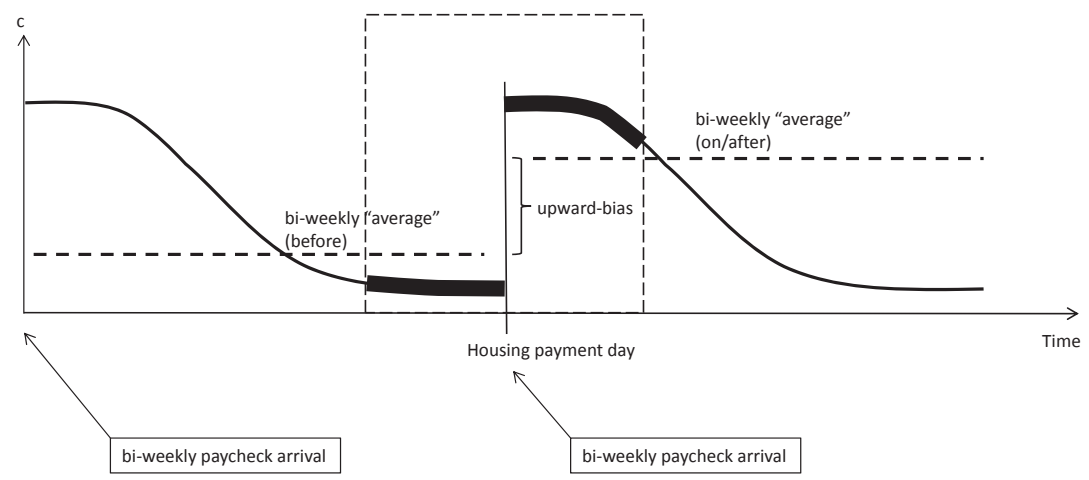

(a) Households make housing payments upon (every other) paycheck arrivals

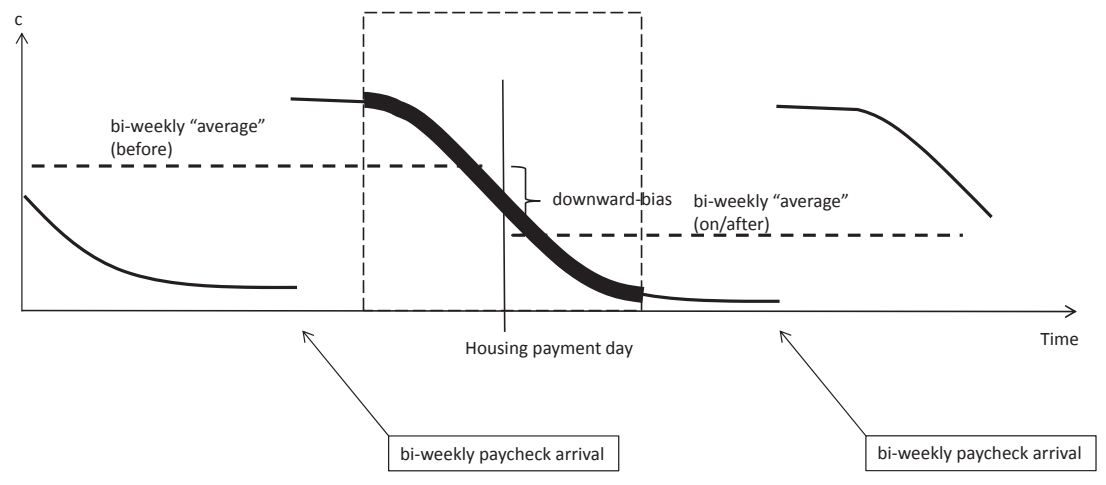

(b) Households make housing payments in the middle of a paycheck window 
Figure 6: Plots of regression results: fluctuation in daily spending, measured in deviation from the day before the housing payment day, by distance from the housing payment day.

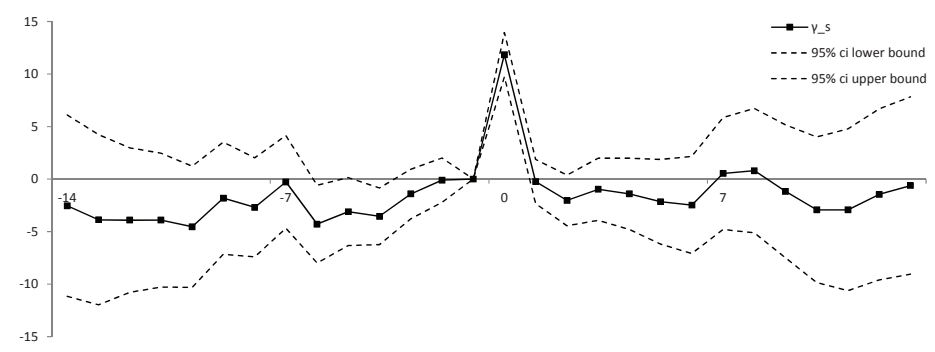

(a) Total non-durable

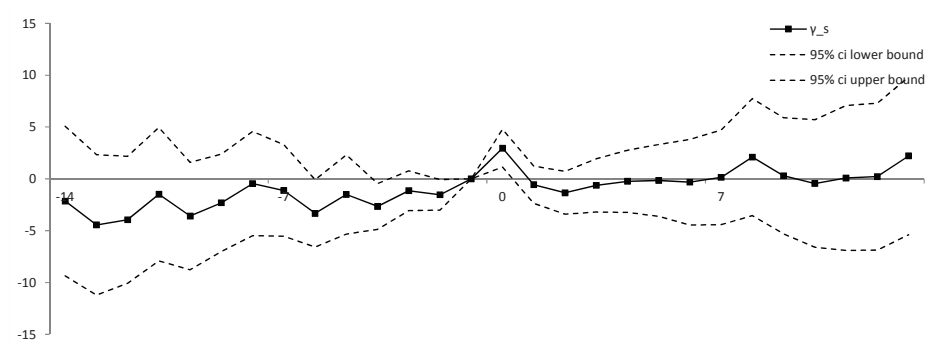

(b) Strictly non-durable

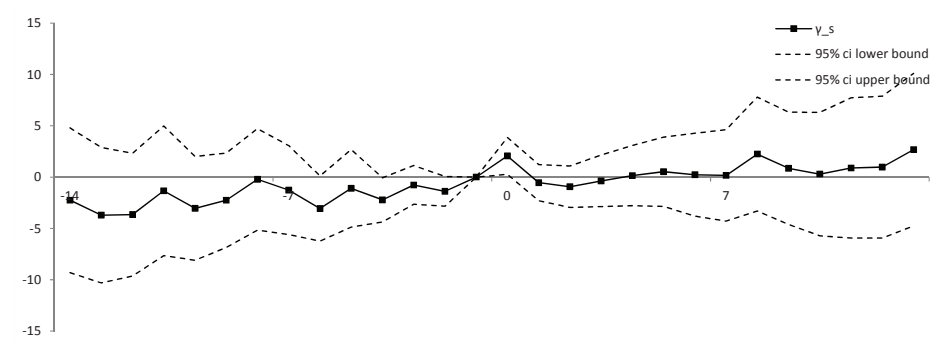

(c) Instantaneous consumption

1. The sample consists of households recording exactly one housing payment in the diary. All households derive at least $70 \%$ of before-tax annual income from weekly or bi-weekly earnings.

2. All regressions include the household-level fixed effect, and control for the day-of-week, and the day-ofsequence in the CEX Diary.

3. All regressions are unweighted. Since spending is observed on a daily basis and the estimates represent daily fluctuation in consumption, the non-uniform of distribution of days over the 28-day window will not bias these estimates. 


\section{Tables}

Table 1: Summary statistics: sample of this study and the full CEX Diary 1998-2011

\begin{tabular}{|c|c|c|c|c|}
\hline & \multicolumn{2}{|c|}{$\begin{array}{l}\text { Weekly/bi-weekly paid } \\
\text { mortgagors/renters }\end{array}$} & \multicolumn{2}{|c|}{$\begin{array}{l}\text { Full CEX Diary } \\
\text { 1998-2011 }\end{array}$} \\
\hline & Mean & S.D. & Mean & S.D. \\
\hline Age of household head & 39.67 & 11.67 & 48.35 & 17.23 \\
\hline$\%$ male head & 0.508 & 0.500 & 0.493 & 0.500 \\
\hline$\%$ non-white head & 0.171 & 0.377 & 0.166 & 0.372 \\
\hline$\%$ head has a college degree & 0.276 & 0.447 & 0.285 & 0.452 \\
\hline$\%$ homeowners & 0.552 & 0.497 & 0.667 & 0.472 \\
\hline Household size & 2.79 & 1.55 & 2.52 & 1.47 \\
\hline Annual before-tax income & 59,911 & 42,258 & 52,109 & 65,000 \\
\hline \multicolumn{5}{|c|}{$\begin{array}{l}\text { Household-level average spending } \\
\text { on goods over diary period }\end{array}$} \\
\hline Total non-durable & 37.15 & 32.54 & 31.22 & 35.43 \\
\hline Strictly non-durable & 15.93 & 19.83 & 13.15 & 22.60 \\
\hline Instantaneous consumption & 12.92 & 19.02 & 10.40 & 21.84 \\
\hline \multicolumn{5}{|l|}{$\begin{array}{l}\text { \% zero spending } \\
\text { over diary period }\end{array}$} \\
\hline Total non-durable & \multicolumn{2}{|c|}{0.001} & \multicolumn{2}{|c|}{0.003} \\
\hline Strictly non-durable & \multicolumn{2}{|c|}{0.007} & \multicolumn{2}{|c|}{0.018} \\
\hline Instantaneous consumption & \multicolumn{2}{|c|}{0.060} & \multicolumn{2}{|c|}{0.154} \\
\hline Number of households & \multicolumn{2}{|c|}{7,602} & \multicolumn{2}{|c|}{97,457} \\
\hline Number of diary days & \multicolumn{2}{|c|}{90,112} & \multicolumn{2}{|c|}{$1,120,735$} \\
\hline
\end{tabular}

My sample consists of households that are mortgagors or renters who derive at least $70 \%$ of annual before-tax income from weekly or bi-weekly labor income, and have recorded one housing payment over the diary period. Sample period is 1998-2011. 1998 is the first year the CEX Diary starts to report frequency of wage payments. All income and spending numbers are in 2010 dollars. 
Table 2: Summary statistics: household characteristics of diary days before the housing payment day, versus on or after

\begin{tabular}{|c|c|c|c|c|c|}
\hline & \multicolumn{2}{|c|}{ Before } & \multicolumn{2}{|c|}{ On or after } & \multirow{2}{*}{ POSTHP } \\
\hline & Mean & S.D. & Mean & S.D. & \\
\hline Age of household head & 39.67 & 11.69 & 39.66 & 11.66 & -0.009 \\
\hline$\%$ male head & 0.517 & 0.500 & 0.515 & 0.500 & -0.003 \\
\hline$\%$ non-white head & 0.163 & 0.370 & 0.178 & 0.383 & $0.015^{* * *}$ \\
\hline$\%$ head has a college degree & 0.281 & 0.449 & 0.271 & 0.444 & -0.010 \\
\hline$\%$ homeowners & 0.558 & 0.497 & 0.547 & 0.500 & -0.011 \\
\hline Household size & 2.80 & 1.52 & 2.81 & 1.56 & 0.013 \\
\hline Annual before-tax income & 60,820 & 41,632 & 59,184 & 40,889 & $-1635.90 * * *$ \\
\hline No. diary days & \multicolumn{2}{|c|}{37,684} & \multicolumn{2}{|c|}{52,428} & \\
\hline
\end{tabular}

1. The "Before" subsample contains diary days as far as 14 days before the housing payment day. The "On or after" subsample contains diary days as far as 13 day after the housing payment day. All income and spending numbers are in 2010 dollars.

2. The coefficient estimate associated with POSTHP is the slope of the regression of a household characteristic on a single variable POSTHP, which equals to 1 if household $i$ 's day $s$ is in the On/After subsample, and 0 if in the Before subsample.

3. Standard errors for the coefficient estimate associated with POSTHP is clustered at the household level.

4. $* * * / * * / *$ indicate significance at $1 \% / 5 \% / 10 \%$, respectively. 


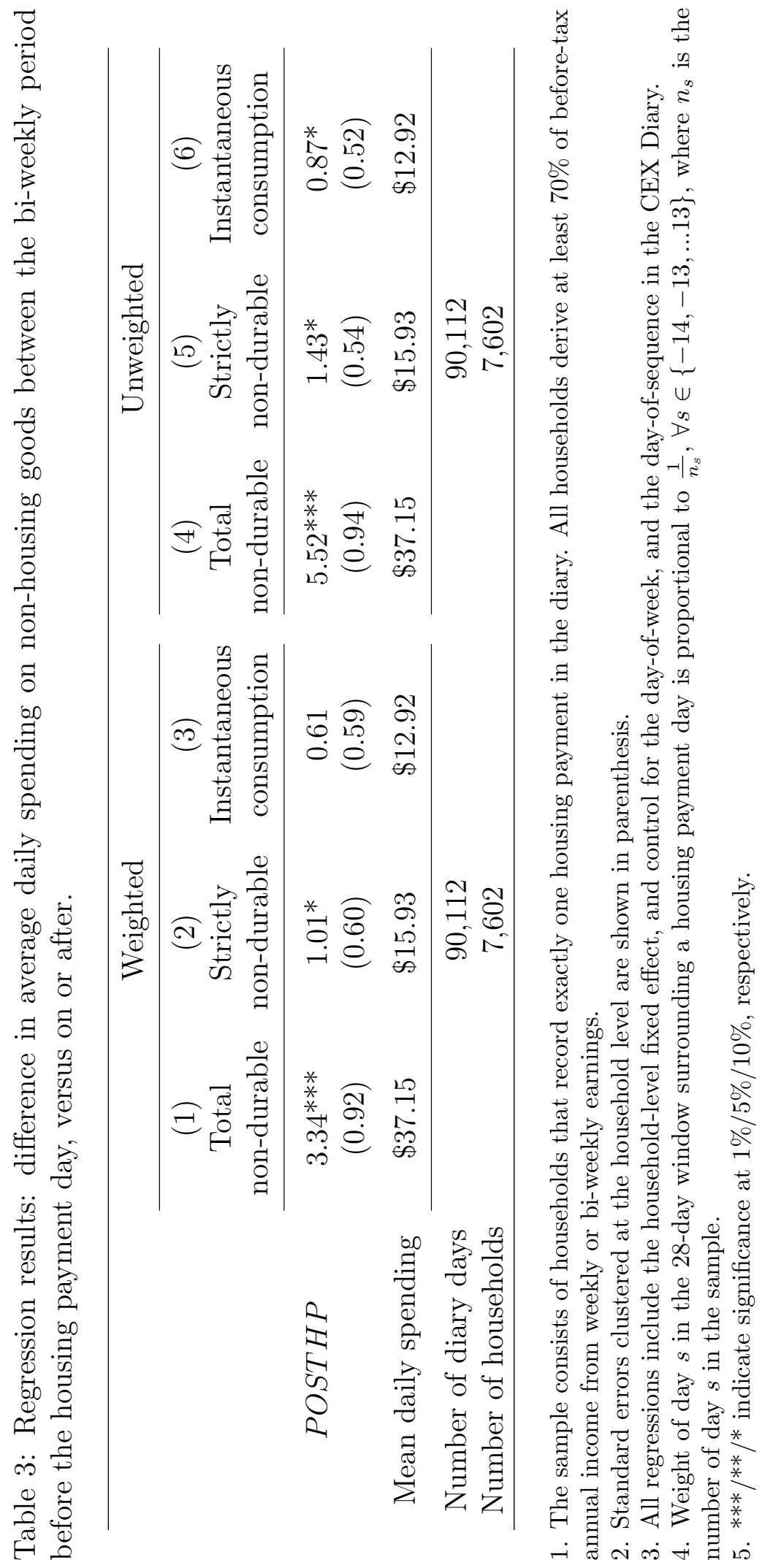


$\frac{7}{9}$

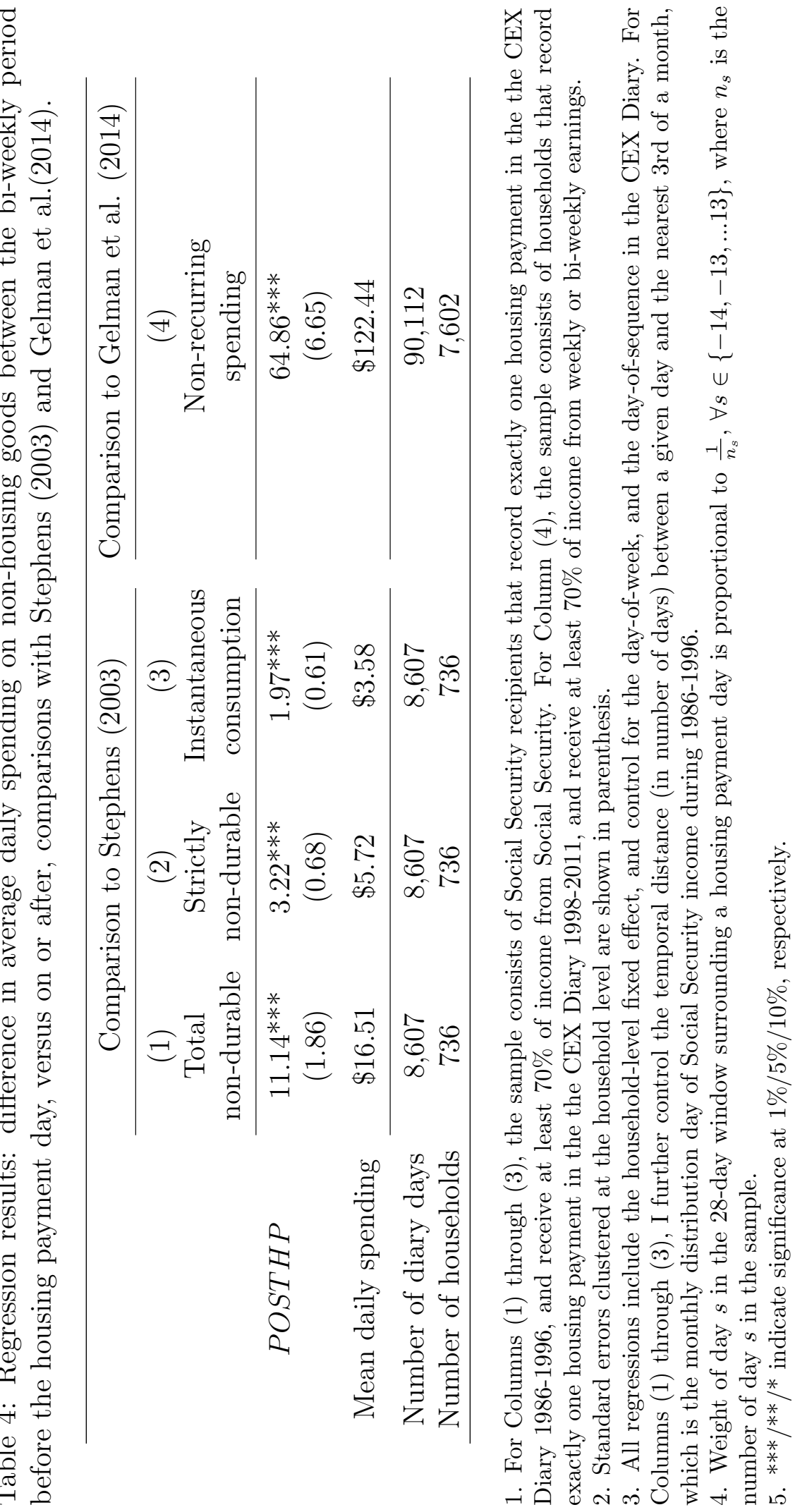


Table 5: Sample comparison (percent of households): this study versus Gelman et al. (2014)

\begin{tabular}{ccc}
\hline & This study & \multicolumn{2}{c}{ Gelman et al.(2014) } \\
\cline { 2 - 3 } Age \\
$18-20$ & 2.19 & 0.59 \\
$21-24$ & 7.02 & 5.26 \\
$25-34$ & 27.81 & 37.85 \\
$35-44$ & 28.35 & 30.06 \\
$45-54$ & 22.87 & 15.00 \\
$55-64$ & 9.97 & 7.76 \\
$65+$ & 1.79 & 3.48 \\
\hline & \multicolumn{2}{c}{ Highest degree } \\
Less than college & 72.34 & 69.95 \\
College & 19.80 & 24.07 \\
Graduate school & 7.86 & 5.98 \\
\hline
\end{tabular}


Table 6: Regression results: difference in average daily spending on non-durable goods between the bi-weekly period before the housing payment day, versus on or after, by socioeconomic groups.

\begin{tabular}{|c|c|c|c|c|}
\hline & $\begin{array}{l}\text { POSTHP interacted } \\
\text { with an indicator for }\end{array}$ & $\begin{array}{c}(1) \\
\text { Total } \\
\text { non-durable }\end{array}$ & $\begin{array}{c}(2) \\
\text { Strictly } \\
\text { non-durable }\end{array}$ & $\begin{array}{c}(3) \\
\text { Instantaneous } \\
\text { consumption }\end{array}$ \\
\hline \multirow{3}{*}{ (a) } & Less than college degree & $\begin{array}{c}4.88^{* * *} \\
(0.85) \\
\$ 35.07\end{array}$ & $\begin{array}{c}1.87^{* * *} \\
(0.58) \\
\$ 14.34\end{array}$ & $\begin{array}{l}1.46^{* *} \\
(0.57) \\
\$ 11.43\end{array}$ \\
\hline & College degree or higher & $\begin{array}{l}-0.60 \\
(2.22) \\
\$ 42.61\end{array}$ & $\begin{array}{l}-1.20 \\
(1.30) \\
\$ 20.09\end{array}$ & $\begin{array}{l}-1.57 \\
(1.26) \\
\$ 16.82\end{array}$ \\
\hline & Prob. $>F$ & 0.017 & 0.022 & 0.023 \\
\hline \multirow{4}{*}{ (b) } & $\begin{array}{l}\text { Lowest income tercile }\left(\gamma_{1}\right) \\
(\text { mean income }=\$ 10,849)\end{array}$ & $\begin{array}{l}5.36^{* * *} \\
(1.35) \\
\$ 23.73\end{array}$ & $\begin{array}{l}1.75^{* *} \\
(0.86) \\
\$ 8.83\end{array}$ & $\begin{array}{l}1.34 \\
(0.84) \\
\$ 6.52\end{array}$ \\
\hline & $\begin{array}{l}\text { Middle income tercile }\left(\gamma_{2}\right) \\
\text { (mean income }=\$ 37,450)\end{array}$ & $\begin{array}{l}3.70^{* * *} \\
(1.05) \\
\$ 30.56\end{array}$ & $\begin{array}{c}1.74^{* * *} \\
(0.63) \\
\$ 12.13\end{array}$ & $\begin{array}{l}1.31^{* *} \\
(0.61) \\
\$ 9.53\end{array}$ \\
\hline & $\begin{array}{l}\text { Highest income tercile }\left(\gamma_{3}\right) \\
\text { (mean income }=\$ 96,645)\end{array}$ & $\begin{array}{l}2.45 \\
(1.49) \\
\$ 47.67\end{array}$ & $\begin{array}{c}0.06 \\
(0.96) \\
\$ 21.81\end{array}$ & $\begin{array}{l}-0.30 \\
(0.95) \\
\$ 18.20\end{array}$ \\
\hline & $\begin{array}{l}\text { Prob. }>F\left(H_{0}: \gamma_{1}=\gamma_{2}\right) \\
\text { Prob. }>F\left(H_{0}: \gamma_{1}=\gamma_{3}\right) \\
\text { Prob. }>F\left(H_{0}: \gamma_{2}=\gamma_{3}\right)\end{array}$ & $\begin{array}{l}0.226 \\
0.121 \\
0.456\end{array}$ & $\begin{array}{l}0.989 \\
0.156 \\
0.102\end{array}$ & $\begin{array}{l}0.967 \\
0.161 \\
0.112\end{array}$ \\
\hline \multirow{4}{*}{ (c) } & $\begin{array}{l}\text { Youngest tercile }\left(\gamma_{1}\right) \\
(\text { mean age }=30)\end{array}$ & $\begin{array}{l}5.38^{* * *} \\
(1.00) \\
\$ 33.95\end{array}$ & $\begin{array}{c}1.88^{* * *} \\
(0.69) \\
\$ 15.03\end{array}$ & $\begin{array}{l}1.39^{* *} \\
(0.67) \\
\$ 12.33\end{array}$ \\
\hline & $\begin{array}{l}\text { Middle age tercile }\left(\gamma_{2}\right) \\
\quad(\text { mean age }=46)\end{array}$ & $\begin{array}{l}-0.06 \\
(1.60) \\
\$ 41.86\end{array}$ & $\begin{array}{l}-0.43 \\
(0.94) \\
\$ 17.51\end{array}$ & $\begin{array}{c}-0.67 \\
(0.92) \\
\$ 14.16\end{array}$ \\
\hline & $\begin{array}{l}\text { Oldest tercile }\left(\gamma_{3}\right) \\
(\text { mean age }=60)\end{array}$ & $\begin{array}{l}6.30^{* * *} \\
(1.67) \\
\$ 34.69\end{array}$ & $\begin{array}{l}2.23^{*} \\
(1.15) \\
\$ 14.35\end{array}$ & $\begin{array}{c}1.63 \\
(1.13) \\
\$ 11.23\end{array}$ \\
\hline & $\begin{array}{l}\text { Prob. }>F\left(H_{0}: \gamma_{1}=\gamma_{2}\right) \\
\text { Prob. }>F\left(H_{0}: \gamma_{1}=\gamma_{3}\right) \\
\text { Prob. }>F\left(H_{0}: \gamma_{2}=\gamma_{3}\right)\end{array}$ & $\begin{array}{l}0.002 \\
0.589 \\
0.004\end{array}$ & $\begin{array}{l}0.031 \\
0.749 \\
0.053\end{array}$ & $\begin{array}{l}0.051 \\
0.827 \\
0.089\end{array}$ \\
\hline
\end{tabular}


Table 6 continued

\begin{tabular}{|c|c|c|c|c|}
\hline & $\begin{array}{l}\text { POSTHP interacted } \\
\text { with an indicator for }\end{array}$ & $\begin{array}{c}(1) \\
\text { Total } \\
\text { non-durable }\end{array}$ & $\begin{array}{c}(2) \\
\text { Strictly } \\
\text { non-durable }\end{array}$ & $\begin{array}{c}(3) \\
\text { Instantaneous } \\
\text { consumption }\end{array}$ \\
\hline \multirow{3}{*}{ (d) } & $\begin{array}{l}\text { Below-median ratio of } \\
\text { housing payments to income } \\
\text { (median ratio }=13.1 \% \text { ) }\end{array}$ & $\begin{array}{c}4.53^{* * *} \\
(1.10) \\
\$ 40.44\end{array}$ & $\begin{array}{c}0.77 \\
(0.74) \\
\$ 17.73\end{array}$ & $\begin{array}{c}0.32 \\
(0.73) \\
\$ 14.66\end{array}$ \\
\hline & $\begin{array}{l}\text { Above-median ratio of } \\
\text { housing payments to income } \\
(\text { median ratio }=30.0 \%)\end{array}$ & $\begin{array}{l}2.14^{*} \\
(1.27) \\
\$ 33.87\end{array}$ & $\begin{array}{l}1.25 \\
(0.76) \\
\$ 14.13\end{array}$ & $\begin{array}{c}0.89 \\
(0.75) \\
\$ 11.18\end{array}$ \\
\hline & Prob. $>F$ & 0.110 & 0.597 & 0.523 \\
\hline \multirow{3}{*}{ (e) } & Homeowner & $\begin{array}{l}2.56^{* *} \\
(1.23) \\
\$ 43.13\end{array}$ & $\begin{array}{c}0.64 \\
(0.70) \\
\$ 18.64\end{array}$ & $\begin{array}{c}0.30 \\
(0.69) \\
\$ 15.20\end{array}$ \\
\hline & Renter & $\begin{array}{c}4.35^{* * *} \\
(1.07) \\
\$ 29.80\end{array}$ & $\begin{array}{l}1.48^{*} \\
(0.80) \\
\$ 12.59\end{array}$ & $\begin{array}{l}1.00 \\
(0.79) \\
\$ 10.12\end{array}$ \\
\hline & Prob. $>F$ & 0.211 & 0.346 & 0.433 \\
\hline \multirow{3}{*}{ (f) } & Household size $=1$ & $\begin{array}{l}4.78^{* * *} \\
(1.62) \\
\$ 25.66\end{array}$ & $\begin{array}{c}0.80 \\
(1.15) \\
\$ 11.57\end{array}$ & $\begin{array}{l}-0.03 \\
(1.14) \\
\$ 9.98\end{array}$ \\
\hline & Household size $\geq 2$ & $\begin{array}{c}2.90^{* * *} \\
(0.99) \\
\$ 40.67\end{array}$ & $\begin{array}{l}1.07^{*} \\
(0.61) \\
\$ 17.26\end{array}$ & $\begin{array}{c}0.80 \\
(0.60) \\
\$ 13.82\end{array}$ \\
\hline & Prob. $>F$ & 0.262 & 0.815 & 0.466 \\
\hline \multirow{4}{*}{ (g) } & $\begin{array}{l}\text { Reporting any net gains } \\
\text { in financial markets }\end{array}$ & $\begin{array}{l}3.16^{* *} \\
(1.41) \\
\$ 42.19\end{array}$ & $\begin{array}{c}0.83 \\
(0.78) \\
\$ 18.74\end{array}$ & $\begin{array}{c}0.38 \\
(0.77) \\
\$ 15.38\end{array}$ \\
\hline & $\begin{array}{l}\text { No reporting of any net gains } \\
\text { in financial markets }\end{array}$ & $\begin{array}{l}3.49^{* * *} \\
(1.01) \\
\$ 33.08\end{array}$ & $\begin{array}{l}1.15 \\
(0.74) \\
\$ 13.65\end{array}$ & $\begin{array}{c}0.80 \\
(0.73) \\
\$ 10.93\end{array}$ \\
\hline & Prob. $>F$ & 0.833 & 0.738 & 0.652 \\
\hline & $\begin{array}{l}\text { Number of diary days } \\
\text { Number of households }\end{array}$ & $\begin{array}{c}90,112 \\
7,602\end{array}$ & $\begin{array}{c}90,112 \\
7,602\end{array}$ & $\begin{array}{c}90,112 \\
7,602\end{array}$ \\
\hline
\end{tabular}

1. The sample consists of households recording exactly one housing payment in the diary. All households derive at least $70 \%$ of before-tax annual income from weekly or bi-weekly earnings.

2. Standard errors clustered at the household level are shown in parenthesis. For each group of households, the mean of daily average spending over the diary period is reported below the standard error.

3. All regressions include the household-level fixed effect, and control for the day-of-week, and the day-of-sequence in the CEX Diary.

4. Weight of day $s$ in the 28-day window surrounding a housing payment day is proportional to $\frac{1}{n_{s}}$, $\forall s \in\{-14,-13, \ldots, 13\}$, where $n_{s}$ is the number of day $s$ in the sample, so that the estimates are driven evenly by each day $s$.

5. $* * * / * * / *$ indicate significance at $1 \% / 5 \% / 10 \%$, respectively. 
Table 7: Regression results: difference in average daily spending on non-durable nonhousing goods between the bi-weekly period before the housing payment day, versus on or after, by groups of calendar days of housing payment day

\begin{tabular}{|c|c|c|c|}
\hline $\begin{array}{l}\text { POSTH P interacted } \\
\text { with an indicator for }\end{array}$ & $\begin{array}{c}\text { (1) } \\
\text { Total } \\
\text { non-durable }\end{array}$ & $\begin{array}{c}(2) \\
\text { Strictly } \\
\text { non-durable }\end{array}$ & $\begin{array}{c}(3) \\
\text { Instantaneous } \\
\text { consumption }\end{array}$ \\
\hline Housing payment on 1 st -7 th & $\begin{array}{c}4.40^{* * * *} \\
(1.15) \\
\$ 34.51\end{array}$ & $\begin{array}{c}1.01 \\
(0.85) \\
\$ 15.11\end{array}$ & $\begin{array}{c}0.52 \\
(0.84) \\
\$ 12.36\end{array}$ \\
\hline Housing payment on 8th - 15 th & $\begin{array}{c}0.68 \\
(2.23) \\
\$ 40.02\end{array}$ & $\begin{array}{c}0.98 \\
(0.85) \\
\$ 16.67\end{array}$ & $\begin{array}{c}0.77 \\
(0.83) \\
\$ 13.45\end{array}$ \\
\hline Housing payment on 16 th -23 rd & $\begin{array}{c}2.99 \\
(1.95) \\
\$ 39.88\end{array}$ & $\begin{array}{c}1.00 \\
(1.30) \\
\$ 16.87\end{array}$ & $\begin{array}{c}0.32 \\
(1.28) \\
\$ 13.67\end{array}$ \\
\hline Housing payment on 24 th -31 st & $\begin{array}{l}3.16^{* *} \\
(1.37) \\
\$ 37.32\end{array}$ & $\begin{array}{c}0.59 \\
(1.05) \\
\$ 16.05\end{array}$ & $\begin{array}{c}0.30 \\
(1.05) \\
\$ 12.95\end{array}$ \\
\hline $\begin{array}{l}\text { Number of diary days } \\
\text { Number of households }\end{array}$ & $\begin{array}{c}90,112 \\
7,602\end{array}$ & $\begin{array}{c}90,112 \\
7,602\end{array}$ & $\begin{array}{c}90,112 \\
7,602\end{array}$ \\
\hline
\end{tabular}

1. The sample consists of households recording exactly one housing payment in the diary. All households derive at least $70 \%$ of before-tax annual income from weekly or bi-weekly earnings.

2. Standard errors clustered at the household level are shown in parenthesis. For each group of households, the mean of daily average spending over the diary period is reported below the standard error.

3. All regressions include the household-level fixed effect, and control for the day-of-week, and the day-of-sequence in the CEX Diary.

4. Weight of day $s$ in the 28-day window surrounding a housing payment day is proportional to $\frac{1}{n_{s}}$, $\forall s \in\{-14,-13 \ldots, 14\}$, where $n_{s}$ is the number of day $s$ in the sample, so that the estimates are driven evenly by each day $s$.

5. $* * * / * * / *$ indicate significance at $1 \% / 5 \% / 10 \%$, respectively. 


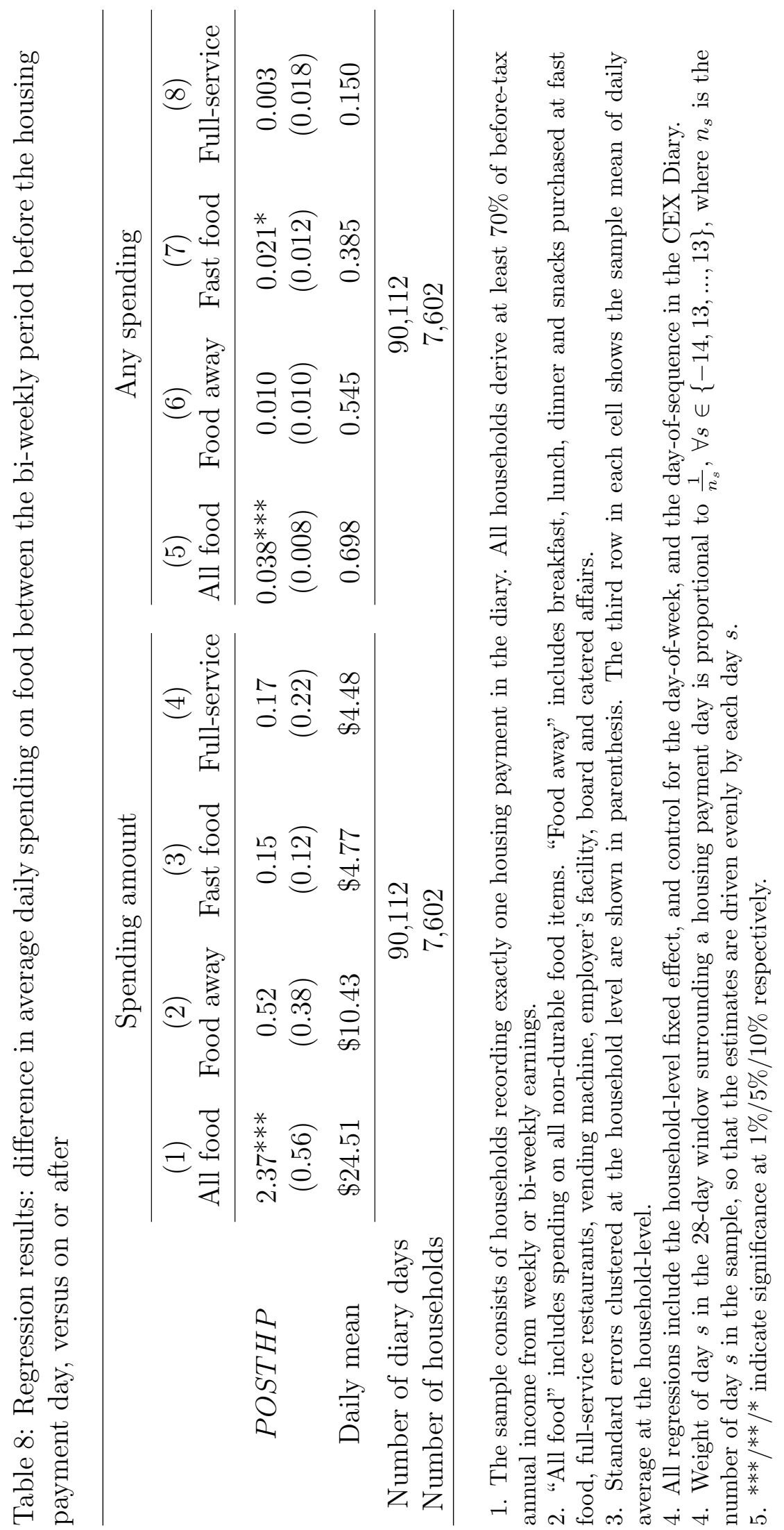




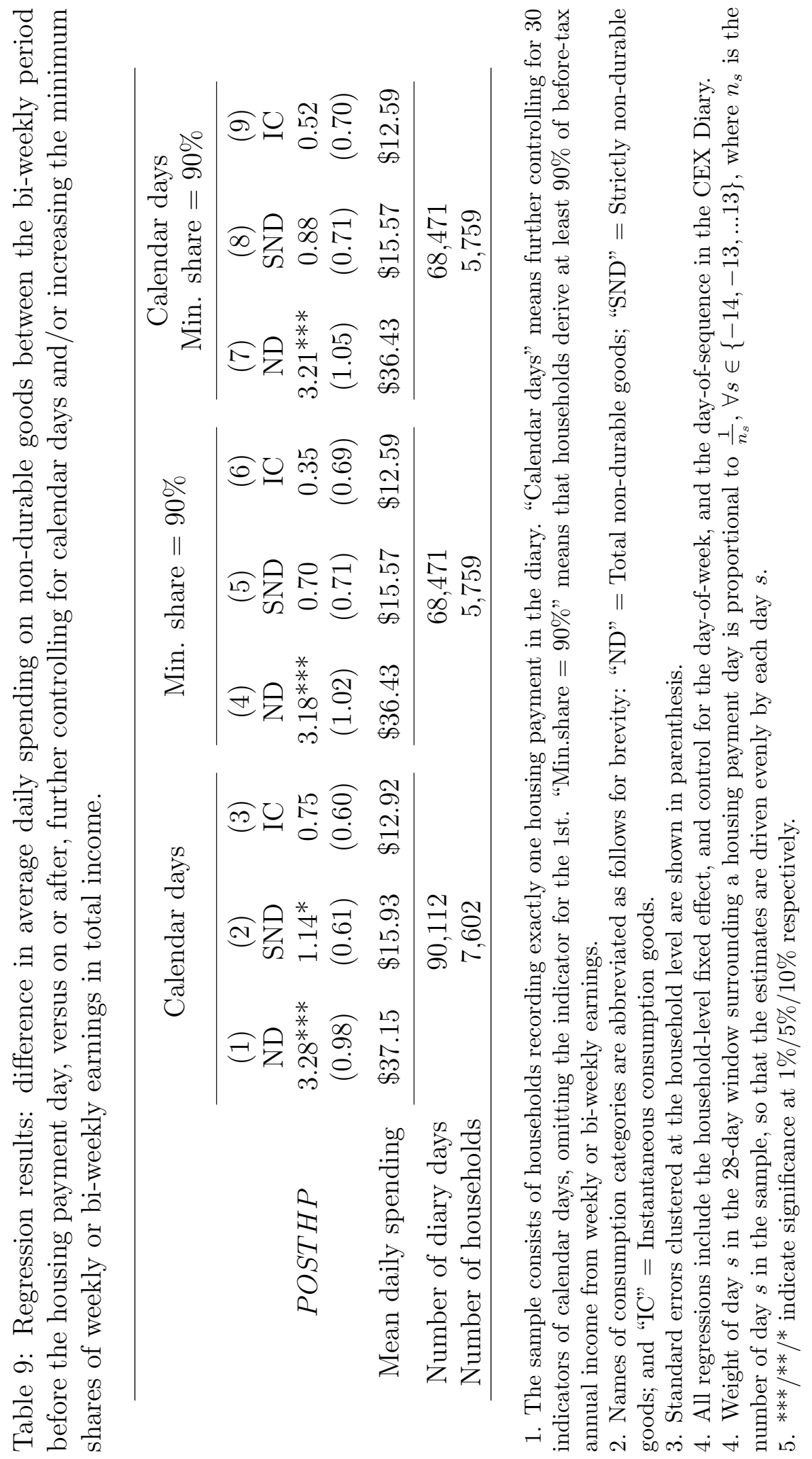




\section{Appendix}

\section{Steps to construct my sample}

The following steps show how I obtain my sample from the full CEX Diary 19982011.

- Start with the full CEX Diary 1998 - 2011 (101,122 households).

- Drop households that have recorded diaries with missing calendar dates (resulting in 97,457 households).

- Drop households that are homeowners without mortgages or with unknown mortgage status, renters paying no rents, and residents in student housing. I also drop households that have switched housing tenure status during the diary period (resulting in 72,166 households). ${ }^{29}$

- Drop households that are mortgagors or renters but did not record any housing payments in the diary, as I cannot determine how far away a diary day is from the housing payment day for them (resulting in 23,989 households).

- Drop households that made housing payments on more than one diary day, as the households of my interest are those who make housing payments monthly (resulting in 22,784 households).

- Drop households that recorded all spending on one single day during the diary period, as the timing of housing payment is unreliable for these households (resulting in 20,180 households). ${ }^{30}$

- Drop households with topcoded before-tax annual income, as I need to compute the share of weekly and bi-weekly earnings, a key determinant of my sample selection that leads to an unbiased estimation later (resulting in 19,588 households).

- Drop households in which some members did not report paycheck frequency, or all members reported zero weekly and bi-weekly earnings (resulting in 10,548 households).

- Drop households deriving less than $70 \%$ of annual before-tax household income from weekly or bi-weekly earnings (resulting in 7,602 households and 91,217 diary days). Recall that I only observe pay frequency but not the timing of paycheck arrivals.

\footnotetext{
${ }^{29}$ The 4 types of housing tenures dropped in this step correspond to 4 of 6 housing tenure codes in the Diary. The other 2 housing tenure codes are "Owned with mortgage", and "Rented".

${ }^{30}$ For diaries with undetermined dates, the BLS have assigned all spending to a single day.
} 
- Lastly, I restrict my attention to diary days that fall in the 28-day window surrounding the housing payment day, so that all months are treated symmetrically. After dropping diary days falling outside of the four-week window surrounding the housing payment day, I have a sample of 7,602 households and 90,112 diary days. 


\section{Chapter 2}

\section{The Effect of Casinos on the Non-Gambling Economy: Evidence from Nationwide House- hold Spending Data}

\section{Introduction}

The past two decades have seen a substantial expansion of casinos in the U.S. Until 1987, casinos were only legal in Nevada and New Jersey. The Indian Gaming Regulatory Act (IGRA) of 1988 sets the stage for Indian gaming on reservation lands across the country. The expansion of tribal casinos suggested a new source of revenue and was immediately followed by the legalization and expansions of commercial casinos in other states. The number of cities with at least one casino grew from 48 in December 1990, mostly in Nevada, to 263 in December 2000, and to 398 in December

2010 (Figure 1). Within the whole U.S. gaming industry, casino gaming has been by far the largest contributor of gaming revenues, and has also experienced the fastest growth from 1988 to 2009. By the end of 2009, casino revenues, including those from commercial and Indian casinos, accounted for two thirds of total gaming revenues in the U.S. The amount of annual casino revenues were over $\$ 70$ billion, equivalent to \$600 annual casino gambling spending per household (Figure 2).

There has been an ongoing debate about how benefits of casinos compare with the costs. Existing research has studied the link between casinos and job creation (Evans 
\& Topoleski, 2002; Reagan \& Gitter, 2007; NORC, 1999), crime (Grinols \& Mustard, 2006), property prices (Baxandall, 2005; Wiley \& Jackson, 2009), and revenues of other gambling goods (Elliott \& Navin, 2002; Fink \& Rork, 2003; Walker \& Jackson, 2008). Researchers have also studied the effect of casinos on other businesses, including hotels, restaurants, and entertainment and recreation services (NGISC, 1999; Siegel \& Anders, 1999; Wiley \& Walker, 2009). Among the studies on the impact of casinos on the non-gambling economy, the focus is usually on a particular geographic region, such as a state or a metropolitan area. The mixed findings indicate that in some areas casinos have crowded out revenues of other sectors, while in other areas, casinos have a complementary effect. However, there is not yet a nationwide study that empirically estimates the impact of casinos on non-gambling sectors.

My paper fills in this gap in the literature. For the first time, I provide empirical evidence of the impact of casinos on the non-gambling economy using nationwide individual household spending data. My data are from the Consumer Expenditure Survey (CEX) Interview survey, which collects quarterly spending data on over 90\% of households expenditures. My sample period, from 1996 to 2013, is a period when the casino sector has substantially expanded across the country. I also gained access to a confidential file provided by the Bureau of Labor Statistics that provides the the county-level geographic identifiers for all the CEX households. For each household in my sample, I approximate its location by the geographic center of its county of residence. I then consider the availability of casinos within a certain distance from the household. Therefore, the effect of casinos on household spending is identified by the changes in household-level quarterly spending when casino availability varies at the county level.

Casinos can influence non-gambling spending through multiple channels. An increase in tourism, or an improvement in labor markets following casino openings, can 
lead to a positive effect, while the effect can also be negative if gambling substitutes for non-gambling spending. These effects can have different strengths when the distance from households to casinos varies. For example, casinos may be a new attraction for weekend trips for households that are 100 miles away, but casinos are unlikely to have a sizable effect on the labor market outcomes of these households. Therefore, my estimation allows the effect of casinos to vary for different distances from households to casinos. In particular, I consider three zones surrounding a household: a circle area centered at the household's location with a radius of 20 miles (Zone 1), a ring area 20 to 50 miles away from the household (Zone 2), and an outer ring area that is 50 to 100 miles away (Zone 3).

I find that household spending on non-gambling goods increases when casinos open within 100 miles from households. In particular, households do not significantly change their spending for Zone-1 casinos, but their spending increases by up to $2.6 \%$ when casinos open in Zone 2 or Zone 3. A possible explanation is that households consider Zone-1 casinos as purely gambling facilities, while consider farther-away casinos as new vacation destinations. When casinos open in Zone 2 and Zone 3, the spending increase is larger for households in the lowest income tercile, up to $3.6 \%$. The positive effect on non-gambling spending occurs for the first presence of casinos, but does not always accumulate when additional casinos are built in nearby areas.

I provide extensive evidence that the positive effect of casinos on non-gambling spending is driven by more visits to casinos or casino towns. Households increase spending on transportation for farther-away casinos, and decrease transportation spending if casinos open in proximity. Spending on food at home decreases, especially when casinos are farther away. Households increase their spending on a set of goods that are complements to casino visits, such as clothes, alcohol, and tobacco. When casinos open, households also report higher gambling spending, and the self- 
reported gambling participation rate also rises. Meanwhile, households reduce their purchase of life insurance and contributions to pensions.

I also investigate whether the impact of casinos persists in the long run. I find that the complementary effect of farther-away casinos on household non-gambling spending do not significantly diminish two years after casino opening. On the other hand, the intertemporal effects of nearby casinos follow a different pattern: nongambling spending per quarter decreases by $3.5 \%$ within the two years after casino opening, and this negative effect is largely offset by a $2.6 \%$ increase after the second year. The temporary decrease in non-gambling spending in response to nearby casinos is consistent with a novelty effect of casinos, that households with the easiest access substitute non-gambling spending for casino gambling in the short run, but then their behavior reverts to the mean over time.

The findings in this paper lead to a few interesting insights. First, the positive effect of casinos on household spending suggests a complementary effect of casinos on the non-gambling economy, which contradicts the crowd-out effects of state lotteries on non-gambling spending documented in the literature (Kearney, 2005). Second, the possibility of a diminishing complementary effect when additional casinos are built in nearby areas suggests that the positive spillovers may be weakened if casinos are geographically concentrated, which is often observed near state borders, as adjacent states compete for gaming revenues. Third, welfare losses may result from the crowd-out effect of casinos on some spending categories. For example, the substantial decrease in purchase of life insurance and pension contributions may be undesirable for household members who are non-gamblers.

The rest of the paper is organized as follows. The next section is a literature review. Section 3 provides details about the data. Section 4 discusses the theories about the effect of casinos on household spending. Section 5 presents the reduced- 
form model. I describe my findings in Section 6, and discuss the implications of my findings in Section 7. Section 8 concludes.

\section{Literature}

This study relates to three strands of literature: the economic impact of casinos, the effect of gambling goods on household spending, and the use of microdata in studies of casinos.

Researchers have investigated the impact of casinos on many socio-economic outcomes. Evans and Topoleski (2002) find that, four years after tribes open casinos, employment has increased by $26 \%$ and tribal population has increased by $12 \%$, whereas bankruptcy rates and crimes increase by $10 \%$ in the hosting counties of casinos. Regan and Gitter (2007) use Census data to study the impact of tribal casinos on Native Americans, finding that casinos increase employment probability of the householder by 14 percentage points in the non-metropolitan area. A 1999 study of the National Opinion Research Center (NORC) shows an association between casino opening and a 1 percent reduction in unemployment rates. Banxandall (2005) find a small positive effect of casinos on self-reported median home values, using 1990 and 2000 Census data. Elliot and Navin (2002) study how casinos cannibalize the revenue of state lotteries, concluding that each additional $\$ 1$ generated by casinos is at the cost of losing $\$ 0.83$ lottery revenues. Their estimate is revised downward to $\$ 0.56$ by Fink and Rork (2003), who take into account the negative selection bias that states with lower lottery revenues are more likely to legalize casinos. Walker and Jackson (2008) also report a cannibalization effect of casinos on lottery revenues, although without quantifying the magnitude. Grinols and Mustard (2006) investigates the impact of casinos on county-level crime rates. They find that crime rates decrease shortly after 
casino opening, but eventually increases over the long run. In particular, between $5.5 \%$ to $30 \%$ of different crimes in casino counties can be attributed to casinos. They also show that the additional crime is created in casino counties, instead of being shifted from neighboring counties.

There is also some exploration about the effect of casinos on non-gambling sectors. Leven and Phares (1998) estimate that about half of casino revenues in Missouri were offset by gamblers' lower spending on non-casino goods inside the state. Siegel and Anders (1999) find a substitution effect of casinos exclusively on other businesses in the entertainment sector, using industry-level sales tax data for eleven Missouri counties. Chhadra (2007) estimates that $30 \%$ of gamblers in Iowa would have chosen to participate other entertainment activities if casinos were not available in town. Wiley and Walker (2009) uses Detroit property sales data to find a positive link between retail property values revenues of casinos in the town, which suggests a complementary effect of casinos on other businesses. All these studies provide useful insights, but their conclusions are based on observations within a city or a state. My paper contributes to this literature by using nationwide household spending data to quantify the impact of casinos on non-gambling sectors.

The second set of papers provide empirical evidence of how gambling goods can influence household spending. Other than the two mentioned studies for casinos in a single state (Leven \& Phares, 1998; Chhadra, 2007), a nationwide study is Kearney (2005). Using the CEX data from 1982 to 1998, she finds that when states legalize lotteries, household spending on non-gambling goods per quarter decreases by $\$ 137$, or $2.4 \%$. She claims that, since the magnitude decrease is greater than the perhousehold lottery sales during her sample period, lottery gambling can be more than completely financed by a reduction in non-gambling consumption. In comparison to Kearney's study of state lotteries, this paper studies a later period in the U.S. gaming 
history when another major gambling good, casino gaming, is substantially developed across many states. While casinos, like state lotteries in Kearney's study, may have a substitution effect on household non-gambling spending, they can simultaneously affect household spending through other channels, such as job creation, or an easier access to the amenities in casino towns.

The third set of papers are those that use individual-level data in studies of casinos. The NORC survey interviewed around 3500 individuals via telephone or in casinos across the country. Welte et al. (2002) interviewed a national sample of 2638 adults, finding that a pathological gambling prevalence rate of $1 \%$ to $2 \%$. Sévigny et al. surveyed 8842 Quebec residents, finding a positive link between casino proximity and gambling participation and expenditures in casinos in the province. Narayanan and Manchanda (2012) use administrative data collected from around 200000 loyalty card holders at an individual casino to study the addictive behavior in casino gambling, finding that only $8 \%$ of their gambler sample display evidence of addiction. In these studies, a trade-off is that larger sample size is at the cost of smaller geographic coverage of the sample, while conclusions based on nationwide data, usually with smaller sample sizes, lack statistical power. Both concerns are mitigated in my paper, as my findings are, for the first time in the casino literature, based on nationwide household-level data collected quarterly from over 220000 households over almost two decades.

\section{Data}

I use the annual Consumer Expenditure Survey (CEX) Interview public-use microdata published by the Bureau of Labor Statistics (BLS) from 1996 to 2013. The CEX is a nationwide representative survey of consumers that the BLS uses to com- 
pute the Consumer Price Index (CPI). Each year about 7,000 households are sampled, and each household participates in up to four consecutive quarterly interviews. ${ }^{1}$ The interview survey collects data on most consumption categories, along with household demographics. About $90 \%$ to $95 \%$ of total household spending is covered by the $\mathrm{CEX}^{2}$

The public-use CEX microdata identify the geographic location of households only up to the state level. Measuring casino availability at the state level can generate substantial measurement errors in the estimates of this study. For example, the Sands Casino opened in May 2009 in Bethlehem, a town in the eastern part of Pennsylvania. While it offers the residents of Philadelphia, PA a convenient new location for gambling, its impact may be limited for the residents of Pittsburgh, PA, a city that is five-hour drive away.

Therefore, to better measure casino availability for households in my sample, I gained access to a restricted access file provided by the BLS, in which I can observe the county of residence for each individual household surveyed by the CEX. The location of a household is approximated by the geographic center of its county of residence. I then consider the availability of casinos in the proximity of the approximated household location. Hence, casino availability in my data is defined for individual households at the county level.

The CEX Interview surveyed 248614 households from 1996 to 2013. In my sample, I exclude all households that live in Alaska and Hawaii. I also exclude Nevada households, as opening and closing dates are unavailable for many casinos in Nevada. ${ }^{3}$

\footnotetext{
${ }^{1}$ For each CEX respondent, there are five quarterly interviews in total. Information in the first interview is only used to prevent subsequent reporting of expenditures from an indefinite past period. Therefore, only the second through the fifth interviews are usable.

${ }^{2}$ The CEX does not cover expenses for housekeeping supplies, personal care products, and nonprescription drugs.

${ }^{3}$ I do not report the number of households in these states, since such information cannot be released as public information according to the BLS's practice of protecting respondent confidentiality.
} 
I drop 5961 households for which household income is invalid or topcoded, as I will use household income as a control variable. I then drop 2361 households that have recorded any negative spending, mostly on medical care, in any interview. Negative spending in the CEX represents reimbursements. Hence, having reimbursements in one quarter may lead to measurement errors in spending data across all interviews completed by a household. Lastly, I drop 1855 households that have recorded less than $\$ 1000$ total non-gambling spending, as these households are likely to be careless reporters who did not complete the entire survey. After these steps, I have a sample of 454520 interviews from 229721 households.

Table 1 compares the summary statistics between my sample and the sample of all CEX households from 1996 to 2013. I report a set of demographic variables that may affect household spending. The comparison suggests that, overall, my sample remains very similar to the full CEX sample. Average income and spending are slightly lower in my sample, as households with topcoded income are excluded. The standard deviations of income and spending are also smaller in my sample, due to the exclusion of both households with topcoded income, and households that report spending less than $\$ 1000$.

I obtain the opening and closing dates of commercial casinos from state gaming authorities. With little systematic public documentation of these dates for most Indian casinos, I use historical news on the Internet or in archived newspapers to determine the dates. I cross-checked these dates with The ChipGuide of the Museum of Gaming History, an online source that contains information shared by casino chip collectors about the opening and closing dates for many Indian casinos.

I focus on three definitions of proximity to the county center in which an individual lives, 20, 50 and 100 miles. 20 miles is a radius that would lead to an area similar 
to the median land area of a Census Metropolitan Statistical Area (MSA). ${ }^{4}$ Hence, it is reasonable to consider households that are 20 miles or less away from a casino to be the "local" residents. The next radius, 50 miles, is employed by Evans and Topoleski (2002) to study the labor market impact of Indian casinos on nearby areas. This distance seems reasonable as an upper bound for most commuters who work in or around a casino. The last radius, $\$ 100$ miles, is chosen because this distance approximately translates to a two-hour drive, which is typical for a one-day trip. Many casino patrons do not stay overnight. For example, a survey of patrons at Illinois riverboat casinos (Better Government Association, 1997) shows that 98 percent spent less than a day to visit a casino and spent no time in hotels.

To simplify notation, hereafter I refer to the circle with a radius of 20 miles around the center of the county in which a household lives as Zone 1, the ring area 20 to 50 miles away from the center of the county in which a household lives as Zone 2, and the outer ring area 50 to 100 miles away as Zone 3, as shown in Figure 3. I measure casino availability in each zone by the appearance of any casino. I abstract from the number of casinos in each zone for two reasons. First, for more than $80 \%$ of households in my sample, casinos in a given zone are all located in the same city. Second, more than $70 \%$ of casino towns host only one casino, and for those with multiple casinos, it appears reasonable to assume high substitutability among casinos within the same town.

While the expansion of the casino sector is evident from the maps in Figure 1, Table 2 quantifies casino availability for households in my sample for five selected years throughout the sample period. It is clear that casino availability has been steadily growing in all zones. In 1996, only 10\% of household-quarters in my sample

\footnotetext{
${ }^{4} \mathrm{~A}$ round area with a radius of 20 miles is about 1,256 square miles, whereas the median land area of a MSA in 1996 is 1,226 square miles.
} 
lived within 20 miles from a casino. This number increased to $26 \%$ in 2013. Similarly, the share of household-quarters with casinos in Zone 2 has almost doubled, from $30 \%$ in 1996 to $58 \%$ 2013, and for Zone 3, the share has also increased from $55 \%$ to $77 \%$.

Table 3 reports the summary statistics of household spending by zone. Zone 1 through 3 subsamples are not exclusive, but any one of the three subsamples and the non-casino household subsample are exclusive. ${ }^{5}$ The comparison of total nongambling spending between the first subsample and the other three shows that, unconditional on other factors that may affect spending, households with a casino within 100 miles spend more on non-gambling goods.

Starting from 2001, the CEX also provides data on gambling spending, as selfreported by respondents. However, researchers have found that gambling spending in the CEX is severely under-reported (Kearney, 2005; Li, 2012). Therefore, analysis using these gambling data should be done with caution. The last row of Table 3 suggests that, unconditional on other factors that may affect gambling spending and reporting behavior, households report higher gambling spending following casino openings.

\section{Theory}

\subsection{Theoretical links between casinos and non-gambling spend- ing}

In this section, I discuss channels through which casinos can influence household non-gambling spending. I also discuss two intertemporal links between casinos and non-gambling spending, the novelty effect and the response of casino location choices

\footnotetext{
${ }^{5}$ For example, a household can have casinos located in Zone 1, and also have other casinos located in Zone 2.
} 
to household spending.

\section{A. Complementary effect on non-gambling sectors}

Casinos may have a positive effect on household spending if visitors to casino towns consider gambling and other activities, such as restaurant dining, as complements. Indeed, many casinos take this possibility into account, and offer a wide variety of amenities such as restaurants, shopping malls and accommodation in the facilities. Outside casinos, other local businesses may also grow, so that they can take advantage of the increase in the volume of visits to the area. The agglomeration of the new businesses can save travel costs for consumers, leading to higher spending. Another possibility is that the quality of non-gambling goods in casino towns is also upgraded, further generating revenues. Many newly established casinos are large facilities that offer a good balance of gambling and non-gambling goods. This is especially the case in some states that recently legalized casinos, including Ohio (in 2012), Maryland (in 2010), Pennsylvania (in 2006), and Florida (in 2006). Researchers have also documented a positive association between casino revenues and retail property prices in the casino town (Wiley \& and Walker, 2009).

\section{B. Substitution between gambling and non-gambling spending}

Households may spend more on gambling when casinos become more accessible, and they may substitute spending on non-gambling goods for casino gaming. The substitution effect is found in the case of state lotteries, especially for instant lottery games such as scratch-off tickets (Kearney, 2005). If the strength of substitution effect is positively dependent on how fast outcomes are revealed after wagering, then the strong substitution effect might also be found in the case of casinos. State-wide evidence on the the substitution effect of casinos on non-gambling spending is found 
in Missouri (Leven \& Phares, 1998), and in Iowa (Chhadra, 2007).

\section{Labor market opportunities}

Household may choose to spend more if their earnings increase with improved labor market outcomes. Proponents of casinos cite job creation and wage increase as one of the major benefits of casinos. Evans and Topoleski (2002) estimate that Indian casinos have a substantial positive impact on labor market outcomes for Native Americans living in reservation areas. Evans and Kim (2006) find that opening of a casino increased the employment and wages of low-skilled workers. It is also possible that the labor market opportunities worsen following casino openings, as job losses or wage decreases can result from excessive gambling or the draining of the local non-gambling sectors due to a strong substitution effect of casino revenues on the revenues of other businesses.

\subsection{Intertemporal links}

\section{A. Novelty effect}

The impact of casinos may vary over time. A study of casinos in California between 1990 and 2006 (Volberg et al., 2006) shows that lifetime participation rates for casino gambling increased between 1990 and 1999, but then decreased between 1999 and 2006. Jacques and Ladouceur (2006) find that participation and spending on casino gambling both increase one year after the opening of a casino in Quebec, Canada, but the trend does not continue in both the 2-year and the 4-year follow-

ups of the same cohort. Both studies reflect what is known as the "novelty effect", that consumers are initially attracted by the new casinos, and after the novelty effect 
erodes over time, they substitute casino gambling for other entertainment activities.

\section{B. Choices of casino locations}

Policy makers may have chosen casino locations in response to household spending, or certain characteristics of local areas that are correlated with household spending but unobserved to econometricians, such as the "potential" of future economic development, which may be correlated with household spending. Indeed, many casinos are built not far from populous towns, with the intention to capture larger markets and attract more visitors who have a high propensity to spend. Even in the case of Indian casinos, which are usually required by law to be located in the reservation land, tribes have sought for the opportunity to build off-reservation casinos legitimately in order to make the access easier for visitors. ${ }^{6}$ Therefore, without taking into account the role of household spending in choices of casino locations, my estimates may be biased.

To sum up, the effect of casinos on household spending is the outcome of multiple factors, and the net effect can be positive, negative or neutral. The effect can differ as distance from households to casinos varies. For example, the labor market effect of casinos might diminish for households that are farther away, as commuting becomes more costly; and the novelty effect could be stronger for consumers who live in casino towns, as they have the easiest access, thus may also easily lose interest after frequent casino visits within a short period. It is also unclear to what extent the location choices of casinos is dependent on local household spending. These are all empirical questions to be addressed in the next sections.

\footnotetext{
${ }^{6}$ For example, the California Proposition 48 in 2014 would have ratified a tribal-state gaming compact for the Northfork tribe to open an off-reservation casino that is closer to population areas.
} 


\section{Estimation}

In this section, I discuss the reduced-form model that estimates the impact of casinos on household spending.

The equation to be estimated is

$$
\begin{aligned}
y_{i j t}=\alpha & +\beta_{1} Z 1_{i t}+\beta_{2} Z 2_{i t}+\beta_{3} Z 3_{i t}+\beta_{4} Z 1_{i t} Z 2_{i t}+\beta_{5} Z 1_{i t} Z 3_{i t}+\beta_{6} Z 2_{i t} Z 3_{i t}+\beta_{7} Z 1_{i t} Z 2_{i t} Z 3_{i t} \\
& +\mathbf{X}_{i t} \gamma+\mathbf{J}_{j t} \delta+\mathbf{M}_{t} \lambda+\omega_{y}+\nu_{j}+\varepsilon_{i j t} .
\end{aligned}
$$

The dependent variable $y_{i j t}$ is the spending on non-gambling goods of households $i$ living in state $j$ during period $t$. Each period covers 3 months, which is the length of recall period in the CEX. $Z 1_{i t}$ is equal to one. if there is at least one casino in Zone 1 for household $i$ during period $t$, and is equal to zero otherwise. The definition follows similarly for $Z 2_{i t}$ and $Z 3_{i t}$. In addition to the three indicators, I also include the interactions terms of these indicators. The interaction terms allow me to detect any difference in the effect of new casinos in a certain zone based on whether there are existing casinos in other zones.

For the three indicators and their interaction terms, positive coefficients indicate that household spending increases when casinos appear. For example, if $\beta_{1}$ is positive, it means that, if there is no casinos in Zone 2 (20 to 50 miles away) or in Zone 3 (50 to 100 miles away), households will increase their spending on non-gambling goods if new casinos appear in Zone 1 (within 20 miles). If $\beta_{4}$ is negative, it means that the effect of casinos in Zone 1 will be dampened by existing casinos in Zone 2 .

Regarding other controls in (1), the vector $\mathbf{X}_{i t}$ consists of household demographic variables, including annual before-tax income and its square, family size, family type, number of household members younger than 18, number of household members older than 64, age, race, gender, educational attainment and marital status of household 
head, and the population of the geographic area where the household lives. ${ }^{7} \mathbf{J}_{j t}$ includes state level control variables that may correlate with household spending, including a polynomial of state unemployment rate, the sales tax rate, the excise tax rates for gasoline, cigarette, and beer, and the availability of multi-state lotteries. The unemployment rate polynomial controls for the macroeconomic condition at the state level. The tax rates account for potential concurrent policy changes at the state level when new casinos were built. The indicator for the availability of multi-state lotteries controls for a major change in the availability of alternative gambling goods during my sample period, during which time the number of participating states of two major multi-state lotteries, Power Ball and Mega Million, increased from 19 to $43 .^{8}$ $\mathbf{M}_{t}$ is a vector of dummies for calendar months, controlling for potential changes in spending behavior across months within a year. $\omega_{y}$ captures the year fixed effect, and $\nu_{j}$ captures the state fixed effect. The zero-mean error term $\varepsilon_{i j t}$ accounts for any unobserved factors that may affect spending decisions, but are uncorrelated with casino availability, such as health status of household members. I assume that households in my sample do not choose their county of residence in response to the appearance of casinos. For my base results in the next section, I also abstract from the possibility that some unobserved characteristics of local areas, such as unobserved "potential" of future economic development, may be correlated with both household spending and casino availability. I discuss this possibility in an alternative specification that follows my discussion of the base results. Across all specifications, I cluster the error term at the household level, since expenditures over consecutive quarters of the same household are not necessarily independent observations.

\footnotetext{
${ }^{7}$ In the CEX, the geographic area for which the population bracket is reported is the Primary Sample Unit (PSU), defined as a set of counties geographically grouped together to become units for sample selection.

${ }^{8}$ In Washington DC, Power Ball is available throughout my sample period.
} 


\section{Results}

\subsection{Effect of the presence of casinos}

\section{A. Effect on total non-gambling spending}

I first focus on the coefficients associated with $Z 1, Z 2$, and $Z 3$ in regression equation (1). Each coefficient estimate represents the effect of the presence of casinos in the corresponding zone, conditional on there is no casino in other zones. The estimates are reported in the first three rows of Table 4. I estimate regression equation (1) for both the amount and the log of non-gambling spending. The results are reported for my full sample in Column (1) and (2), and separately for households in three in-

come terciles in Column (3) through (8). Column (1) shows that, for the full sample, households slightly decrease non-gambling spending when casinos appear in Zone 1, although the estimate is not statistically significant. However, when casinos appear farther away in Zone 2 and Zone 3, households increase non-gambling spending by $1.6 \%$ and $2.6 \%$ when casinos appear in Zone 2 and Zone 3, respectively, and the positive coefficient estimates on log of spending are at least $5 \%$ statistically significant. The income group comparison shows that the spending increase presents for households in all income terciles, but is the strongest for households in the lowest income group, up to $3.6 \%$, also with higher statistical significance.

\section{B. Effects on non-gambling spending categories}

I further explore the effect of casinos on spending categories. I decompose total spending into ten spending categories, and estimate (1) for each category separately. The ten categories include food at home, mortgage, rent and utility bills, furniture and home improvement, medical care, transportation, apparels, food away from home and entertainment activities (excluding gambling), alcohol and tobacco, education, 
and life insurance and pensions. In addition to the amount and log of spending, I also estimate (1) for the indicator of any spending for all subcategories. I present the estimates for my full sample in Table 5, and for households in the lowest income tercile in Table 6.

Results in Table 5 and 6 offer a few interesting observations. First, results in Column (1) through (3) show that, although nearby (Zone-1) casinos do not have a significant effect on total spending, there are significant effects on spending categories: spending decreases on food away and entertainment, and life insurance and pensions, while a significant spending increase occurs on alcohol and tobacco. These results are unsurprising, considering that casino town residents may substitute other entertainment activities and life savings for casino gambling, and spend more on alcohol and tobacco, arguably the two main complements of casino games for many patrons.

Second, there is extensive evidence that the effects on spending categories result from more visits to casinos or casino towns. Households increase spending on transportation for farther-away casinos, and decrease transportation spending if casinos open in proximity. Spending on food at home decreases, especially when casinos are farther away. Households increase their spending on a set of goods that are complements to casino visits, such as clothes, alcohol, and tobacco. Also, households reduce their purchase of life insurance and contributions to pensions. Many of these effects are larger in magnitude and with a higher level of statistical significance for households in the lowest income tercile. Altogether, these results suggest a complementary effect of casinos on the non-gambling economy driven by consumers. These results do not reject the hypothesis that spending changes may occur due to changes in labor markets when casinos open. However, the effect through the labor market channel might be secondary compared to the complementary effect of casinos on non-gambling sectors, because if the labor market effect dominates, the direction 
of spending changes should be more homogeneous across categories. For example, if casinos substantially raises local wages, then instead of finding a spending decrease on clothes and a spending increase on food away and entertainment for Zone-1 casinos, it would be more plausible to find an increase in spending on both categories.

Third, nearby and farther-away casinos seem to appear differently to households, as suggested by the different effects on spending categories of casinos in different zones. For example, when casinos open in Zone 1, spending on food away and entertainment significantly decreases, while spending on this category significantly increases for Zone-2 and Zone-3 casinos. In addition, the positive effect of casinos on spending on alcohol and tobacco monotonically decreases in distance between households and casinos. The monotonic relationship also holds for the negative effect on spending on life insurance and pensions. One explanation is that households consider nearby casinos purely as gambling facilities, while they consider farther-away casinos and casino towns as vacation destinations. This possibility may also account for the absence of a positive effect on total spending of casinos in Zone 1, since it predicts that casino town residents will substitute a larger amount of non-gambling spending for casino gambling, compared to visitors of casino towns.

Last, as Table 6 shows, lower-income households spend significantly more on housing and home improvement when casinos appear. The higher housing spending is consistent with the complementary effect of casinos on local property prices found by other researchers (Baxandall, 2005; Wiley and Jackson, 2009). My results are also consistent with the spillover of the complementary effect to areas outside casino towns, and the spillover to upstream and downstream industries of the housing sector. However, the comparison between results in Table 5 and 6 suggests that higher-income households do not increase housing spending when casinos appear in nearby areas. This finding seems plausible, as existing research finds that casinos raise home prices 
by more in rural counties where households generally earn less (Baxandall, 2005), and the prices of properties held by higher-income households may be negatively affected by an increase in crime in proximity of casinos (Grinols \& Mustard, 2006).

\section{Effect on self-reported gambling spending}

The interpretation of many findings above would be further confirmed if I could directly estimate the effect of casinos on gambling spending. As mentioned in the Data section, self-reported gambling spending data are available in the CEX since 2001, but are severely under-reported. Hence, if I use the under-reported gambling spending as the dependent variable, the magnitude of coefficient estimates would be unreliable. However, as long as household reporting behavior does not systematically change before and after casino openings, the effect of casinos on self-reported gambling spending can still reveal the sign of the effect on actual gambling spending.

I present the estimates in Table 7. For brevity, I present the estimates on the three zone indicators, although the higher-order interaction terms of these indicators are all controlled for in all specifications. Column (1) through (12) reports the estimated effect of casinos on self-reported gambling spending, log of self-reported gambling spending, and the probability of reporting for all households in my sample from 2001 to 2013, and the three income groups. Across specifications and income groups, many of the estimates are positive, especially the probability of reporting

any gambling spending. Hence, it appears that gambling participation has increased following casino openings, and households may have spent more in casinos, too. 


\subsection{Effect of additional casinos}

I now turn to the coefficient estimates associated with the interaction terms of casino indicators, reported in the fourth through the seventh row in Table 4. These estimates should be interpreted as the additional effect of casinos on household spending, conditional on the presence of casinos in other zones. Unlike the results in the first three rows, most of the coefficient estimates for the interaction terms are statistically insignificant, and the additional effects can be positive, neutral, or negative. ${ }^{9}$ The mixed signs and large standard errors of many coefficient estimates on the interaction terms may result from my abstract geospatial setting in Figure 3. For example, consider an incumbent casino in Zone 2 and a new casino built in Zone 3. If both casinos are north of a household, then the new casino may have little effect on household spending. Alternatively, if one casino is to the north and the other is to the south, then the new casino may further affect household spending, as it offers a new vacation destination in a different area. Despite the heterogeneity across individual cases, the estimates on the interaction terms reflect, on average, how the effect of casinos on the non-gambling economy accumulates as more casinos are built in nearby areas. The appearance of many negative estimates suggests that the positive effect of casinos may not always significantly accumulate, sometimes even disappear, for additional casinos built in the nearby areas of existing ones.

\subsection{Intertemporal links}

As discussed in Section 4, the effect of casinos on household spending may not necessarily last in the long run. Casinos may have a novelty effect that first attracts visitors shortly after it opens, but then experience a decrease in visits when gambling

\footnotetext{
${ }^{9}$ Two statistically significant estimates occur when the effect is separately estimated for the income groups.
} 
participation reverts to mean over time. I test this hypothesis by replacing each casino availability indicator in (1), as well as their interactions, by an indicator for casino availability during the most recent two years, and another indicator for casino availability during the preceding eight years. Hence, for each pair of new indicators, the coefficients represent, respectively, the short run effect and the additional effect that exhibits only in the long run.

The results for casino appearance in each of the three zones, conditional on there is no existing casinos in other zones, are reported in Column (1) and (2) in Table 8. The coefficient remains statistically significantly positive for the short run indicator, and is insignificant for the long run indicators for casinos in Zone 2 and Zone 3. The lack of a sufficiently large and statistically significant estimate for the long run indicators suggests that the complementary effect of casinos on the non-gambling economy persists in the long run.

Perhaps the more interesting results are the intertemporal effects of casinos in Zone 1 (within 20 miles): households reduce non-gambling spending by $\$ 404$ per quarter or $4.3 \%$ during the two years after casino opening, but the effect is largely offset by their higher spending after the second year. These results are consistent with a negative novelty effect of Zone-1 casinos, that there is a temporary crowd-out of non-gambling spending for households in the closest proximity. ${ }^{10}$

Another type of intertemporal link discussed in Section 4 relates to the choices of casino locations. Jurisdictions may approve casino locations by taking into account spending of local residents, or other factors that may be correlated with local spending. Here, I consider whether the positive estimated effect of casinos on non-gambling spending can be driven by higher spending that have occurred before casino appear-

\footnotetext{
${ }^{10}$ This finding echoes the assumption made by Grinols (1999) in his modeling of the distance effect of casinos on consumption. He assumes that consumers closer to casinos visit casinos more often, while spend less per visit.
} 
ance, as policy makers may believe that more revenues can be raised from households that have a higher propensity to spend.

To address this issue, I further include in my regressions lead terms of casino availability, namely, indicators for casino availability during the two years after the quarter when household spending is observed. A positive estimate implies that household spending has been higher in areas where new casinos are built in the next two years. The estimates of the lead terms for casino availability in the three zones, along with those for the short run and long run indicators, are reported in Column (3) and (4) in Table 8. For the lead term, the coefficient is estimated to be insignificant for casinos in Zone 1 and Zone 3. The estimate in the log-linear specification for casinos in Zone 2 is $-1.6 \%$ and significant at $10 \%$. However, the negative sign indicates that the positive impact of casinos in Zone 2 on household spending is even larger after controlling for the response of casino availability in Zone 2 to household spending. ${ }^{11}$ After controlling for future casino availability, the temporary spending decrease still presents following the opening of Zone-1 casinos. The magnitude remains statistically significant but is smaller: within two years following casino opening, non-gambling spending decreases by 3.5\%; after two years, most of the decrease is offset by a long run increase of $2.6 \%$; the estimates on the amount of spending lose statistical significance.

To sum up, the intertemporal analysis shows supportive evidence that a novelty effects exists for nearby casinos, the complementary effect of casinos on the nongambling economy persists in the long run, and there is lack of evidence that the complementary effect is attenuated by the correlation between current household spending and future choices of casino locations. To further address the concern about

\footnotetext{
${ }^{11} \mathrm{~A}$ possible explanation for the negative lead effect is that casinos are chosen to be located in poorer areas where spending is also lower, because the marginal benefit of local economy development can be larger in these areas.
} 
endogenous choice of casino locations, it would be interesting to verify my findings by taking into account other local area characteristics that can reflect the "potential" of future development, perhaps with additional data sources such as data on revenues of local businesses in the non-gambling sectors.

\section{Discussion}

My findings in the previous section provide a few interesting insights. First, the positive effect of the casinos that are firstly available to households suggests that casinos can have a complementary effect on non-gambling sectors. The complementary effect is in contrast to the crowd-out effect on household non-gambling spending of state lotteries, the second largest source of gaming revenue (Kearney, 2005).

Second, the possibility that the complementary effect may diminish or even disappear for additional casinos built in nearby areas suggests that the positive spillover of casinos to local non-gambling sectors may be weakened if casinos are geographically concentrated, which is often observed near state borders, a result of competition among adjacent states for gaming revenues.

Lastly, casinos may still crowd out non-gambling spending on some categories, such as purchase of life insurance and pension contributions. While this reallocation of resources may lead to welfare gains if the households are rational and informed consumers as a whole, it is also possible that individual preferences are heterogeneous within a household, thus welfare losses can result if the choice of substituting such spending for casino gambling is not favored by some household members. 


\section{Conclusion}

Casinos have been steadily contributing over two thirds of the gaming revenues in the U.S. over years. This paper is the first study of the effect of casinos on the non-gambling economy using nationwide individual household spending data, and a restricted access file containing the information of household locations at the county level. The effect of casinos on household spending is identified by the changes in household-level quarterly spending when casino availability varies at the county level. The sample period is from 1996 to 2013, during which time households across the country experienced a substantial increase in the availability of casinos.

My findings show that households increase non-gambling spending when casinos open within 100 miles. The spending increase can be as large as $2.6 \%$, and persists in the long run, suggesting a complementary effect of casinos on the non-gambling economy. This finding is in contrast to the negative effect of state lotteries on nongambling spending documented in literature. The comparison among income groups shows that the positive effect of casinos on household spending is the largest for households in the lowest income tercile, up to $3.6 \%$. The positive effect on non-gambling spending occurs for the first presence of casinos, but does not always accumulate when additional casinos are built in nearby areas.

I provide extensive evidence that the positive effect of casinos on non-gambling spending is driven by more visits to casinos or casino towns. Households increase spending on transportation for farther-away casinos, and decrease transportation spending if casinos open in proximity. Spending on food at home decreases, especially when casinos are farther away. Households increase their spending on a set of goods that are complements to casino visits, such as clothes, alcohol, and tobacco. When casinos open, households also report higher gambling spending, and the self-reported 
gambling participation rate also rises. Meanwhile, households reduce their purchase of life insurance and contributions to pensions.

There are two limitations in this study. First, the CEX spending data do not report the locations where the purchases were made. Hence, the estimated effects presented here cannot be further disaggregated by smaller geographic area, thus gauging the economic impact of casinos on the economy of casino towns remains an outstanding task. Second, this study abstracts from the the heterogeneity in casino characteristics, such as square footage, types of game offered, and amenities available. Nowadays, many newly approved casinos are large facilities that offer a wide range of goods and services beyond gambling. It should be therefore interesting to learn the impact of these casinos specifically. These unanswered questions lead to future research, such as using data on entry, exit and sales of firms to estimate the effect of casinos on local businesses, and using industry data with detailed information of individual casinos to examine the heterogeneity of the effects. 


\section{References}

[1] Akee, R., K. Spilde and J. Taylor. (2015). "The Indian Gaming Regulatory Act and Its Effects on American Indian Economic Development". Journal of Economic Perspectives. 29.3, 185-208.

[2] Baxandall, P. (2005). "Betting on the Future: The Economic Impact of Legalized Gambling". Harvard University Rappaport Institute for Greater Boston..

[3] Better Government Association. (1997). "Statement to the Metro Ethics Coalition Project".

[4] California Proposition 48, Referendum on Indian Gaming Compacts (2014).

[5] Chhabra, D. (2007). "Estimating Benefits and Costs of Casino Gambling in Iowa, United States". Journal of Travel Research. 46.2, 173-182.

[6] Elliott, S. and J. Navin. (2002). "Has Riverboat Gambling Reduced Stater Lottery Revenue?" Public Finance Review. 30.3, 235-247.

[7] Evans, W. and W. Kim. (2006). "The Impact of Local Labor Market Conditions on the Demand for Education: Evidence from Indian Casinos". working paper.

[8] Evans, W. and J. Topoleski. (2002). "The Social and Economic Impact of Native American Casinos". NBER working paper 9198.

[9] Fink, S. and J. Rork. (2003). "The Importance of Self-Selection in Casino Cannibalization of State Lotteries". Economics Bulletin. 8.1, 1-8.

[10] Grinols, E. and D. Mustard. (2006). "Casinos, Crime, and Community Costs". Review of Economics and Statistics. 88.1, 28-45. 
[11] Grinols, E. (1999). "Distance Effects in Consumption: Measuring Distance Value with Application to Casino Siting". Review of Regional Studies. 29.1, 63-76.

[12] Jacques, C. and R. Ladouceur. (2006). "A Prospective Study of the Impact of Opening a Casino on Gambling Behaviours: 2- and 4-Year Follow-Ups". Canadian Journal of Psychiatry. 51.12, 764-773.

[13] Kearney, M. (2005). "State Lotteries and Consumer Behavior". Journal of Public Economics. 89, 2269-2299.

[14] Leven, C. and D. Phares. (1998). "Casino Gambling in Missouri: The Spending Displacement Effect and Net Economic Impact". Proceedings of the Ninetieth Annual Conference on Taxation. Washington, DC: National Tax Association.

[15] Li, G. (2012). "Gamblers as Personal Finance Activists". Finance and Economics Discussion Series, Federal Reserve Board.

[16] Narayanan, S. and P. Manchanda. (2012). "An Empirical Analysis of Individual Level Casino Gambling Behavior". Quantitative Marketing and Economics. 10.1, $27-62$.

[17] National Gambling Impact Study Commission (1999). Final Report. Washington, D.C.

[18] National Opinion Research Center. (1999). "Gambling Impact and Behavior Study".

[19] Reagan, P. and R. Gitter. (2007). "Is Gaming the Optimal Strategy? The Impact of Gaming Facilities on the Income and Employment of American Indians". working paper. 
[20] Sévigny, S., R. Ladouceur, C. Jacques and M. Cantinotti (2008). "Links Between Casino Proximity and Gambling Participation, Expenditure and Pathology". Psychology of Addictive Behaviors. 22.2, 295-301.

[21] Siegel, D. and G. Anders. (1999). "Public Policy and the Displacement Effects of Casinos: A Case Study of Riverboat Gambling in Missouri". Journal of Gambling Studies. 15.2, 105-121.

[22] Volberg, R., K. Nysse-Carris and D. Gerstein (2006). "2006 California Problem Gambling Prevalence Survey". submitted to California Department of Alcohol and Drug Programs, Office of Problem and Pathological Gambling.

[23] Walker, D. and J. Jackson (2008). "Do U.S. Gambling Industries Cannibalize Each Other?". Public Finance Review. 36.3, 308-333.

[24] Wiley, A. and D. Walker. (2011). "Casino Revenues and Retail Property Values: The Detroit Case". Journal of Real Estate Finance and Economics. 42, 99-114.

[25] Welte, J., G. Barnes, W. Wieczorek, M. Tidwell and J. Parker(2002). "Gambling Participation in the U.S.-Results from a National Survey". Journal of Gambling Studies. 18.4, 313-337. 


\section{Figures}

Figure 1: Expansion of casinos: cities in the continental U.S. with at least one casinos, December 1990, 2000 and 2010

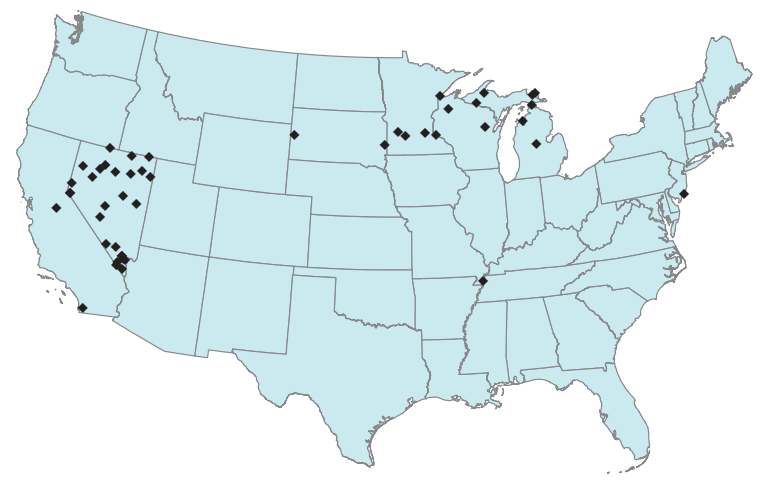

(a) Casino cities in December 1990

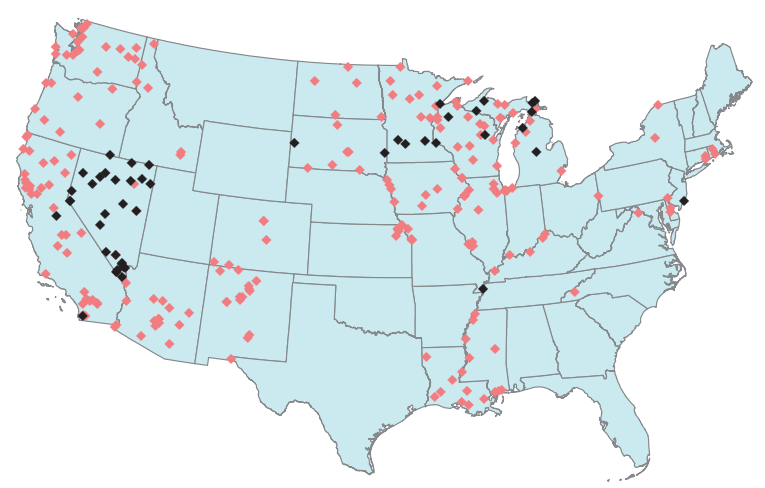

(b) Casino cities in December 2000, new casino cities after December 1990 in pink

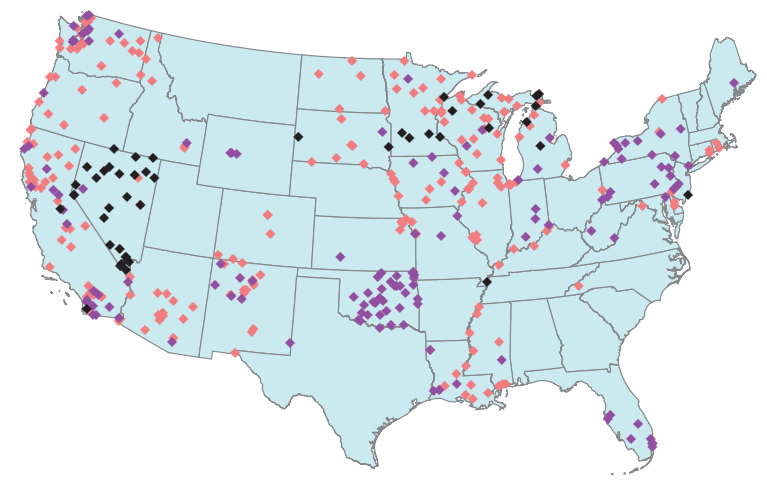

(c) Casino cities in December 2000, new casino cities after December 1990 in pink, and new casino cities after December 2010 in purple 
Figure 2: U.S. gaming revenues by gaming type, 1988-2009

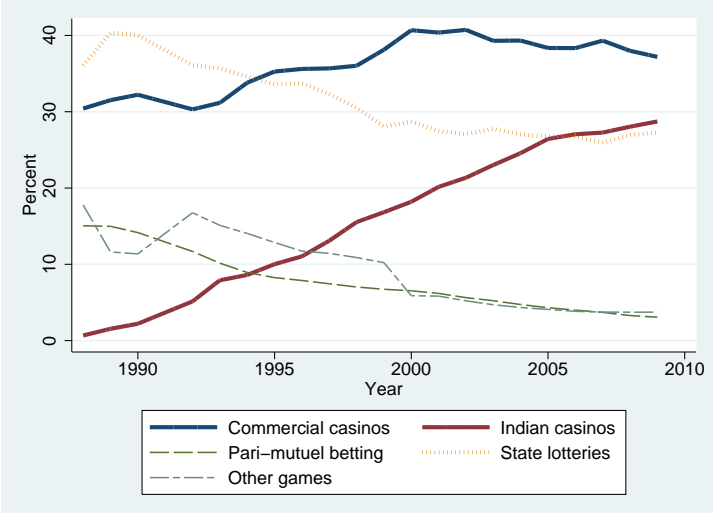

(a) Share of revenues

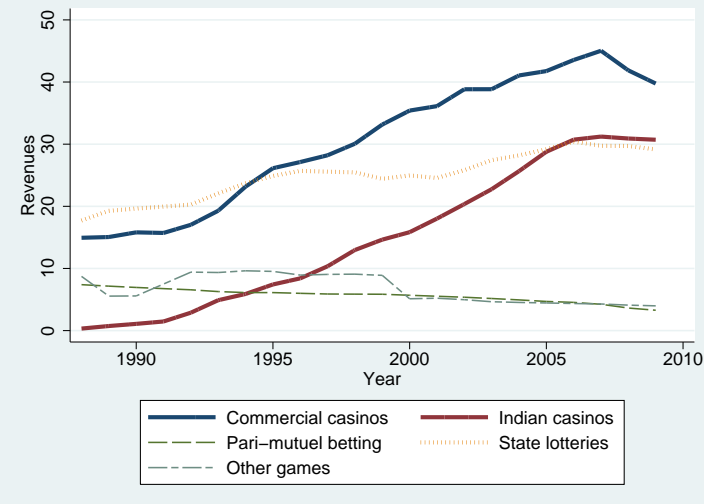

(b) Revenues (billions of 2010 dollars)

Data source: Akee et al. (2015)

Figure 3: Graphical representation: measuring casino availability

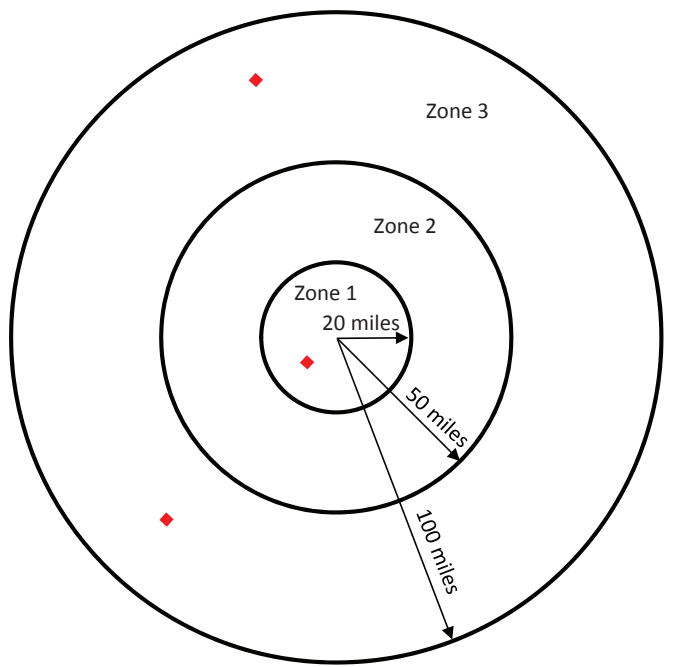

Casino availability in each zone is measured by any appearance of casinos in the zone. Zone 1 is the round area centered at the center of county where the household lives with a radius of 20 miles, Zone 2 is the inner ring area that is 20 to 50 miles away from the center, and Zone 3 is the outer ring area that is 50 to 100 miles away from the center. In this figure, the red diamonds represent casinos. Therefore, $Z 1=1, Z 2=0$, and $Z 3=1$. 


\section{Tables}

Table 1: Sample characteristics: Consumer Expenditure Survey Interview 1996-2013

\begin{tabular}{|c|c|c|c|c|}
\hline & \multicolumn{2}{|c|}{ Sample of this study } & \multicolumn{2}{|c|}{ All CEX households } \\
\hline & Mean & S.D. & Mean & S.D. \\
\hline Annual before tax household income & 45068.08 & 46181.40 & 49902.99 & 59985.15 \\
\hline Family size & 2.51 & 1.50 & 2.51 & 1.50 \\
\hline Number of members younger than 18 & 0.66 & 1.09 & 0.67 & 1.09 \\
\hline Number of members older than 64 & 0.30 & 0.60 & 0.30 & 0.60 \\
\hline \multicolumn{5}{|l|}{ Household head characteristics } \\
\hline Age & 47.89 & 17.71 & 47.84 & 17.67 \\
\hline$\%$ minority & 0.18 & 0.38 & 0.18 & 0.39 \\
\hline$\%$ college graduate & 0.27 & 0.44 & 0.28 & 0.45 \\
\hline$\%$ married & 0.51 & 0.50 & 0.51 & 0.50 \\
\hline$\%$ female & 0.50 & 0.50 & 0.50 & 0.50 \\
\hline \multicolumn{5}{|l|}{ Quaterly spending on } \\
\hline Total non-gambling & 11341.01 & 9678.45 & 11808.64 & 10664.23 \\
\hline Food at home & 1178.06 & 786.44 & 1195.22 & 812.00 \\
\hline Mortgage, rent and utility bills & 3049.80 & 3143.10 & 3178.64 & 3501.86 \\
\hline Home improvement & 743.61 & 1877.69 & 795.42 & 2116.54 \\
\hline Medical care & 679.16 & 1018.50 & 686.69 & 1063.47 \\
\hline Transportation & 2532.44 & 5207.42 & 2601.17 & 5385.03 \\
\hline Apparels & 419.66 & 672.47 & 441.37 & 886.10 \\
\hline Food away and entertainment & 1105.73 & 2072.53 & 1174.38 & 2288.36 \\
\hline Alcohol and tobacco & 174.80 & 323.12 & 180.00 & 334.13 \\
\hline Education & 247.05 & 1315.11 & 269.78 & 1454.88 \\
\hline Life insurance and pensions & 1210.69 & 1707.30 & 1285.98 & 1908.77 \\
\hline Number of households & \multicolumn{2}{|c|}{229721} & \multicolumn{2}{|c|}{248614} \\
\hline Number of quarterly interviews & \multicolumn{2}{|c|}{454520} & \multicolumn{2}{|c|}{479279} \\
\hline
\end{tabular}

The following households are excluded: households in Alaska, Hawaii and Nevada, households with income topcoded by the CEX, households with any quarterly negative spending in any category, and households with total non-gambling spending less than $\$ 1,000$. All dollars are inflation adjusted to year 2010 . 


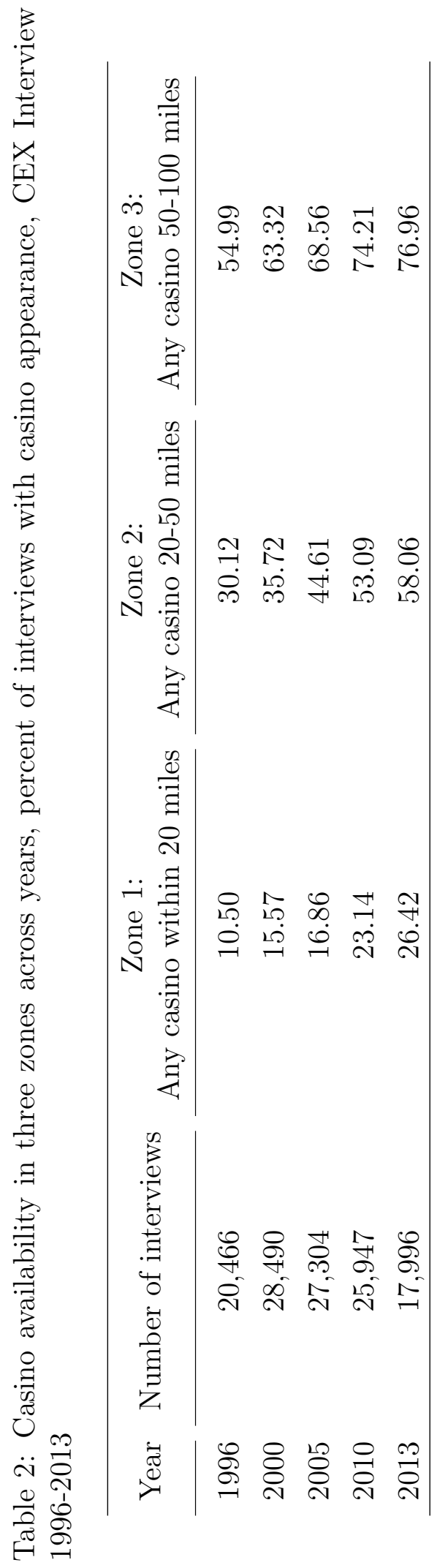




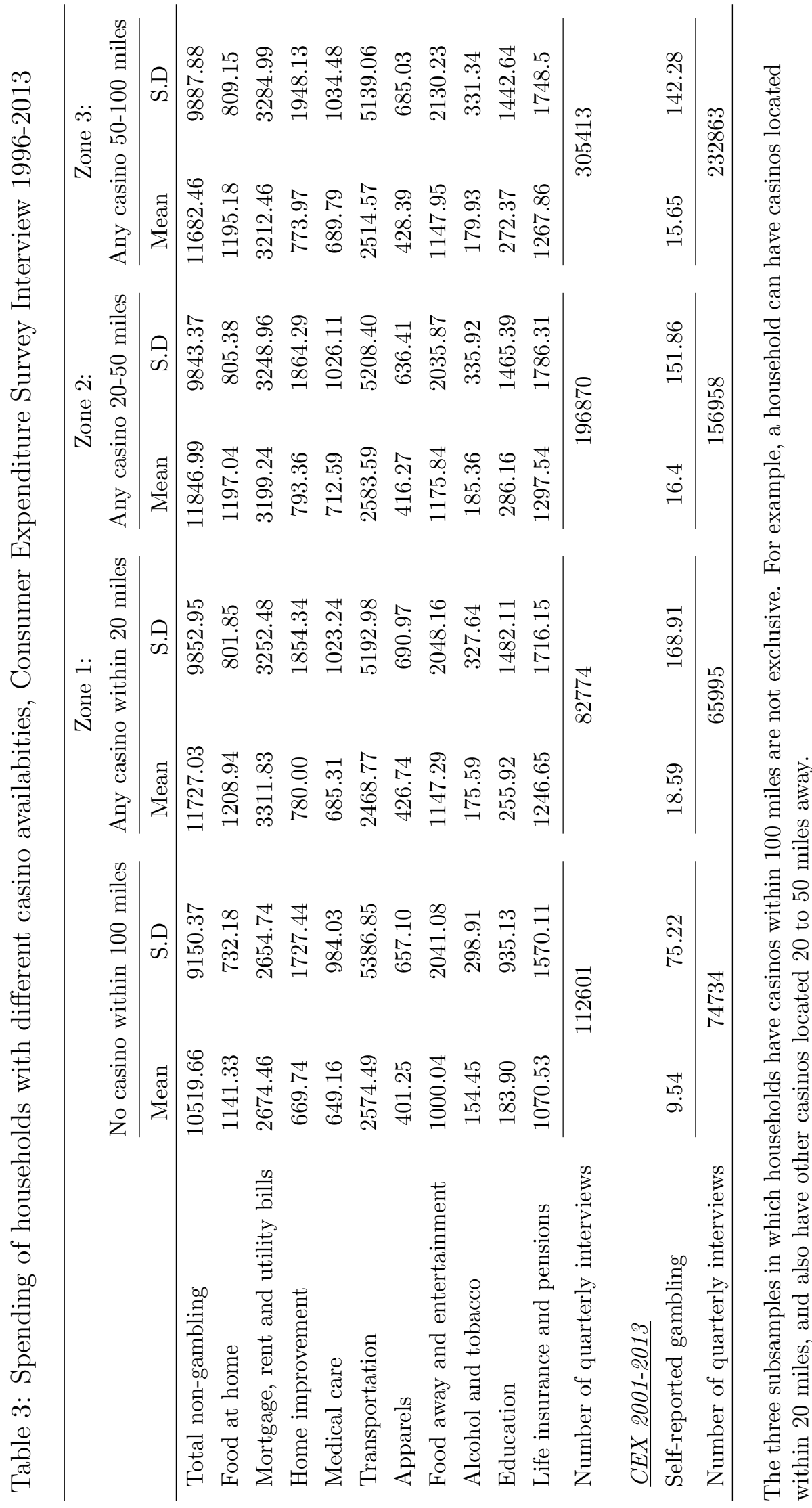


Table 4: Regression results: Effect of casino availability on household spending, CEX Interview 1996-2013

\begin{tabular}{|c|c|c|c|c|c|c|c|c|}
\hline & \multicolumn{2}{|c|}{ Full Sample } & \multicolumn{2}{|c|}{ Lowest income tercile } & \multicolumn{2}{|c|}{ Middle income tercile } & \multicolumn{2}{|c|}{ Highest income tercile } \\
\hline & $\begin{array}{l}\text { Level } \\
(1)\end{array}$ & $\begin{array}{l}\mathrm{Ln} \\
(2)\end{array}$ & $\begin{array}{c}\text { Level } \\
(3)\end{array}$ & $\begin{array}{l}\mathrm{Ln} \\
(4) \\
\end{array}$ & $\begin{array}{c}\text { Level } \\
(5)\end{array}$ & $\begin{array}{l}\mathrm{Ln} \\
(6) \\
\end{array}$ & $\begin{array}{c}\text { Level } \\
(7)\end{array}$ & $\begin{array}{l}\mathrm{Ln} \\
(8) \\
\end{array}$ \\
\hline$Z 1$ (within 20 miles) & $\begin{array}{c}-69.24 \\
(143.37)\end{array}$ & $\begin{array}{l}-0.003 \\
(0.010)\end{array}$ & $\begin{array}{c}162.51 \\
(218.08)\end{array}$ & $\begin{array}{c}0.001 \\
(0.021)\end{array}$ & $\begin{array}{c}-86.61 \\
(161.58)\end{array}$ & $\begin{array}{c}0.001 \\
(0.014)\end{array}$ & $\begin{array}{c}144.98 \\
(315.81)\end{array}$ & $\begin{array}{c}0.003 \\
(0.014)\end{array}$ \\
\hline$Z 2(20$ to 50 miles $)$ & $\begin{array}{l}75.36 \\
(84.21)\end{array}$ & $\begin{array}{c}0.016^{* *} \\
(0.006)\end{array}$ & $\begin{array}{c}184.24 \\
(125.44)\end{array}$ & $\begin{array}{c}0.036^{* * *} \\
(0.013)\end{array}$ & $\begin{array}{c}102.16 \\
(107.66)\end{array}$ & $\begin{array}{l}0.015 \\
(0.01)\end{array}$ & $\begin{array}{l}-11.00 \\
(174.03)\end{array}$ & $\begin{array}{c}0.009 \\
(0.008)\end{array}$ \\
\hline$Z 3$ (50 to 100 miles $)$ & $\begin{array}{l}191.86 \\
(62.83)\end{array}$ & $\begin{array}{c}0.026^{* * *} \\
(0.005)\end{array}$ & $\begin{array}{c}213.31^{* *} \\
(99.49)\end{array}$ & $\begin{array}{c}0.033 * * * \\
(0.009)\end{array}$ & $\begin{array}{l}111.92 \\
(76.17)\end{array}$ & $\begin{array}{c}0.017^{* * *} \\
(0.007)\end{array}$ & $\begin{array}{c}193.09 \\
(130.78)\end{array}$ & $\begin{array}{c}0.020 * * * \\
(0.006)\end{array}$ \\
\hline$Z 1 \times Z 2$ & $\begin{array}{c}274.79 \\
(197.46)\end{array}$ & $\begin{array}{l}0.020 \\
(0.015)\end{array}$ & $\begin{array}{l}-94.57 \\
(304.62)\end{array}$ & $\begin{array}{l}-0.001 \\
(0.03)\end{array}$ & $\begin{array}{c}206.44 \\
(237.93)\end{array}$ & $\begin{array}{l}0.008 \\
(0.021)\end{array}$ & $\begin{array}{c}292.27 \\
(417.74)\end{array}$ & $\begin{array}{l}0.018 \\
(0.019)\end{array}$ \\
\hline$Z 2 \times Z 3$ & $\begin{array}{l}149.82 \\
(96.65)\end{array}$ & $\begin{array}{l}-0.003 \\
(0.007)\end{array}$ & $\begin{array}{c}308.41^{* *} \\
(149.4)\end{array}$ & $\begin{array}{c}0.002 \\
(0.014)\end{array}$ & $\begin{array}{c}50.77 \\
(121.55)\end{array}$ & $\begin{array}{l}-0.005 \\
(0.011)\end{array}$ & $\begin{array}{c}46.13 \\
(193.16)\end{array}$ & $\begin{array}{l}-0.007 \\
(0.009)\end{array}$ \\
\hline$Z 1 \times Z 3$ & $\begin{array}{l}-138.28 \\
(163.05)\end{array}$ & $\begin{array}{l}-0.013 \\
(0.012)\end{array}$ & $\begin{array}{l}-74.53 \\
(246.63)\end{array}$ & $\begin{array}{l}0.019 \\
(0.024)\end{array}$ & $\begin{array}{l}-133.36 \\
(189.58)\end{array}$ & $\begin{array}{l}-0.027 \\
(0.017)\end{array}$ & $\begin{array}{c}-717.24^{* *} \\
(354.07)\end{array}$ & $\begin{array}{c}-0.043^{* * * *} \\
(0.016)\end{array}$ \\
\hline$Z 1 \times Z 2 \times Z 3$ & $\begin{array}{c}5.61 \\
(222.2)\end{array}$ & $\begin{array}{c}0.003 \\
(0.017) \\
\end{array}$ & $\begin{array}{l}-117.24 \\
(340.33) \\
\end{array}$ & $\begin{array}{l}-0.026 \\
(0.033)\end{array}$ & $\begin{array}{l}158.93 \\
(273.56)\end{array}$ & $\begin{array}{c}0.031 \\
(0.024)\end{array}$ & $\begin{array}{r}325.95 \\
(464.59) \\
\end{array}$ & $\begin{array}{c}0.027 \\
(0.022)\end{array}$ \\
\hline Mean spending & \multicolumn{2}{|c|}{$\$ 11341.01$} & \multicolumn{2}{|c|}{$\$ 6962.96$} & \multicolumn{2}{|c|}{$\$ 8517.98$} & \multicolumn{2}{|c|}{$\$ 16764.47$} \\
\hline Number of interviews & \multicolumn{2}{|c|}{454520} & \multicolumn{2}{|c|}{142743} & \multicolumn{2}{|c|}{153887} & \multicolumn{2}{|c|}{157890} \\
\hline
\end{tabular}

1. $Z 1$ is equal to 1 if one or more casinos are available in Zone 1 , defined as no more than 20 miles from a household, and is equal to 0 otherwise. $Z 2$ and $Z 3$ are defined similar for casino availability from 20 to 50 miles, and from 50 to 100 miles, respectively.

2. Standard errors clustered at the household level are shown in parenthesis.

3. All regressions control for the annual before-tax income and its square, family size, family type, number of household members younger than 18, number of household members older than 64, age, race, gender, educational attainment and marital status of household head, and the population of the geographic area the household is in. All regressions also include controls for a polynomial of state unemployment rate to the fifth order, the sales tax rate, the excise tax rates for gasoline, cigarette, and beer, and the availability of multi-state lotteries, as well as the month, year and state fixed effects.

4. The cutoffs of annual household before-tax income for income terciles are $\$ 16,577$ and $\$ 52,113$, respectively.

5 . $* * * / * * / *$ indicate significance at $1 \% / 5 \% / 10 \%$, respectively. 
Table 5: Regression results: Effect of new casinos within 100 miles from households on household spending, by spending categories, CEX Interview 1996-2013

\begin{tabular}{|c|c|c|c|c|c|c|c|c|c|}
\hline & \multicolumn{3}{|c|}{$\begin{array}{c}\text { Zone } 1 \\
0 \text { to } 20 \text { miles } \\
\end{array}$} & \multicolumn{3}{|c|}{$\begin{array}{c}\text { Zone } 2 \\
20 \text { to } 50 \text { miles }\end{array}$} & \multicolumn{3}{|c|}{$\begin{array}{c}\text { Zone } 3 \\
50 \text { to } 100 \text { miles }\end{array}$} \\
\hline & $\begin{array}{l}\text { Level } \\
(1)\end{array}$ & $\begin{array}{c}\text { Any } \\
(2)\end{array}$ & $\begin{array}{l}\text { Ln } \\
(3)\end{array}$ & $\begin{array}{l}\text { Level } \\
(4)\end{array}$ & $\begin{array}{c}\text { Any } \\
(5)\end{array}$ & $\begin{array}{l}\text { Ln } \\
(6)\end{array}$ & $\begin{array}{l}\text { Level } \\
(7)\end{array}$ & $\begin{array}{c}\text { Any } \\
(8)\end{array}$ & $\begin{array}{l}\text { Ln } \\
(9)\end{array}$ \\
\hline Total spending & $\begin{array}{l}-69.24 \\
(143.37)\end{array}$ & & $\begin{array}{l}-0.003 \\
(0.010)\end{array}$ & $\begin{array}{c}75.35 \\
(84.21)\end{array}$ & & $\begin{array}{c}0.016^{* *} \\
(0.006)\end{array}$ & $\begin{array}{c}191.86 * * * \\
(62.83)\end{array}$ & & $\begin{array}{c}0.026^{* * *} \\
(0.005)\end{array}$ \\
\hline Food at home & $\begin{array}{c}-9.38 \\
(11.92)\end{array}$ & $\begin{array}{l}-0.002 \\
(0.001)\end{array}$ & $\begin{array}{l}-0.013 \\
(0.010)\end{array}$ & $\begin{array}{l}10.17 \\
(7.66)\end{array}$ & $\begin{array}{c}-0.002^{* *} \\
(0.001)\end{array}$ & $\begin{array}{l}-0.010 \\
(0.006)\end{array}$ & $\begin{array}{c}2.88 \\
(5.42)\end{array}$ & $\begin{array}{c}-0.002^{* * *} \\
(0.001)\end{array}$ & $\begin{array}{c}-0.009^{*} \\
(0.005)\end{array}$ \\
\hline Mortgage, rent and utilities & $\begin{array}{l}-22.40 \\
(65.82)\end{array}$ & $\begin{array}{l}-0.002 \\
(0.002)\end{array}$ & $\begin{array}{l}-0.018 \\
(0.015)\end{array}$ & $\begin{array}{c}13.57 \\
(33.74)\end{array}$ & $\begin{array}{c}0.000 \\
(0.001)\end{array}$ & $\begin{array}{c}0.000 \\
(0.010)\end{array}$ & $\begin{array}{c}87.14^{* * *} \\
(23.82)\end{array}$ & $\begin{array}{l}-0.001 \\
(0.001)\end{array}$ & $\begin{array}{c}0.022 * * * \\
(0.007)\end{array}$ \\
\hline Home improvement & $\begin{array}{c}41.84 \\
(29.06)\end{array}$ & $\begin{array}{c}0.039 * * * \\
(0.007)\end{array}$ & $\begin{array}{c}0.038 \\
(0.030)\end{array}$ & $\begin{array}{c}-9.67 \\
(17.47)\end{array}$ & $\begin{array}{c}0.023^{* * *} \\
(0.005)\end{array}$ & $\begin{array}{c}0.015 \\
(0.019)\end{array}$ & $\begin{array}{l}10.40 \\
(14.29)\end{array}$ & $\begin{array}{c}0.018^{* * * *} \\
(0.003)\end{array}$ & $\begin{array}{c}0.043^{* * *} * \\
(0.014)\end{array}$ \\
\hline Medical care & $\begin{array}{c}19.32 \\
(17.96)\end{array}$ & $\begin{array}{c}0.001 \\
(0.007)\end{array}$ & $\begin{array}{l}-0.021 \\
(0.025)\end{array}$ & $\begin{array}{c}13.61 \\
(11.46)\end{array}$ & $\begin{array}{c}0.014^{* * * *} \\
(0.004)\end{array}$ & $\begin{array}{c}0.021 \\
(0.015)\end{array}$ & $\begin{array}{c}32.21^{* * *} \\
(8.12)\end{array}$ & $\begin{array}{c}0.013^{* * *} \\
(0.003)\end{array}$ & $\begin{array}{c}0.027^{* *} \\
(0.011)\end{array}$ \\
\hline Transportation & $\begin{array}{l}-48.35 \\
(75.40)\end{array}$ & $\begin{array}{c}-0.009^{* *} \\
(0.005)\end{array}$ & $\begin{array}{l}-0.028 \\
(0.022)\end{array}$ & $\begin{array}{c}52.39 \\
(47.97)\end{array}$ & $\begin{array}{c}0.004 \\
(0.003)\end{array}$ & $\begin{array}{l}0.024^{*} \\
(0.014)\end{array}$ & $\begin{array}{c}20.44 \\
(34.10)\end{array}$ & $\begin{array}{l}0.004^{*} \\
(0.002)\end{array}$ & $\begin{array}{c}0.025^{* * *} * \\
(0.010)\end{array}$ \\
\hline Clothes & $\begin{array}{l}13.73 \\
(9.98)\end{array}$ & $\begin{array}{c}0.032^{* * *} \\
(0.006)\end{array}$ & $\begin{array}{c}0.068^{* * *} \\
(0.022)\end{array}$ & $\begin{array}{c}7.47 \\
(6.99)\end{array}$ & $\begin{array}{c}0.025^{* * *} \\
(0.003)\end{array}$ & $\begin{array}{c}0.040^{* * *} \\
(0.014)\end{array}$ & $\begin{array}{l}9.99^{*} \\
(5.43)\end{array}$ & $\begin{array}{c}0.016^{* * * *} \\
(0.003)\end{array}$ & $\begin{array}{c}0.045^{* * *} \\
(0.010)\end{array}$ \\
\hline Food away and entertainment & $\begin{array}{c}-54.59^{* *} \\
(23.84)\end{array}$ & $\begin{array}{c}0.003 \\
(0.004)\end{array}$ & $\begin{array}{l}-0.020 \\
(0.018)\end{array}$ & $\begin{array}{c}8.26 \\
(18.35)\end{array}$ & $\begin{array}{c}0.004 \\
(0.002)\end{array}$ & $\begin{array}{c}0.036 * * * \\
(0.012)\end{array}$ & $\begin{array}{c}34.18^{* *} \\
(15.36)\end{array}$ & $\begin{array}{c}0.001 \\
(0.002)\end{array}$ & $\begin{array}{c}0.026^{* * * *} \\
(0.008)\end{array}$ \\
\hline Alcohol and Tobacco & $\begin{array}{c}26.16^{* * * *} \\
(6.91)\end{array}$ & $\begin{array}{c}0.074 * * * \\
(0.010)\end{array}$ & $\begin{array}{c}0.039 \\
(0.031)\end{array}$ & $\begin{array}{c}8.37 * * \\
(4.27)\end{array}$ & $\begin{array}{c}0.028^{* * *} \\
(0.006)\end{array}$ & $\begin{array}{l}-0.007 \\
(0.020)\end{array}$ & $\begin{array}{c}1.04 \\
(3.00)\end{array}$ & $\begin{array}{c}0.009 * * \\
(0.004)\end{array}$ & $\begin{array}{l}-0.016 \\
(0.014)\end{array}$ \\
\hline Education & $\begin{array}{l}-6.38 \\
(21.46)\end{array}$ & $\begin{array}{c}0.027^{* * *} \\
(0.009)\end{array}$ & $\begin{array}{c}-0.106 * * * \\
(0.038)\end{array}$ & $\begin{array}{c}-4.76 \\
(12.72)\end{array}$ & $\begin{array}{c}0.032^{* * *} \\
(0.005)\end{array}$ & $\begin{array}{c}-0.077^{* * *} \\
(0.023)\end{array}$ & $\begin{array}{l}-9.19 \\
(8.79)\end{array}$ & $\begin{array}{c}0.027^{* * *} \\
(0.004)\end{array}$ & $\begin{array}{l}-0.022 \\
(0.016)\end{array}$ \\
\hline Life insurance and pensions & $\begin{array}{l}-29.19 \\
(26.17)\end{array}$ & $\begin{array}{l}-0.009 \\
(0.008)\end{array}$ & $\begin{array}{c}-0.076^{* * *} \\
(0.024)\end{array}$ & $\begin{array}{l}-24.07 \\
(15.37)\end{array}$ & $\begin{array}{c}-0.020^{* * *} \\
(0.005)\end{array}$ & $\begin{array}{c}-0.030^{* *} \\
(0.013)\end{array}$ & $\begin{array}{c}2.75 \\
(10.89)\end{array}$ & $\begin{array}{r}-0.006^{*} \\
(0.003)\end{array}$ & $\begin{array}{c}0.007 \\
(0.009)\end{array}$ \\
\hline
\end{tabular}

1. Number of interviews $=454520$.

2. Standard errors clustered at the household level are shown in parenthesis.

3. All regressions control for the annual before-tax income and its square, family size, family type, number of household members younger than 18 , number of household members older than 64 , age, race, gender, educational attainment and marital status of household head, and the population of the geographic area the household is in. All regressions also include controls for a polynomial of state unemployment rate to the fifth order, the sales tax rate, the excise tax rates for gasoline, cigarette, and beer, and the availability of multi-state lotteries, as well as the month, year and state fixed effects.

5. $* * * / * * / *$ indicate significance at $1 \% / 5 \% / 10 \%$, respectively. 
Table 6: Regression results: Effect of new casinos within 100 miles from households on household spending, by spending categories, lowest income tercile, CEX Interview 1996-2013

\begin{tabular}{|c|c|c|c|c|c|c|c|c|c|}
\hline & \multicolumn{3}{|c|}{$\begin{array}{c}\text { Zone } 1 \\
0 \text { to } 20 \text { miles }\end{array}$} & \multicolumn{3}{|c|}{$\begin{array}{c}\text { Zone } 2 \\
20 \text { to } 50 \text { miles }\end{array}$} & \multicolumn{3}{|c|}{$\begin{array}{c}\text { Zone } 3 \\
50 \text { to } 100 \text { miles }\end{array}$} \\
\hline & $\begin{array}{l}\text { Level } \\
(1)\end{array}$ & $\begin{array}{c}\text { Any } \\
(2)\end{array}$ & $\begin{array}{l}\mathrm{Ln} \\
(3)\end{array}$ & $\begin{array}{l}\text { Level } \\
(4)\end{array}$ & $\underset{(5)}{\text { Any }}$ & $\begin{array}{l}\operatorname{Ln} \\
(6)\end{array}$ & $\begin{array}{l}\text { Level } \\
(7)\end{array}$ & $\underset{(8)}{\operatorname{Any}}$ & $\begin{array}{l}\operatorname{Ln} \\
(9)\end{array}$ \\
\hline Total Spending & $\begin{array}{c}162.51 \\
(218.08)\end{array}$ & & $\begin{array}{c}0.001 \\
(0.021)\end{array}$ & $\begin{array}{c}184.24 \\
(125.44)\end{array}$ & & $\begin{array}{c}0.036 * * * \\
(0.013)\end{array}$ & $\begin{array}{c}213.31^{* *} \\
(99.49)\end{array}$ & & $\begin{array}{c}0.033^{* * *} \\
(0.009)\end{array}$ \\
\hline Food at home & $\begin{array}{c}9.27 \\
(17.75)\end{array}$ & $\begin{array}{l}-0.001 \\
(0.003)\end{array}$ & $\begin{array}{l}-0.001 \\
(0.018)\end{array}$ & $\begin{array}{c}10.54 \\
(11.88)\end{array}$ & $\begin{array}{c}-0.003^{*} \\
(0.002)\end{array}$ & $\begin{array}{l}-0.007 \\
(0.011)\end{array}$ & $\begin{array}{c}-15.01^{*} \\
(8.65)\end{array}$ & $\begin{array}{c}-0.004^{* * *} \\
(0.002)\end{array}$ & $\begin{array}{c}-0.033^{* * *} * \\
(0.008)\end{array}$ \\
\hline Mortgage, rent and utilities & $\begin{array}{l}165.46^{*} \\
(86.13)\end{array}$ & $\begin{array}{l}-0.003 \\
(0.004)\end{array}$ & $\begin{array}{c}0.033 \\
(0.028)\end{array}$ & $\begin{array}{l}96.86^{*} \\
(50.23)\end{array}$ & $\begin{array}{c}0.002 \\
(0.002)\end{array}$ & $\begin{array}{c}0.018 \\
(0.017)\end{array}$ & $\begin{array}{l}76.93^{* *} \\
(34.38)\end{array}$ & $\begin{array}{l}-0.001 \\
(0.002)\end{array}$ & $\begin{array}{l}0.024^{*} \\
(0.013)\end{array}$ \\
\hline Home improvement & $\begin{array}{c}55.07 \\
(43.28)\end{array}$ & $\begin{array}{c}0.038^{* *} \\
(0.015)\end{array}$ & $\begin{array}{c}0.039 \\
(0.068)\end{array}$ & $\begin{array}{l}52.03^{*} \\
(27.13)\end{array}$ & $\begin{array}{c}0.042^{* * * *} \\
(0.009)\end{array}$ & $\begin{array}{c}0.093^{* *} \\
(0.042)\end{array}$ & $\begin{array}{c}38.58 \\
(25.78)\end{array}$ & $\begin{array}{c}0.032^{* * *} \\
(0.007)\end{array}$ & $\begin{array}{c}0.094^{* * *} \\
(0.030)\end{array}$ \\
\hline Medical care & $\begin{array}{l}-1.30 \\
(25.23)\end{array}$ & $\begin{array}{c}-0.025^{*} \\
(0.014)\end{array}$ & $\begin{array}{l}-0.044 \\
(0.052)\end{array}$ & $\begin{array}{l}15.20 \\
(15.42)\end{array}$ & $\begin{array}{l}0.015^{*} \\
(0.008)\end{array}$ & $\begin{array}{l}0.045^{*} \\
(0.026)\end{array}$ & $\begin{array}{c}15.61 \\
(12.15)\end{array}$ & $\begin{array}{c}0.017^{* * * *} \\
(0.006)\end{array}$ & $\begin{array}{l}-0.007 \\
(0.020)\end{array}$ \\
\hline Transportation & $\begin{array}{l}-78.30 \\
(100.57)\end{array}$ & $\begin{array}{c}-0.028^{* * *} \\
(0.013)\end{array}$ & $\begin{array}{l}-0.059 \\
(0.046)\end{array}$ & $\begin{array}{l}-1.17 \\
(63.02)\end{array}$ & $\begin{array}{l}0.016^{* *} \\
(0.007)\end{array}$ & $\begin{array}{c}0.022 \\
(0.027)\end{array}$ & $\begin{array}{l}95.37^{* *} \\
(46.21)\end{array}$ & $\begin{array}{c}0.007 \\
(0.005)\end{array}$ & $\begin{array}{c}0.038^{* *} \\
(0.020)\end{array}$ \\
\hline Clothes & $\begin{array}{c}33.23 * * \\
(15.57)\end{array}$ & $\begin{array}{c}0.041^{* * * *} \\
(0.013)\end{array}$ & $\begin{array}{c}0.095 * * \\
(0.044)\end{array}$ & $\begin{array}{c}24.87 * * \\
(11.17)\end{array}$ & $\begin{array}{c}0.038^{* * * *} \\
(0.008)\end{array}$ & $\begin{array}{c}0.058 * * \\
(0.026)\end{array}$ & $\begin{array}{c}8.19 \\
(8.49)\end{array}$ & $\begin{array}{c}0.027^{* * * *} \\
(0.006)\end{array}$ & $\begin{array}{c}0.047 * * \\
(0.019)\end{array}$ \\
\hline Food away and entertainment & $\begin{array}{l}-17.32 \\
(34.71)\end{array}$ & $\begin{array}{l}-0.002 \\
(0.010)\end{array}$ & $\begin{array}{l}-0.036 \\
(0.035)\end{array}$ & $\begin{array}{l}18.85 \\
(29.01)\end{array}$ & $\begin{array}{c}0.004 \\
(0.006)\end{array}$ & $\begin{array}{c}0.049^{* *} * \\
(0.022)\end{array}$ & $\begin{array}{c}5.51 \\
(23.56)\end{array}$ & $\begin{array}{l}-0.006 \\
(0.005)\end{array}$ & $\begin{array}{c}0.021 \\
(0.016)\end{array}$ \\
\hline Alcohol and tobacco & $\begin{array}{c}19.44^{* *} \\
(8.79)\end{array}$ & $\begin{array}{c}0.084^{* * * *} \\
(0.017)\end{array}$ & $\begin{array}{l}0.036 \\
(0.051)\end{array}$ & $\begin{array}{l}10.40^{*} \\
(5.81)\end{array}$ & $\begin{array}{c}0.029^{* * *} \\
(0.010)\end{array}$ & $\begin{array}{c}0.020 \\
(0.035)\end{array}$ & $\begin{array}{l}-0.15 \\
(4.19)\end{array}$ & $\begin{array}{l}0.003 \\
(0.007)\end{array}$ & $\begin{array}{l}-0.019 \\
(0.025)\end{array}$ \\
\hline Education & $\begin{array}{c}22.39 \\
(39.06)\end{array}$ & $\begin{array}{c}0.000 \\
(0.016)\end{array}$ & $\begin{array}{l}-0.017 \\
(0.083)\end{array}$ & $\begin{array}{l}-17.00 \\
(20.50)\end{array}$ & $\begin{array}{c}0.038^{* * * *} \\
(0.010)\end{array}$ & $\begin{array}{c}-0.092^{* *} \\
(0.044)\end{array}$ & $\begin{array}{l}-21.25 \\
(15.64)\end{array}$ & $\begin{array}{c}0.024^{* * *} \\
(0.007)\end{array}$ & $\begin{array}{l}-0.042 \\
(0.032)\end{array}$ \\
\hline Life insurance and pensions & $\begin{array}{l}-45.41^{*} \\
(25.29)\end{array}$ & $\begin{array}{c}-0.049 * * * \\
(0.018)\end{array}$ & $\begin{array}{c}-0.139 * * \\
(0.059)\end{array}$ & $\begin{array}{l}-26.34^{*} \\
(13.47)\end{array}$ & $\begin{array}{c}-0.030 * * * \\
(0.011)\end{array}$ & $\begin{array}{l}-0.061^{*} \\
(0.036)\end{array}$ & $\begin{array}{c}9.54 \\
(10.53)\end{array}$ & $\begin{array}{l}-0.004 \\
(0.008)\end{array}$ & $\begin{array}{c}0.022 \\
(0.026)\end{array}$ \\
\hline
\end{tabular}

1. Households in the sample are those in the lowest income tercile, characterized by annual household before-tax income less than $\$ 16,577$. Number of interviews $=142743$.

2. Standard errors clustered at the household level are shown in parenthesis.

3. All regressions control for the annual before-tax income and its square, family size, family type, number of household members younger than 18, number of household members older than 64 , age, race, gender, educational attainment and marital status of household head, and the population of the geographic area the household is in. All regressions also include controls for a polynomial of state unemployment rate to the fifth order, the sales tax rate, the excise tax rates for gasoline, cigarette, and beer, and the availability of multi-state lotteries, as well as the month, year and state fixed effects.

5. $* * * / * * / *$ indicate significance at $1 \% / 5 \% / 10 \%$, respectively. 


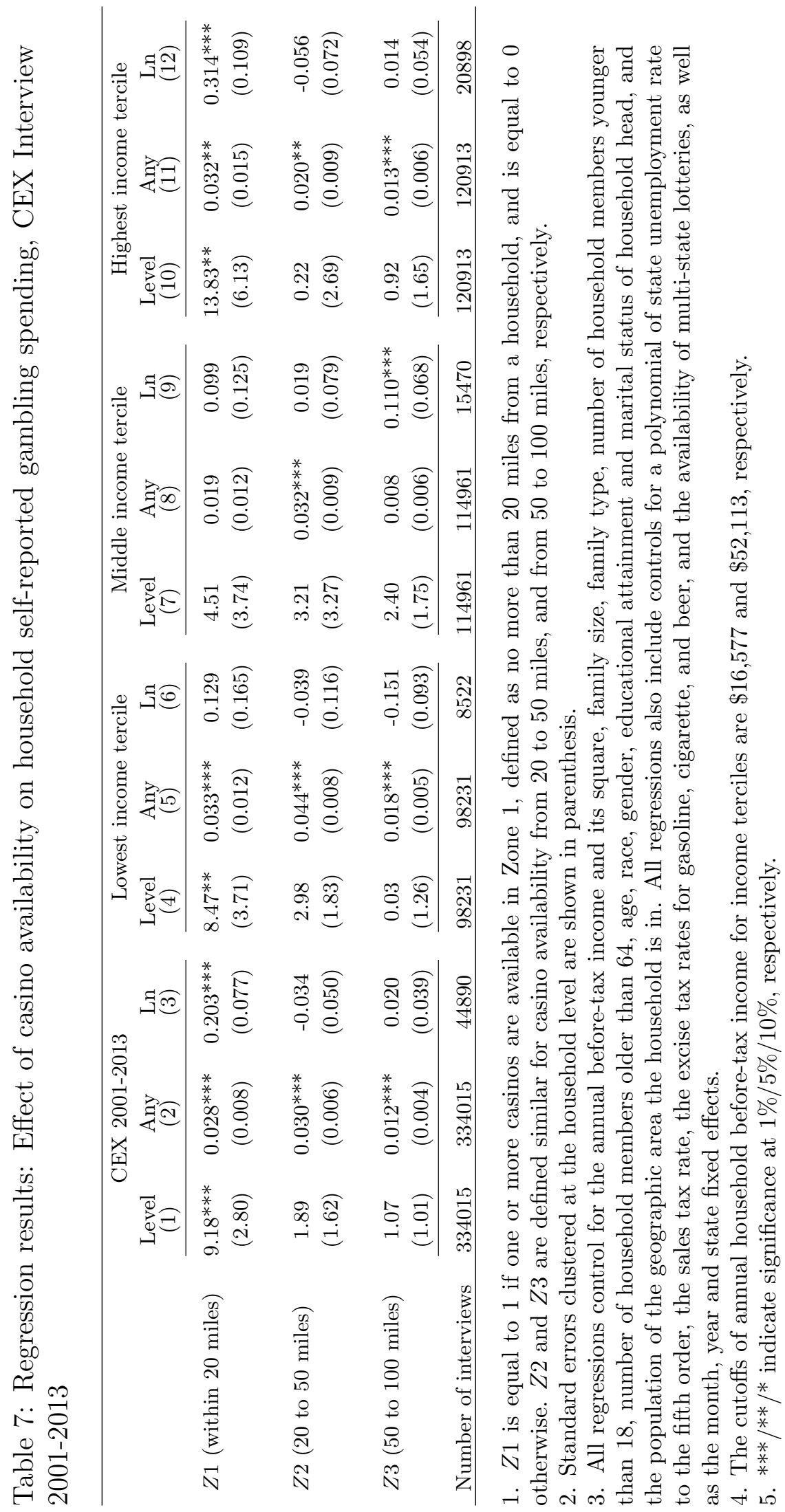


Table 8: Regression results: Intertemporal relationship between casino availability and household spending, CEX Interview 1996-2013

\begin{tabular}{|c|c|c|c|c|}
\hline & $\begin{array}{l}\text { Level } \\
(1)\end{array}$ & $\begin{array}{l}\operatorname{Ln} \\
(2)\end{array}$ & $\begin{array}{l}\text { Level } \\
(3)\end{array}$ & $\begin{array}{l}\mathrm{Ln} \\
(4)\end{array}$ \\
\hline Casinos in Zone 1 , year $0+1$ & $\begin{array}{c}-404.11^{* *} \\
(173.31)\end{array}$ & $\begin{array}{c}-0.043^{* * *} \\
(0.012)\end{array}$ & $\begin{array}{l}-218.38 \\
(200.05)\end{array}$ & $\begin{array}{c}-0.035^{* *} \\
(0.014)\end{array}$ \\
\hline Casinos in Zone 1 , year $2+$ & $\begin{array}{l}338.90^{*} \\
(202.85)\end{array}$ & $\begin{array}{r}0.036^{* *} \\
(0.014)\end{array}$ & $\begin{array}{c}205.96 \\
(205.04)\end{array}$ & $\begin{array}{l}0.026^{*} \\
(0.015)\end{array}$ \\
\hline Casinos in Zone 1 , future years $1+2$ & & & $\begin{array}{c}-13.39 \\
(203.90)\end{array}$ & $\begin{array}{c}0.007 \\
(0.015)\end{array}$ \\
\hline Casinos in Zone 2 , year $0+1$ & $\begin{array}{c}163.44 \\
(134.41)\end{array}$ & $\begin{array}{c}0.022^{* *} \\
(0.010)\end{array}$ & $\begin{array}{c}229.22 \\
(164.95)\end{array}$ & $\begin{array}{c}0.030^{* * *} \\
(0.012)\end{array}$ \\
\hline Casinos in Zone 2 , year $2+$ & $\begin{array}{l}-115.83 \\
(130.28)\end{array}$ & $\begin{array}{l}-0.007 \\
(0.010)\end{array}$ & $\begin{array}{l}-109.59 \\
(130.16)\end{array}$ & $\begin{array}{l}-0.007 \\
(0.010)\end{array}$ \\
\hline Casinos in Zone 2 , future years $1+2$ & & & $\begin{array}{l}-154.53 \\
(136.57)\end{array}$ & $\begin{array}{r}-0.016^{*} \\
(0.010)\end{array}$ \\
\hline Casinos in Zone 3 , year $0+1$ & $\begin{array}{l}132.48 \\
(99.94)\end{array}$ & $\begin{array}{c}0.021^{* * *} \\
(0.008)\end{array}$ & $\begin{array}{c}97.58 \\
(122.70)\end{array}$ & $\begin{array}{l}0.018^{*} \\
(0.009)\end{array}$ \\
\hline Casinos in Zone 3, year $2+$ & $\begin{array}{c}40.99 \\
(97.10)\end{array}$ & $\begin{array}{c}0.003 \\
(0.007)\end{array}$ & $\begin{array}{l}35.36 \\
(97.51)\end{array}$ & $\begin{array}{c}0.002 \\
(0.007)\end{array}$ \\
\hline Casinos in Zone 3 , future years $1+2$ & & & $\begin{array}{c}45.94 \\
(94.51)\end{array}$ & $\begin{array}{c}0.005 \\
(0.007)\end{array}$ \\
\hline
\end{tabular}

1. In each zone, casinos are defined as available in year $0+1$ if there is at least one casino within the two years before the interview, and are defined as available in year $2+$ if there is at least one casino within two years to ten years before the interview. Casinos are defined as available in the future years $1+2$ if there is at least one casino within the two years after the interview. The regressions also include the second order and third order interactions of the indicators of casino availability across all zones. Number of interviews $=454520$.

2. Standard errors clustered at the household level are shown in parenthesis.

3. All regressions control for the annual before-tax income and its square, family size, family type, number of household members younger than 18 , number of household members older than 64 , age, race, gender, educational attainment and marital status of household head, and the population of the geographic area the household is in. All regressions also include controls for a polynomial of state unemployment rate to the fifth order, the sales tax rate, the excise tax rates for gasoline, cigarette, and beer, and the availability of multi-state lotteries, as well as the month, year and state fixed effects.

4. $* * * / * * / *$ indicate significance at $1 \% / 5 \% / 10 \%$, respectively. 


\section{Chapter 3}

\section{Lottery Jackpots and Household Spending}

\section{Introduction}

Lotteries are popular in the U.S. By the end of 2010, annual lottery sales reached $\$ 53$ billion, equivalent to $\$ 400$ annual spending on lotteries per household, or an average monthly spending of $\$ 33$. Many households concentrate spending during the weeks when jackpots accumulate to massive size, sometimes hundreds of millions of dollars. For example, the jackpot of Powerball, a multi-state lotto, was at $\$ 15$ million on June 30, 2007, generating weekly sales of $\$ 26$ million. Six weeks later, the jackpot increased to $\$ 245$ million, generating weekly sales of more than $\$ 100$ million.

The increased lottery spending during high-jackpot days can affect household spending on other goods, especially for poorer households that often have limited savings. For example, in the presence of large jackpots, consumers may reduce spending on food or delay payments of bills. Whether or to what extent such spending changes exist, and what the implications are, still remain unanswered questions in the economics literature.

This paper provides the first empirical evidence on how household daily spending changes when lottery jackpots increase. I use data from the Consumer Expenditure Survey (CEX) Diary survey, a nationwide survey which consists of household daily spending diaries. I then merge the daily spending data with the historical data on daily jackpots of Powerball and Mega Million, two multi-state lotto games that 
produce the highest jackpots among all the lotteries in the U.S. Hence, the response in household spending to lottery jackpots is identified by the daily changes in spending when jackpot sizes change.

I find that household total spending on non-gambling goods is $\$ 4.28$ per day or $3.4 \%$ lower during the days when the jackpot, defined as the higher advertised jackpot of the two games, is at or above $\$ 100$ million, compared to the days when the jackpot is below $\$ 50$ million. The lower spending during the high-jackpot days is mostly driven by spending change of households in the lowest income tercile, at $\$ 4.81$ less per day or $5.7 \%$. By further breaking down the difference in spending by spending categories, I find that the lower non-gambling spending is concentrated on mortgage or rent payments. Since housing payments are rarely made on a daily basis, my finding suggests that lower-income households choose to postpone housing payments during high-jackpot periods. I confirm this by showing that, during high-jackpot periods, lower-income households are somewhat less likely to make housing payments at the beginning or the end of the month, compared to the other days of the month.

My finding indicates potential welfare losses for lower-income lottery players if they postpone housing payments during periods when jackpots are high. Existing research shows that many lower-income households are in financial hardships and have difficulty making mortgage or rent payments in time (Boushey et al. 2001). Hence, further delaying housing payments to gamble for large lottery prizes may lead to undesired consequences for these households, such as lower credit scores, utility disconnections, and evictions.

The rest of the paper is organized as follows. The next section reviews the literature. I provide the background of Powerball and Mega Millions in Section 3. Details about data are in Section 4. Section 5 first provides my econometric specification and then reports and discusses the results. Section 6 concludes. 


\section{Literature}

This paper complements the work of Oster (2004), who finds that lottery games with accumulating jackpots can mitigate the regressivity concern associated with lotteries. This paper also relates to Kearney (2005), in which the author finds lower household spending on non-gambling goods when states legalize lotteries.

Oster (2004) studies how the sales of Powerball changes when the jackpot changes. She defines the elasticity of sales as the response in log of sales to $\$ 1$-million change in the amount of jackpot. Using zip-code level sales data in Connecticut from 1999 to 2001, she finds a 0.035 elasticity of sales for a zip-code area with the average household income, and a positive income elasticity of sales of 0.0021 , implying that a $10 \%$ increase in median income at the zip-code level is associated with a $0.02 \%$ increase in elasticity of sales. Hence, she argues that the elasticity of sales can be very different across different income levels, given the large differences in household income across different areas in the state. Because the positive response in lottery purchases to larger jackpots is larger as the income of a location rises, this mitigates concerns about the regressivity of lotteries.

My paper complements Oster (2004) in two ways. First, I study the response of spending at the household level to changes in lottery jackpots. Therefore, my analysis is less subject to measurement errors, since, as Oster argues, the link between zip-code level sales and individual behavior may be weak if some households bought lottery tickets in multiple zip-code areas. My nationwide sample is also more representative than Oster's Connecticut sample. Second, my findings show that lower-income households may postpone housing payments during high-jackpot days. Hence, the bad consequences resulting from late housing payments suggest that, besides the benefit of regressivity mitigation, there can also be costs associated with having accumulating 
jackpots in lottery games.

Kearney (2005) finds that, when states legalize lotteries, household quarterly spending on non-gambling goods decreases by $\$ 137$ (in 2000 dollars) or $2.4 \%$, using the CEX Interview data from 1982 to 1998. She claims that, since the magnitude of the decrease is greater than the per-household lottery sales during her sample period, lottery gambling may be more than completely financed by a reduction in non-gambling consumption. My paper studies a different but related topic: conditional on having access to lottery games, how households change their spending decisions when the prizes of lotteries vary.

\section{Background}

Powerball began to be sold in eight states and D.C. in late 1980's. Another twenty-three states joined between 1990 and 2009, followed by a further expansion to thirteen more states after January 2010. Mega Millions started in June, 2002 as a lotto cross-sold in seven states. Five more states joined between 2002 and 2005. The game expanded to another thirty-two states and D.C. after January 2010 (Table 1). ${ }^{1}$ Tickets are sold everyday in many supermarkets, convenience stores, gas stations, and other vendors. In both games, players choose five numbers from a larger pool, plus one number from another smaller pool. The jackpot is won by matching all the numbers chosen by the player and the numbers on the balls drawn. Smaller prizes are awarded to partial matching, but at exponentially smaller amounts. ${ }^{2}$ The drawings are held twice a week, on Wednesdays and Saturdays for Powerball, and on Tuesdays and Fridays for Mega Millions. During the years from 2002 to 2011, the pool sizes

\footnotetext{
${ }^{1}$ The expansion in 2010 is a simultaneous one for Powerball and Mega Millions. Before January 31, 2010, none of states offers both games, while most of the multi-state lottery participant states offer both games after the expansion.

${ }^{2}$ See Powerball.com and MegaMillions.com for current payout tables.
} 
have changed slightly for both games (Table 2). The price per ticket of both games have stayed constant at $\$ 1 .^{3}$

The jackpot is often displayed conspicuously at the vendors, sometimes even along highways, easily observable for drivers. For jackpot winners, the advertised jackpot is a gross amount that is subject to around $40 \%$ federal tax, plus the applicable state tax. Winners have the option to receive the prize as a lump-sum or as a 30-year annuity. Still, the advertised jackpot is arguably the most salient number to the general public and is widely cited by media, and I will use it in my regressions.

The advertised jackpot accumulates similarly in both games. If a winning ticket (or multiple winning tickets) is confirmed be sold after a drawing, the jackpot next day will be downward adjusted to the specified minimum jackpot amount. If no winning ticket is sold, then the jackpot will continue to rise, by at least the specified minimum amount of increase. Table 3 lists the changes in the minimum jackpot and the minimum increase in jackpot per drawing for the two games between 2002 and 2011. Over the ten years, the minimum jackpot ranges from $\$ 10$ million to $\$ 20$ million for Powerball, and from $\$ 10$ million to $\$ 12$ million for Mega Millions. The minimum increase in jackpot per drawing ranges from $\$ 1$ to $\$ 5$ millions. The actual increase is often more than the minimum between drawings, as jackpots can increase on a daily basis based on daily sales. Overall, the changes in jackpot accumulation rules do not appear to affect the pattern of jackpot accumulation over time significantly (Figure 1).

Sales of both games increase substantially as the jackpot increases. In comparison to when jackpots are below $\$ 50$ million, daily sales of Powerball are about $\$ 11$ million higher in all 2010 participant states during the days when jackpots are at or above $\$ 100$ million, a $145 \%$ increase normalized by average daily sales in 2010. Mega Millions

\footnotetext{
${ }^{3}$ The price per ticket increased to $\$ 2$ for Powerball starting from January 15, 2012.
} 
has a similar responsiveness in sales to jackpots, at $140 \%$.

\section{Data}

My household spending data come from the Consumer Expenditure Survey (CEX) Diary surveys published by the Bureau of Labor Statistics (BLS). Each year, the CEX Diary samples about 6,000 to 7,000 households across the country, asking them to record all their daily expenditures in two consecutive weekly diaries. ${ }^{4}$ For each entry of an expense, the calendar date is recorded. Household demographics are also collected along with the diaries. My sample period is from 2002 to 2011. The year 2002 marks the first year when Mega Millions has today's game format, while the year 2011 is the last year when the CEX Diary reports the calendar days on which purchases were made by households. After 2011, the daily spending records in the CEX Diary can no longer be matched with lottery jackpots.

The CEX Diary reports state identifiers for individual households, although the state codes of some households, mostly those living in less populous states or areas, are suppressed due to the BLS's practice of protecting respondent confidentiality. Out of all 66575 households surveyed by the CEX Diary from 2002 to 2011, 57146 households have valid state codes. Among those with valid state codes, I further exclude 6722 households in states (years) where (when) neither Powerball or Mega Millions is sold. I also exclude 581 households that have the top $1 \%$ of average total non-gambling spending during the diary period, as some households have recorded very large spending amount on certain days, and including these households may substantially increase the noise of estimates. ${ }^{5}$ After these steps, I have a sample of

\footnotetext{
${ }^{4}$ Some households quit after one week. I keep these one-week diaries in my sample.

${ }^{5}$ The cutoff for the $1 \%$ topcoding is $\$ 909.11$, which is determined by the distribution of daily average non-gambling spending over the diary period of all households in the CEX Diary from 2002
} 
538464 spending days from 49843 households. Table 4 compares a set of household characteristics that may affect spending and daily average spending over the diary period between my sample and the sample of all CEX Diary households, showing high similarity. Households in my sample receives slightly higher income, perhaps because households in less populated areas, many of whom earn less, are more likely be subject to the BLS's state code suppression practice. ${ }^{6}$ Households in my sample have lower average spending on non-gambling goods, an unsurprising result due to the $1 \%$ topcoding, which reduces the maximum daily average spending over the diary period from $\$ 11212.79$ to $\$ 909.11$. Self-reported gambling spending is also available in the CEX Diary, but is known to be severely under-reported (Kearney, 2005). The severeness of under-reporting can be confirmed by annualizing the $\$ 0.23$ daily average self-reported gambling spending, which would give an annual total gambling spending of around $\$ 84$. This is far less than even just the annual sales of lotteries per household, which ranges from $\$ 350$ to $\$ 400$ during my sample period. Therefore, I do not use gambling spending as a regression outcome in this analysis.

I collect historical jackpot data from LottoReport.com, an online source that documents jackpot data for many U.S. lotteries. ${ }^{7}$ The jackpots are recorded in the LottoReport data as they were advertised on the days when the lotteries were drawn (Wednesdays and Saturdays for Powerball, and Tuesdays and Fridays for Mega Millions), although the actual jackpot accumulation between drawings is often gradual

to 2011 .

${ }^{6}$ The suppression of state codes is one of many steps taken by the BLS to protect respondents from identified by the copious amount of information collected by the surveys. Hence, households living in rural or less populous areas are more likely to receive a blank or invalid state code.

${ }^{7}$ The jackpot data are cross-checked with a few other online sources, including LottoStrategies.com, and USAMega.com, for accuracy. From 2002 to 2011, less than 1\% of jackpots are slightly different between different data sources, due to update of jackpots after the drawing day with updated daily sales data. When discrepancies occur, I use the original advertised jackpot on the drawing day provided by LottoReport.com. The discrepancies in data from different sources will not affect my results, as jackpots will be categorized into brackets in my analysis. 
and on a daily basis. Therefore, for each game, I linearly interpolated the jackpot numbers for the other five days of the week, subject to the rules of minimum jackpots and minimum increase in jackpots specified for both games.

During the first eight years of my sample period, each sample state offers either Powerball or Mega Million. After January 31, 2010, when both games expanded across the country, eleven of the twelve Mega Millions participant states started to offer Power Ball, and twenty-three of the thirty one Power Ball participant states started to offer Mega Millions, too. Since then, the jackpots of both games are usually advertised side-by-side by vendors. Hence, it is then necessary to specify, for about $30 \%$ of spending days in my sample, how the jackpot is measured in the presence of both games. I use the larger amount of the two advertised jackpots when both games are sold in the same state, as the highly similar rules and payout tables between the two games suggest high substitutability. The nationwide sales records also show that the sales of the two games appear to crowd out each other after the 2010 cross expansion (Table 5).

\section{Analysis}

\subsection{Econometric specification}

To estimate how households change their daily spending in response to the changes in lottery jackpots, I estimate the following reduced-form equation:

$$
y_{i t}=\alpha_{i}+\sum_{b=2}^{B} \beta_{b} J P_{b t}+\sum_{k=2}^{7} \eta_{k} D O W_{t k}+\sum_{l=2}^{14} \lambda_{l} D O S_{i t l}+\varepsilon_{i t}
$$

where $y_{i t}$ is household $i$ 's daily spending on non-gambling goods on day $t$. The household fixed-effect $\alpha_{i}$ captures the time-invariant factors affecting daily spending, such 
as household size, permanent household income, and so on, so the effect of jackpot size is identified from within-household spending changes over time. I categorize the size of advertised jackpot in $B$ brackets, and the indicators $J P_{b t}$, the variables of interest, equal 1 if the the jackpot advertised on day $t$ falls in bracket $b$, and equal 0 otherwise. I inflation adjust household spending, the dependent variable, but not the advertised jackpots, considering that players are more likely to interpret the jackpot numbers crudely (e.g. as "small", "medium" and "large" jackpots), instead of meticulously calculating the jackpot's purchasing power. The $D O W_{s k}$ variables are day-of-week indicators, for Sunday, Monday, etc. The associated parameters $\eta_{k}$ capture differences in spending by day of the week; this is especially important for weekends. The $D O S_{i s l}$ variables are day-of-sequence indicators in a diary for day 1 to 14. The associated parameters $\lambda_{l}$ capture the "survey fatigue" effect, as households tend to record less spending as they move towards the end of a diary. The conditional zero-mean error term $\varepsilon_{\text {is }}$ accounts for unobserved or unpredictable factors that may affect spending over time. One unobserved factor that can affect daily spending is the timing of income arrivals (Gelman et al. 2014). Here, I assume that income arrivals are independent from daily jackpots.

The parameters of interest are $\beta_{2}, \ldots, \beta_{B}$. A negative $\beta_{b}$ represents a decrease in daily spending when a jackpot falls in bracket $b$, compared to the daily spending when a jackpot falls in bracket 1 , the base bracket that contains the set of the smallest jackpots.

\subsection{Results}

\section{A. Base results}

Table 6 reports the estimates for $\beta_{b}$ 's in (1), with jackpots grouped in 3 brackets: less 
than $\$ 50$ million, at or above $\$ 50$ million and less than $\$ 100$ million, and at or above $\$ 100$ million. The estimates in Column (1) show that, for the full sample, daily total spending is $\$ 4.28$ lower during the days when the jackpot is in the highest bracket (at or above $\$ 100$ million), compared to the days when the jackpot is in the lowest bracket (below $\$ 50$ million). The lower spending is statistically significant at $5 \%$. Normalized by mean spending, this difference is about 3.4\%. I repeat the estimation for three subsamples of household income terciles, and report the estimates in Column (2) through (4). The estimates of income groups show that this difference is largely driven by spending changes made by households in the lowest income tercile, at $\$ 4.81$ per day, or $5.7 \%$, between the highest-bracket and the lowest-bracket days, with a statistical significance of $10 \%$.

\section{B. Which spending categories do households change their spending on?}

I explore more details about which subcategories of spending experience reductions by lower-income households when jackpots increase. I do this by replacing the dependent variable in regression equation (1) by spending on ten categories: food and non-alcoholic beverage, alcohol, tobacco, other non-durable goods, mortgage or rent, medical care, non-housing and non-medical bills, clothes and linens, other durable goods, and investments and insurance premiums. Table 7 reports the results, showing that most of the decrease in spending during the days when jackpot is at or above $\$ 100$ million occurs for the category of spending on housing. As housing payments are usually made on a monthly basis, but with some flexibility about the actual payment day, the negative estimate on housing spending implies that lower-income households choose to postpone their mortgage or rent payments when they spend more on lotteries when jackpots are large. ${ }^{8}$

\footnotetext{
${ }^{8}$ Results in Table 7 also suggest possible spending decreases or delays for payments of non-
} 
To confirm that lower-income households postpone housing payments during highjackpot days, I compare the distribution of housing payment days over a month across days that offer jackpots in different brackets. If the delay does not occur, then the distribution of payment days should be similar regardless of jackpot size.

I show the comparison for mortgagors and renters in two separate figures (Figure 2-a, b). In general, mortgage and rent payments are due on the first of each calendar month, subject to a "grace period" up to two weeks after the first. Hence, I consider housing payments as "not delayed" if they are made during first and last week of a month. Both figures show that there are less housing payments occurring during the first and the last week, suggesting housing payment delays. It appears that more delays have occurred for mortgagors, an unsurprising result as mortgagors are usually given a longer grace period compared to renters.

\section{Do household spending changes when anticipated jackpots change?}

It is also possible that households change spending in anticipation of the jackpot by the next drawing. ${ }^{9}$ Hence, I further control for $J P N E X T_{b t}$, the brackets of jackpots on the next drawing day, in regression equation (1), and report the estimates in Table 8. The coefficient estimates on the two future jackpot brackets show that there is no significant difference when the jackpot by the next drawing increases from the second bracket $(\geq 50$ million and $<100$ million) to the third bracket $(\geq 100$ million), but there is a significantly positive change in non-gambling spending when the jackpot by the next drawing increases from the first bracket $(<50$ million $)$ to the second bracket,

housing and non-medical bills. Although the coefficient estimate is statistically insignificant at $10 \%$, the associated standard error is small. Hence, it is possible that some households postpone both housing payment and other bill payments during high-jackpot days.

${ }^{9}$ For example, knowing that there is no winner of a previous jackpot in the size between $\$ 85$ million and $\$ 90$ million, the new jackpot by the next drawing will typically reach some number between $\$ 100$ million and $\$ 105$ million. 
ranging from $5.68 \%$ to $9.19 \%$ per day across income groups.

One possibility is that there is a complementarity between lotteries and some nongambling goods such as groceries, due to the presence of travel costs to stores where both goods are sold, and this complementary effect may dominate the substitution effect between the two types of goods when both current and anticipated jackpots are small (below $\$ 50$ million). To test this hypothesis, I examine how household spending on home-town transportation changes when lottery jackpots vary. ${ }^{10}$ Since the positive estimates in Table 8 suggest that the complementary effect occurs mostly when the future jackpot is in the first bracket, I estimate (1) by replacing the $J P_{b t}$ indicators by $J P N E X T_{1 t}$, which is equal to 1 if the jackpot by the next drawing is below $\$ 50$ million, and 0 otherwise. The dependent variable is the amount of home-town transportation spending, or an indicator of any such spending. Table 9 reports the estimates, showing that households are somewhat less likely to spend on home-town transportation during days when jackpot is anticipated to stay at less than $\$ 50$ million. The magnitude of the coefficient is not large, perhaps because not all households have positive transportation spending when they travel to stores.

\subsection{Discussion}

The above findings indicate that, during the days when lottery jackpots are high, lower-income households choose to postpone their mortgage or rent payments, suggesting that they face a temporary liquidity constraint that prevents them from simultaneously spending more on lotteries and making regular payments when jackpots are large. Postponing housing payments may cost these households. The National

\footnotetext{
${ }^{10}$ This category includes spending on gasoline, parking, tolls, and public transportation in home town, which is positively associated with trips to stores where both lotteries and other goods are sold. Unfortunately, the CEX Diary does not report whether households have made any grocery trip on each day.
} 
Survey of American Families data show that among households with income below 200\% Federal Poverty Line (FPL), a group accounting for about one third of all U.S. households, $25 \%$ have missed housing or utility bill payments during the past 12 months, and $10 \%$ have experienced telephone disconnection for more than 24 hours during the past 12 months, while these percentages are only $8 \%$ and $3 \%$ for households with income above the 200\% FPL (Boushey et al. 2001). Speculatively, there should be more lower-income households that are in financial hardships and can barely pay their housing payments and bills before deadlines. Hence, further delaying payments to gamble for large lottery prizes may lead to bad consequences for these households, such as lower credit scores, utility disconnections, and evictions.

\section{Conclusion}

This paper studies how household spending changes as lottery jackpots increase, using nationwide microdata in household spending diaries. The lottery games of interest, Powerball and Mega Millions, are sold across forty-three states and D.C. during my sample period, 2002 to 2011. The jackpots start to accumulate daily from no more than $\$ 15$ million, and can often reach $\$ 100$ million or more, increasing daily sales by tens of millions of dollars.

I find that household total spending on non-gambling goods is $\$ 4.28$ per day or $3.4 \%$ lower during the days when the jackpot, defined as the higher advertised jackpot of the two games, is at or above $\$ 100$ million, compared to the days when the jackpot is below $\$ 50$ million. The lower spending during the high-jackpot days is larger in magnitude for households in the lowest income tercile, at $\$ 4.81$ per day or $5.7 \%$. By further breaking down the difference in spending by spending categories, I find that the lower non-gambling spending concentrates on mortgage or rent payments, which 
suggests that lower-income households choose to postpone housing payments when they spend more on lotteries during the days when jackpots are high, even though bad consequences may result from the late housing payments.

States may find appealing to set rules of lottery games in a way to increase the likelihood of large jackpots, as larger prizes may attract more players from the higher end of income distribution, mitigating the concern of regressivity associated with lotteries (Oster, 2004). The findings in this paper indicate that doing so is not without costs, as poorer households may change their non-gambling spending in an undesirable way to spend more on lotteries during high-jackpot periods. The trend to create larger jackpots is continuing: a set of changes in game rules such as increasing the minimum jackpot, increasing the minimum increase in jackpot per drawing, and decreasing the chances of winning the jackpot by changing the pool sizes, started to apply in 2012. Within about three years, the U.S. record of the largest lottery jackpot won was broken ten times, with the current record at $\$ 1586$ million. It would be interesting to learn from future research how consumer behavior is affected in presence of these even larger jackpots, and its implications on the optimal design of lottery games. 


\section{References}

[1] Boushey, H., C. Brocht, B. Gundersen and J. Bernstein. (2001). "Hardships in America, The Real Story of Working Families". Economic Policty Institute.

[2] Gelman, M., S. Kariv, M. Shapiro, D. Silverman and S. Tadelis (2014). "Harnessing Naturally Occurring Data to Measure the Response of Spending to Income". Science: Microeconomics. 345.6193, 212-215.

[3] Kearney, M. (2005). "State Lotteries and Consumer Behavior". Journal of Public Economics. 89, 2269-2299.

[4] Oster, E. (2004). "Are All Lotteries Regressive? Evidence from the Powerball". National Tax Journal. 


\section{Figures}

Figure 1: Advertised jackpot, millions of nominal dollars, 2002-2011

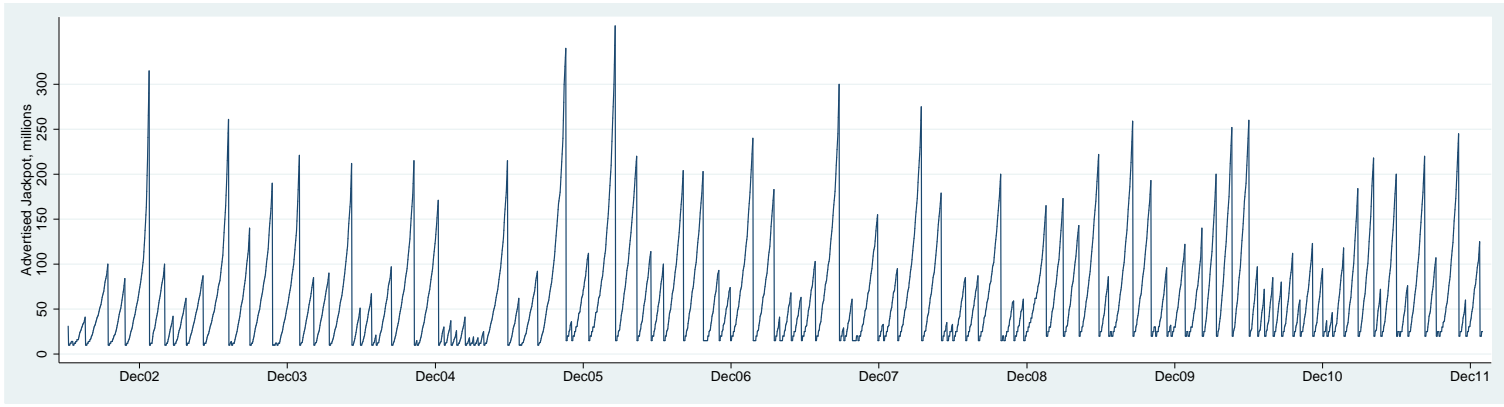

(a) Powerball

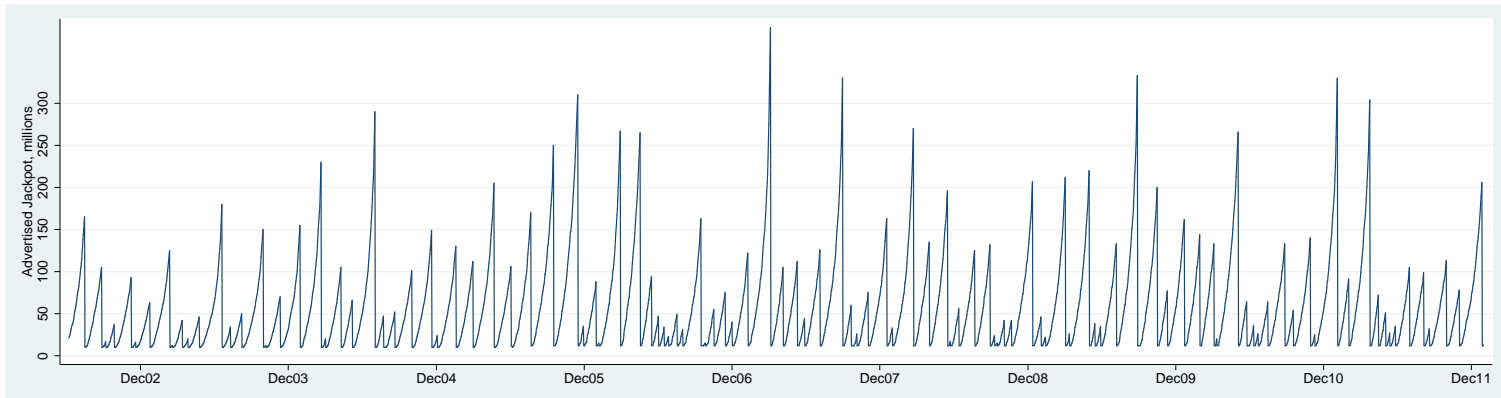

(b) Mega Millions 
Figure 2: Kernel density of calendar days when housing payments are made, comparison among lottery jackpot brackets, households in the lowest income tercile, CEX Diary 2002-2011.

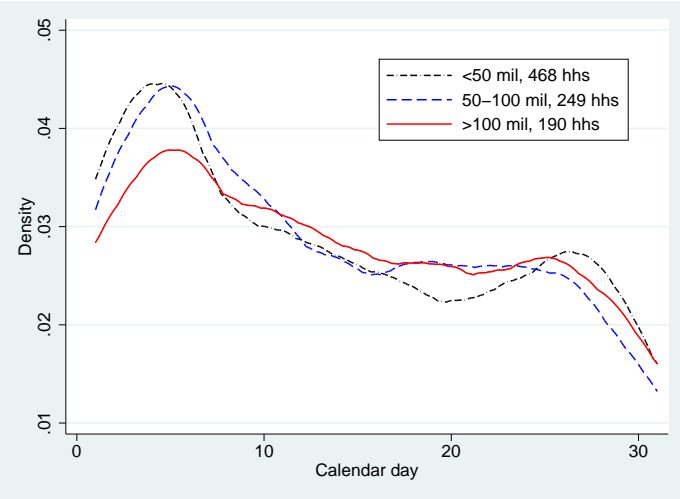

(a) Mortgagors

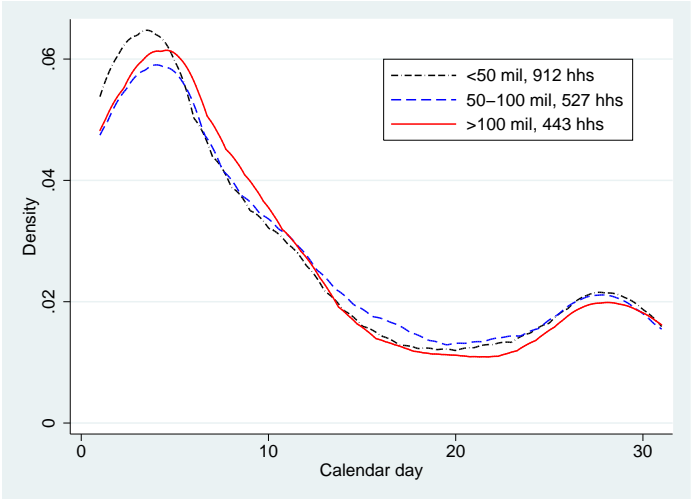

(b) Renters

Lottery jackpot is defined as the advertised jackpot of Powerball or Mega Millions if there is only one game being sold in the state where the households resides, and is defined as the higher advertised jackpot of Powerball and Mega Millions if both games are available. Kernel function is Epanechnikov. 


\section{Tables}

Table 1: Dates joining Powerball and Mega Millions, all states and D.C.

\begin{tabular}{|c|c|c|c|c|c|}
\hline State & Powerball & Mega Millions & State & Powerball & Mega Millions \\
\hline District of Columbia & 02/13/1988 & $01 / 31 / 2010$ & Georgia & $01 / 31 / 2010$ & 09/06/1996 \\
\hline Iowa & 02/13/1988 & $01 / 31 / 2010$ & Illinois & $01 / 31 / 2010$ & 09/06/1996 \\
\hline Kansas & $02 / 13 / 1988$ & $01 / 31 / 2010$ & Maryland & $01 / 31 / 2010$ & 09/06/1996 \\
\hline Missouri & $02 / 13 / 1988$ & $01 / 31 / 2010$ & Massachusetts & $01 / 31 / 2010$ & 09/06/1996 \\
\hline Oregon & $02 / 13 / 1988$ & $03 / 28 / 2010$ & Michigan & $01 / 31 / 2010$ & 09/06/1996 \\
\hline Rhode Island & 02/13/1988 & $01 / 31 / 2010$ & New Jersey & $01 / 31 / 2010$ & 05/01/1999 \\
\hline West Virginia & 02/13/1988 & $01 / 31 / 2010$ & New York & $01 / 31 / 2010$ & $05 / 17 / 2002$ \\
\hline Wisconsin & 08/10/1989 & $01 / 31 / 2010$ & Texas & $01 / 31 / 2010$ & $12 / 05 / 2003$ \\
\hline Montana & $11 / 09 / 1989$ & 03/01/2010 & Virginia & $01 / 31 / 2010$ & 09/06/1996 \\
\hline Idaho & 02/01/1990 & $01 / 31 / 2010$ & Washington & $01 / 31 / 2010$ & $09 / 06 / 2002$ \\
\hline Minnesota & 08/14/1990 & $01 / 31 / 2010$ & Ohio & $04 / 16 / 2010$ & $05 / 17 / 2002$ \\
\hline Indiana & $10 / 14 / 1990$ & $01 / 31 / 2010$ & California & $04 / 08 / 2013$ & $06 / 22 / 2005$ \\
\hline South Dakota & $11 / 15 / 1990$ & $05 / 16 / 2010$ & Wyoming & $08 / 24 / 2014$ & $08 / 24 / 2014$ \\
\hline Kentucky & 01/10/1991 & $01 / 31 / 2010$ & & & \\
\hline Delaware & 01/14/1991 & $01 / 31 / 2010$ & & & \\
\hline Arizona & 04/04/1994 & $04 / 18 / 2010$ & & & \\
\hline Nebraska & $07 / 21 / 1994$ & $03 / 20 / 2010$ & Non-participant states & & \\
\hline Louisiana & 03/05/1995 & $11 / 16 / 2011$ & Alabama & & \\
\hline New Hampshire & $11 / 05 / 1995$ & $01 / 31 / 2010$ & Alaska & & \\
\hline Connecticut & $11 / 28 / 1995$ & $01 / 31 / 2010$ & Hawaii & & \\
\hline New Mexico & $10 / 20 / 1996$ & $01 / 31 / 2010$ & Mississippi & & \\
\hline Colorado & 08/02/2001 & $05 / 16 / 2010$ & Nevada & & \\
\hline Pennsylvania & $06 / 29 / 2002$ & $01 / 31 / 2010$ & Utah & & \\
\hline South Carolina & $10 / 06 / 2002$ & $01 / 31 / 2010$ & & & \\
\hline Vermont & $07 / 01 / 2003$ & $01 / 31 / 2010$ & & & \\
\hline North Dakota & $03 / 25 / 2004$ & $01 / 31 / 2010$ & & & \\
\hline Tennessee & $04 / 21 / 2004$ & $01 / 31 / 2010$ & & & \\
\hline Maine & $07 / 30 / 2004$ & $05 / 09 / 2010$ & & & \\
\hline Oklahoma & $01 / 12 / 2006$ & $01 / 31 / 2010$ & & & \\
\hline North Carolina & $05 / 30 / 2006$ & $01 / 31 / 2010$ & & & \\
\hline Florida & $01 / 04 / 2009$ & $05 / 15 / 2013$ & & & \\
\hline Arkansas & $10 / 31 / 2009$ & $01 / 31 / 2010$ & & & \\
\hline
\end{tabular}


Table 2: Historical changes in Powerball and Mega Millions pool sizes, 2002-2011

\begin{tabular}{|c|c|c|c|c|c|c|}
\hline \multirow[b]{2}{*}{$\begin{array}{l}\text { Beginning of } \\
\text { sample period }\end{array}$} & \multicolumn{3}{|c|}{ Powerball } & \multicolumn{3}{|c|}{ Mega Millions } \\
\hline & $\begin{array}{c}\text { Pick } 5 \\
\text { from }\end{array}$ & $\begin{array}{l}\text { Pick } 1 \\
\text { from }\end{array}$ & $\operatorname{Pr}($ all matched $)$ & $\begin{array}{l}\text { Pick } 5 \\
\text { from }\end{array}$ & $\begin{array}{l}\text { Pick } 1 \\
\text { from }\end{array}$ & $\operatorname{Pr}($ all matched $)$ \\
\hline 06/07/2002 & 49 & 42 & $1: 80,089,127$ & 52 & 52 & $1: 135,145,920$ \\
\hline \multicolumn{7}{|l|}{ Changes } \\
\hline $10 / 09 / 2002$ & 53 & 42 & $1: 120,526,769$ & & & \\
\hline $06 / 22 / 2005$ & & & & 56 & 46 & $1: 175,711,536$ \\
\hline $08 / 28 / 2005$ & 55 & 42 & $1: 146,107,961$ & & & \\
\hline $01 / 07 / 2009$ & 59 & 39 & $1: 195,249,054$ & & & \\
\hline
\end{tabular}

Table 3: Historical changes in Powerball and Mega Millions jackpot rules, millions of nominal dollars, 2002-2011

\begin{tabular}{|c|c|c|c|c|}
\hline \multirow[b]{2}{*}{$\begin{array}{l}\text { Beginning of } \\
\text { sample period }\end{array}$} & \multicolumn{2}{|c|}{ Powerball } & \multicolumn{2}{|c|}{ Mega Millions } \\
\hline & $\begin{array}{l}\text { Minimum } \\
\text { jackpot }\end{array}$ & $\begin{array}{l}\text { Minimum } \\
\text { increase }\end{array}$ & $\begin{array}{l}\text { Minimum } \\
\text { jackpot }\end{array}$ & $\begin{array}{l}\text { Minimum } \\
\text { increase }\end{array}$ \\
\hline $06 / 07 / 2002$ & 10 & 2 & 10 & 1 \\
\hline \multicolumn{5}{|l|}{ Changes } \\
\hline 06/03/2006 & & & 12 & 2 \\
\hline $10 / 22 / 2005$ & 15 & 5 & & \\
\hline $01 / 17 / 2009$ & 20 & 5 & & \\
\hline
\end{tabular}

If the jackpot is hit after the previous drawing, then the new advertised jackpot will be restored to the minimum jackpot. Otherwise, the advertised jackpot will increase by at least the minimum increase amount. The actual increase of the jackpot may be higher than the minimum increase, depending on daily sales growth. 
Table 4: Summary statistics: sample of this study and the full CEX Diary 2002-2011

\begin{tabular}{|c|c|c|c|c|}
\hline \multirow[b]{2}{*}{ Household characteristics } & \multicolumn{2}{|c|}{$\begin{array}{l}\text { Households in } \\
\text { PB/MM states }\end{array}$} & \multicolumn{2}{|c|}{$\begin{array}{l}\text { Full CEX Diary } \\
\text { 2002-2011 }\end{array}$} \\
\hline & Mean & S.D. & Mean & S.D. \\
\hline Age of household head & 48.73 & 17.01 & 48.65 & 17.14 \\
\hline$\%$ male head & 0.472 & 0.499 & 0.474 & 0.499 \\
\hline$\%$ non-white head & 0.176 & 0.381 & 0.172 & 0.377 \\
\hline$\%$ head has a college degree & 0.309 & 0.462 & 0.295 & 0.456 \\
\hline$\%$ homeowners & 0.663 & 0.473 & 0.668 & 0.471 \\
\hline Household size & 2.48 & 1.44 & 2.50 & 1.46 \\
\hline Annual before-tax income & 56260.57 & 68154.27 & 55663.61 & 67905.82 \\
\hline \multicolumn{5}{|l|}{$\begin{array}{l}\text { Household-level average spending } \\
\text { over diary period }\end{array}$} \\
\hline Non-gambling spending & 125.03 & 137.63 & 138.93 & 245.37 \\
\hline Self-reported gambling spending & 0.23 & 2.85 & 0.24 & 3.63 \\
\hline Number of households & \multicolumn{2}{|c|}{49893} & \multicolumn{2}{|c|}{66575} \\
\hline Number of diary days & \multicolumn{2}{|c|}{538464} & \multicolumn{2}{|c|}{725652} \\
\hline
\end{tabular}

My sample consists of households living in states where at least one game of Powerball (PB) and Mega Millions (MM) is sold. State codes are suppressed for some states in some years in the CEX Diary. Households with suppressed state codes are dropped. Households with top $1 \%$ daily average spending over diary period (greater than \$909.11) are also dropped. The maximum daily average spending over diary period decreases from $\$ 11212.79$ to $\$ 909.11$ after dropping these top-1\% spending households. All income and spending numbers are in 2010 dollars. 
Table 5: Aggregate sales of all participant states, billions of 2010 dollars, 2003-2011

\begin{tabular}{cccc}
\hline Year & Powerball & Mega Millions & Total sales \\
\hline 2003 & 2.01 & 2.28 & 4.29 \\
2004 & 2.49 & 2.08 & 4.58 \\
2005 & 2.90 & 2.19 & 5.09 \\
2006 & 2.49 & 2.59 & 5.08 \\
2007 & 2.98 & 2.24 & 5.22 \\
2008 & 2.65 & 2.04 & 4.69 \\
2009 & 3.07 & 2.47 & 5.55 \\
2010 & 2.77 & 2.76 & 5.54 \\
2011 & 2.76 & 2.87 & 5.63 \\
\hline
\end{tabular}

Data source: Lotto Report. Cross expansion of the two games started on January 31, 2010. See Table 1 for more details on joining dates of individual states. 


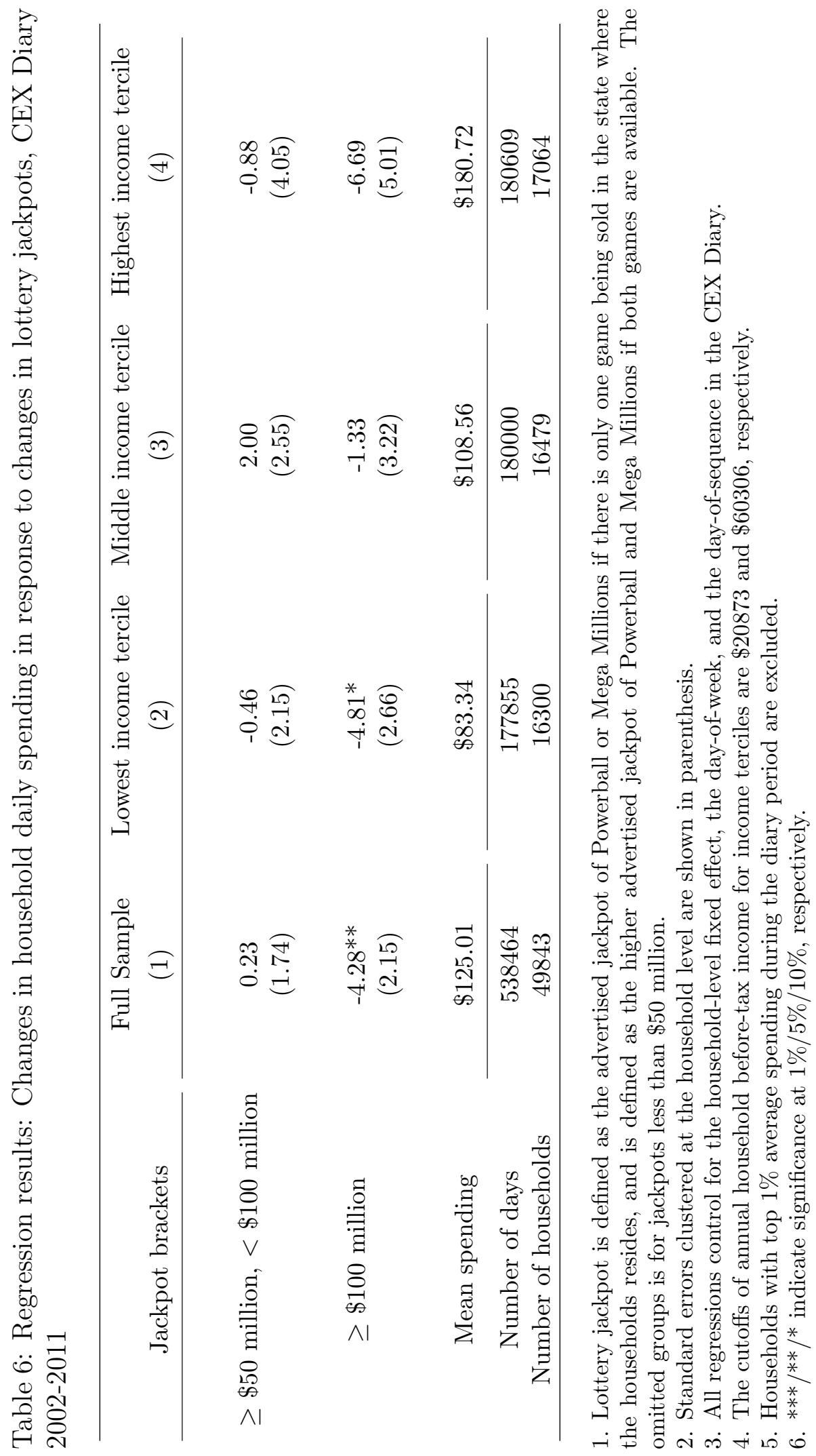


Table 7: Regression results: Changes in household daily spending on subcategories in response to changes in lottery jackpots, households in the lowest income tercile, CEX Diary 2002-2011

\begin{tabular}{|c|c|c|c|}
\hline & Mean & $\begin{array}{c}<50 \text { million, } \\
\geq 100 \text { million } \\
\quad(1)\end{array}$ & $\begin{array}{c}\geq 100 \text { million } \\
(2)\end{array}$ \\
\hline Food \& Non-alcoholic beverage & $\$ 15.26$ & $\begin{array}{c}0.49 \\
(0.31)\end{array}$ & $\begin{array}{c}0.18 \\
(0.37)\end{array}$ \\
\hline Alcohol & $\$ 0.88$ & $\begin{array}{c}0.03 \\
(0.06)\end{array}$ & $\begin{array}{c}0.07 \\
(0.09)\end{array}$ \\
\hline Tobacco & $\$ 0.74$ & $\begin{array}{c}0.04 \\
(0.04)\end{array}$ & $\begin{array}{c}0.04 \\
(0.05)\end{array}$ \\
\hline Other non-durable goods & $\$ 4.64$ & $\begin{array}{l}-0.15 \\
(0.28)\end{array}$ & $\begin{array}{c}0.02 \\
(0.31)\end{array}$ \\
\hline Mortgage or Rent & $\$ 16.22$ & $\begin{array}{c}0.00 \\
(1.16)\end{array}$ & $\begin{array}{c}-3.43^{* *} \\
(1.44)\end{array}$ \\
\hline Medical care & $\$ 5.32$ & $\begin{array}{c}0.20 \\
(0.49)\end{array}$ & $\begin{array}{c}0.98 \\
(0.66)\end{array}$ \\
\hline Non-housing \& non-medical bills & $\$ 16.05$ & $\begin{array}{c}0.01 \\
(0.90)\end{array}$ & $\begin{array}{l}-1.86 \\
(1.20)\end{array}$ \\
\hline Clothes \& Linens & $\$ 4.64$ & $\begin{array}{c}0.20 \\
(0.27)\end{array}$ & $\begin{array}{l}-0.13 \\
(0.30)\end{array}$ \\
\hline Other durable goods & $\$ 17.04$ & $\begin{array}{l}-0.93 \\
(0.75)\end{array}$ & $\begin{array}{l}-0.57 \\
(0.94)\end{array}$ \\
\hline Investment \& Insurance & $\$ 2.57$ & $\begin{array}{l}-0.36 \\
(0.39)\end{array}$ & $\begin{array}{l}-0.12 \\
(0.40)\end{array}$ \\
\hline $\begin{array}{c}\text { Number of days } \\
\text { Number of households }\end{array}$ & & \multicolumn{2}{|c|}{$\begin{array}{c}177855 \\
16300\end{array}$} \\
\hline
\end{tabular}

1. Lottery jackpot is defined as the advertised jackpot of Powerball or Mega Millions if there is only one game being sold in the state where the households resides, and is defined as the higher advertised jackpot of Powerball and Mega Millions if both games are available. The omitted groups is for jackpots less than or equal to $\$ 50$ million.

2. Standard errors clustered at the household level are shown in parenthesis.

3. All regressions control for the household-level fixed effect, the day-of-week, and the day-ofsequence in the CEX Diary.

4. The lowest income tercile is characterized by annual household before-tax income less than $\$ 20873$.

5. Households with top $1 \%$ average spending during the diary period are excluded.

6. $* * * / * * *$ indicate significance at $1 \% / 5 \% / 10 \%$, respectively. 


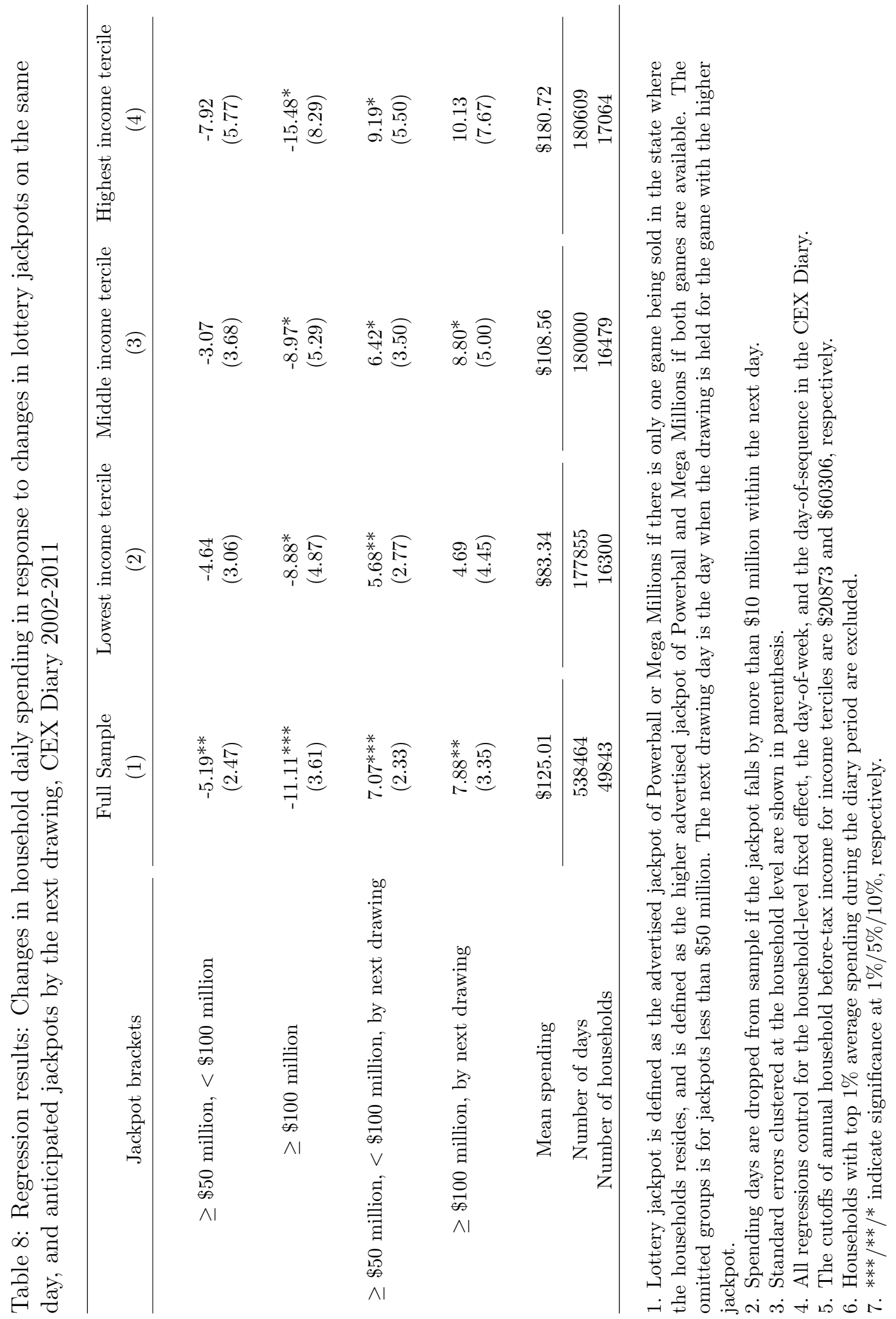


Table 9: Regression results: Changes in household daily spending on transportation in home town, anticipated jackpot by the next drawing below $\$ 50$ million, compared to at or above $\$ 50$ million CEX Diary 2002-2011

\begin{tabular}{|c|c|c|c|c|}
\hline & \multicolumn{2}{|c|}{ Level } & \multicolumn{2}{|c|}{ Any } \\
\hline & Mean & (1) & Mean & $(2)$ \\
\hline $\begin{array}{c}\text { Full Sample } \\
\text { (49843 households, 538464 days) }\end{array}$ & $\$ 7.24$ & $\begin{array}{c}0.01 \\
(0.08)\end{array}$ & 0.3354 & $\begin{array}{l}-0.0029^{*} \\
(0.0016)\end{array}$ \\
\hline $\begin{array}{l}\text { Lowest income tercile } \\
\text { (16300 households, } 177855 \text { days) }\end{array}$ & $\$ 5.18$ & $\begin{array}{l}-0.01 \\
(0.11)\end{array}$ & 0.3048 & $\begin{array}{l}-0.0034 \\
(0.0025)\end{array}$ \\
\hline $\begin{array}{c}\text { Middle income tercile } \\
\text { (16479 households, } 180000 \text { days })\end{array}$ & $\$ 6.44$ & $\begin{array}{c}0.07 \\
(0.12)\end{array}$ & 0.3329 & $\begin{array}{c}0.0016 \\
(0.0028)\end{array}$ \\
\hline $\begin{array}{l}\text { Highest income tercile } \\
\text { (17064 households, } 180609 \text { days) }\end{array}$ & $\$ 9.98$ & $\begin{array}{l}-0.02 \\
(0.17)\end{array}$ & 0.3669 & $\begin{array}{c}-0.0071^{* *} \\
(0.0031)\end{array}$ \\
\hline
\end{tabular}

1. Lottery jackpot is defined as the advertised jackpot of Powerball or Mega Millions if there is only one game being sold in the state where the households resides, and is defined as the higher advertised jackpot of Powerball and Mega Millions if both games are available. The omitted groups is for jackpots less than $\$ 50$ million.

2. Spending days are dropped from sample if the jackpot falls by more than $\$ 10$ million within the next day for the specification in Column (2). Spending days with jackpot falling by more than $\$ 10$ million within the next two days are further dropped from sample for the specification In Column (3).

3. Standard errors clustered at the household level are shown in parenthesis.

4. All regressions control for the household-level fixed effect, the day-of-week, and the day-ofsequence in the CEX Diary.

5. The lowest income tercile is characterized by annual household before-tax income less than $\$ 20873$.

6. Households with top $1 \%$ average spending during the diary period are excluded.

7. $* * * / * * / *$ indicate significance at $1 \% / 5 \% / 10 \%$, respectively. 